UNIVERSIDADE DE SÃO PAULO

ESCOLA POLITÉCNICA

GUILHERME GRAZZIOTIN BONGIOLO

Análise de sobretensões transitórias causadas por manobras de disjuntores a vácuo

São Paulo

2019 
GUILHERME GRAZZIOTIN BONGIOLO

\section{Análise de sobretensões transitórias causadas por manobras de disjuntores a vácuo}

\section{Versão Corrigida}

(Versão original encontra-se na unidade que aloja o Programa de Pós-Graduação)

Dissertação apresentada à Escola Politécnica da Universidade de São Paulo para obtenção do título de Mestre em Ciências.

Área de Concentração: Sistemas de Potência

Orientador: Professor Dr. Luiz Cera Zanetta Junior

São Paulo 
Autorizo a reprodução e divulgação total ou parcial deste trabalho, por qualquer meio convencional ou eletrônico, para fins de estudo e pesquisa, desde que citada a fonte.

Este exemplar foi revisado e corrigido em relação à versão original, sob responsabilidade única do autor e com a anuência de seu orientador.

São Paulo, de de

Assinatura do autor:

Assinatura do orientador:

\section{Catalogação-na-publicação}

Bongiolo, Guilherme Grazziotin

Análise de sobretensões transitórias causadas por manobras de disjuntores a vácuo / G. G. Bongiolo -- versão corr. -- São Paulo, 2019.

$92 \mathrm{p}$.

Dissertação (Mestrado) - Escola Politécnica da Universidade de São Paulo. Departamento de Engenharia de Energia e Automação Elétricas.

1.Sistemas Elétricos de Potência 2.Disjuntores 3.Simulação 4.Engenharia Elétrica I.Universidade de São Paulo. Escola Politécnica. Departamento de Engenharia de Energia e Automação Elétricas II.t. 


\section{RESUMO}

BONGIOLO, Guilherme Grazziotin. Análise de sobretensões transitórias causadas por manobras de disjuntores a vácuo. 2018. 83f. Dissertação (Mestrado em Ciências) - Escola Politécnica, Universidade de São Paulo, São Paulo, 2018.

Esta dissertação realiza uma análise comparativa de sobretensões transitórias que ocorrem durante o chaveamento de disjuntores a vácuo. Estas sobretensões podem ocasionar a falha da isolação dos equipamentos conectados aos disjuntores, conforme vários relatos da literatura. Esse fenômeno está associado às características intrínsecas dos disjuntores a vácuo, na formação do arco elétrico em seu interior e de sua interrupção, na sua capacidade de recuperação da rigidez dielétrica, na sua capacidade de interromper correntes de alta frequência, além de características do circuito protegido. Devido à natureza complexa e aleatória das sobretensões transitórias, observou-se a necessidade do desenvolvimento de ferramentas para reprodução dos fenômenos associados às características operacionais dos disjuntores a vácuo. Esse trabalho busca preencher tal lacuna, desenvolvendo um modelo que contempla o comportamento do disjuntor a vácuo tanto para a manobra de abertura quanto para de fechamento, de modo a colaborar com o entendimento dos fenômenos e no cálculo das sobretensões no domínio do tempo. O algoritmo desenvolvido foi implementado no programa Alternative Transient Program (ATP) por meio da linguagem Models. A partir da preparação desse modelo e da escolha de um experimento de referência, foi possível analisar o comportamento do modelo proposto do disjuntor e dos modelos dos principais componentes elétricos dos programas de cálculo de transitórios elétricos, como transformadores e cabos, cujos méritos e deficiências são discutidos ao longo do trabalho. A pesquisa foi orientada em buscar resultados que pudessem ser mais representativos para validação do modelo de disjuntor ao se alterar os modelos dos demais componentes elétricos do circuito, sendo o ajuste dos parâmetros dos disjuntores a vácuo realizados de forma a obter os resultados mais próximos da referência. Por fim, foram simuladas condições onde os fenômenos de sobretensão se agravam e soluções que podem ser incorporadas ao circuito para redução das sobretensões e das frequências dos transitórios.

Palavras-chaves: Disjuntores. Vácuo. Sobretensão. Modelagem. Transitórios. Simulações. Alta frequência. 


\begin{abstract}
BONGIOLO, Guilherme Grazziotin. Analysis of Transient Overvoltages Caused by Vacuum Circuit Breaker Switching. 2018. 83f. Dissertação (Mestrado em Ciências) - Escola Politécnica, Universidade de São Paulo, São Paulo, 2018.

The current dissertation project performs a comparative analysis of the transient overvoltages generated during the switching of vacuum circuit breakers. The overvoltage phenomenon for these cases can lead to the insulation failure of the equipment connected to the circuit-breakers, according to several reports in the literature. This phenomenon is associated to intrinsic characteristics of the vacuum circuit-breakers, as the formation of the electric arc in their interior and its interruption, their dielectric strength recovery, in their capacity to interrupt high frequency currents interruption, beyond characteristics from the circuit. Due to the complex and random nature of the transient overvoltage, the necessity of developing tools to reproduce such phenomenon associated to the operational features of the vacuum circuit-breaker arose. This dissertation seeks filling this gap, by developing a model that contemplates the vacuum circuitbreaker behavior for both opening and closing switching, in order to collaborate with the understanding of such phenomenon and in the calculations of overvoltages in the time domain. The developed algorithm was implemented in the software Alternative Transient Program (ATP) by means of the programming language Models. From the preparation of this model and from the choice of a reference experiment, it was possible to analyze the behavior of the proposed model and of the models from the main electrical components present in software to calculate electrical transients, e.g. transformers and cables, which merits and deficiencies are discussed along the dissertation. The research was oriented in searching for results that could be more representative to the validation of the circuit-breaker model when changing the models of the remaining electrical components of the circuit, being the parameters adjustment of the vacuum circuit-breakers performed in order to achieve the results closer to the reference. Finally, conditions to aggravate the transitory and the incorporation of solution to reduce the overvoltage and frequencies of the transients were also simulated.
\end{abstract}

Keywords: Circuit breakers. Vacuum. Overvoltage. Modeling. Transients. Simulation. High frequency. 


\section{LISTA DE ILUSTRAÇÕES}

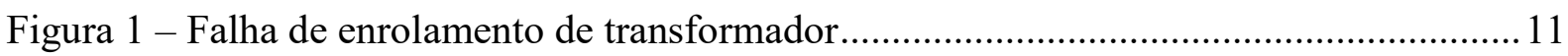

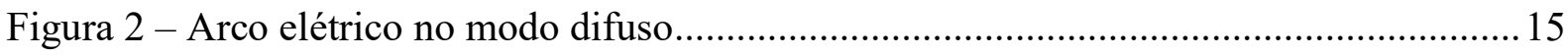

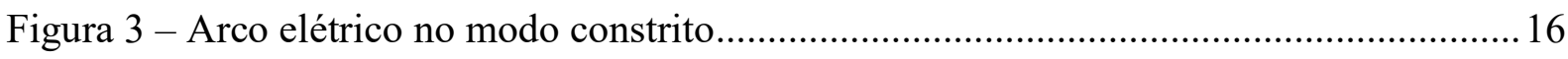

Figura 4 - Composição de tensões de ruptura dielétrica em uma série de testes completa para disjuntor de $7,2 \mathrm{kV}$ para tensão igual a $45 \mathrm{kV}$ e resistência do circuito de teste igual a $339 \mathrm{k} \Omega 18$ Figura 5 - Comparativo do valor da tensão de ruptura dielétrica em função da distância entre os contatos

Figura 6 - Tensão de ruptura dielétrica em função da distância entre contatos e diâmetro dos contatos 22

Figura 7 - Tensão de ruptura dielétrica em função do tempo após abertura com contatos de cobre e diâmetro igual a $30 \mathrm{~mm}$ .23

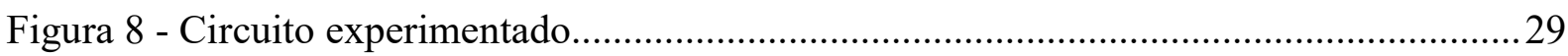

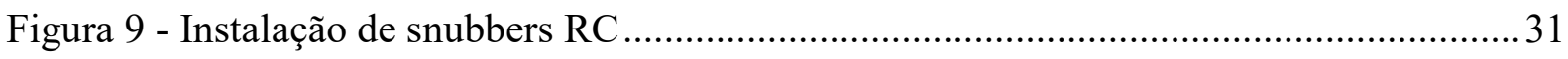

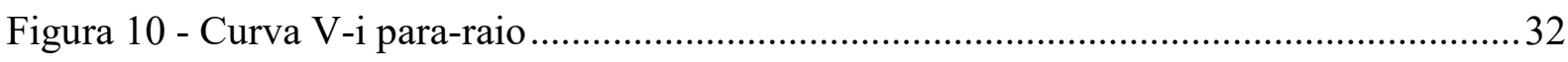

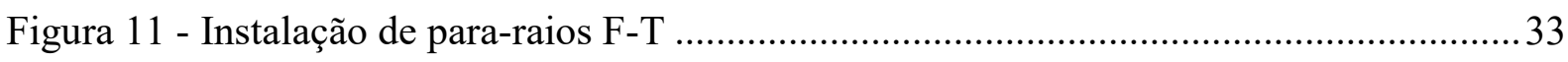

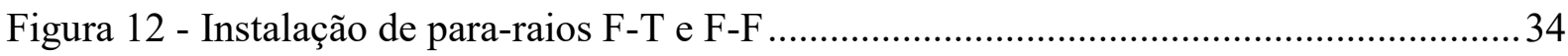

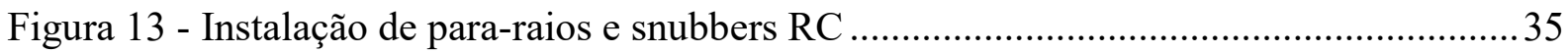

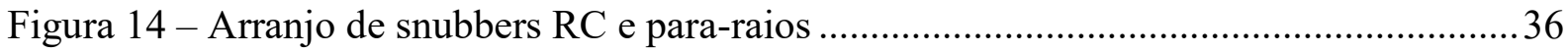

Figura 15 - Para-raios F-T e no ponto médio dos enrolamentos dos transformadores..............37

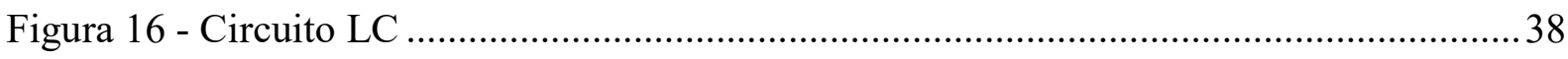

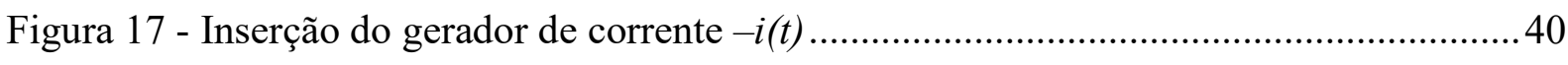

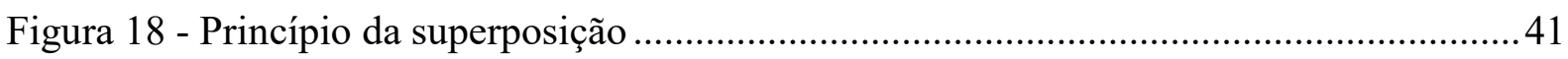

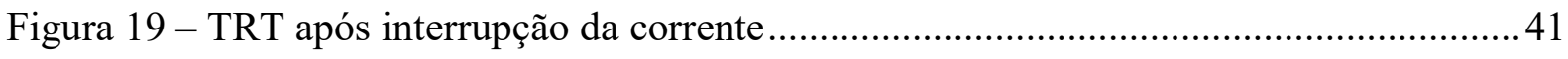

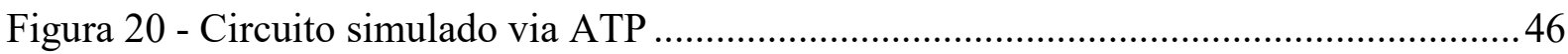

Figura 21 - Tensão entre os terminais do disjuntor (corrente igual a zero no momento de

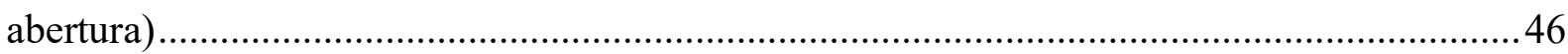

Figura 22 - Comparação entre resultados do ATP e Matlab .................................................... 47

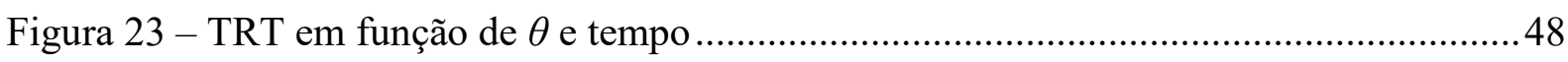

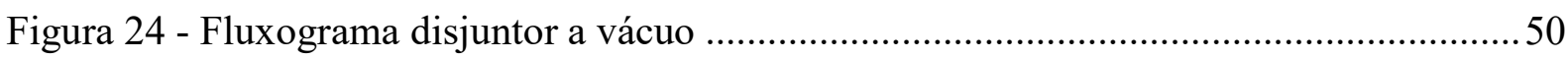

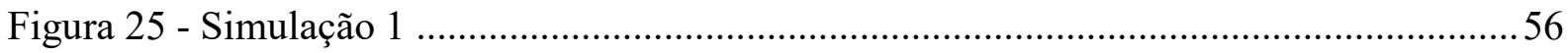

Figura 26 - Tensões no primário do transformador 2 a) Abertura b) Fechamento...................58

Figura 27 - Tensões no primário do transformador 2 observadas na simulação 1 ..................60

Figura 28 - Tensões no primário do transformador 2 observadas na simulação 2 …...............61 
Figura 29 - Tensões no primário do transformador 2 observadas na simulação 3

Figura 30 - Tensões no primário do transformador 2 observadas na simulação 4

Figura 31 - Tensões no primário do transformador 2 observadas na simulação 5

Figura 32 - Tensões no primário do transformador 2 (uso de transformador Hybrid e cabos

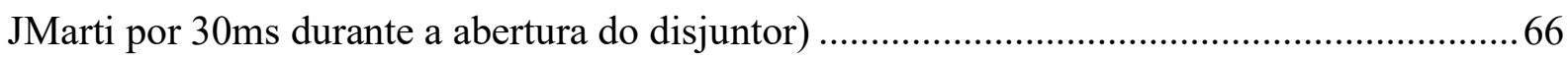

Figura 33 - Tensão sobre os terminais do disjuntor durante a abertura ..................................70

Figura 34 - Tensão sobre os terminais do disjuntor durante a abertura ampliada ....................71

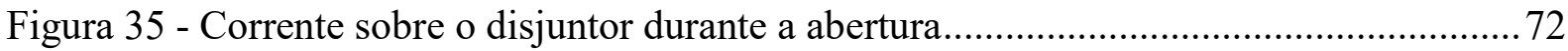

Figura 36 - Capacidade de extinção de correntes na fase A................................................... 73

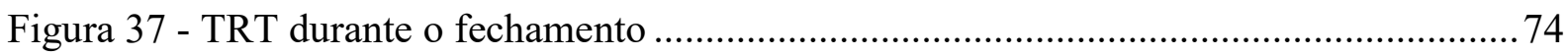

Figura 38 - Correntes sobre o disjuntor durante o fechamento ............................................ 74

Figura 39 - Capacidade de extinção de correntes na fase A................................................. 75

Figura 40 - Tensões no primário do transformador 20kVA - Redução do cabo.......................76

Figura 41 - Tensões no primário do transformador 20kVA - Redução do cabo e carga de 10kVA

Figura 42 - Tensões no primário do transformador 2 após instalação de snubbers RC ...........78

Figura 43 - Tensões no primário do transformador 2 após instalação de para-raios F-T.........79

Figura 44 - Tensões no primário do transformador 2 após instalação de para-raios F-F e F-T80

Figura 45 - Tensões no primário do transformador 2 após instalação de para-raios F-T e snubbers RC

Quadro 1 - Casos de falhas devido a manobras de disjuntores 10

Quadro 2 - Características gerais de disjuntores a vácuo 


\section{LISTA DE TABELAS}

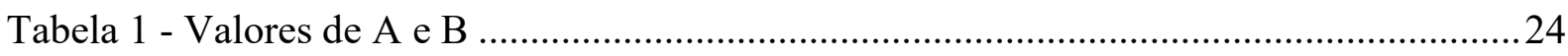

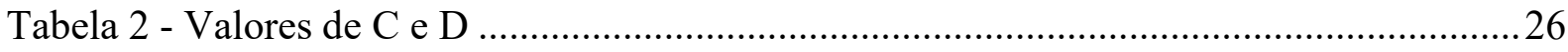

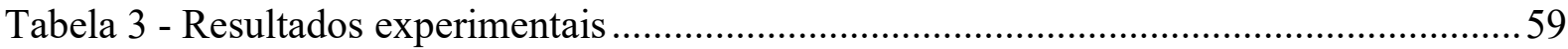

Tabela 4 - Comparação dos resultados do experimento com as simulações ............................68

Tabela 5 - Comparação das correntes interrompidas por fase e por simualação .....................69

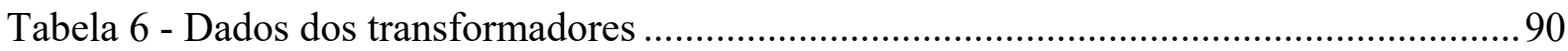

Tabela 7 - Características físicas do cabo RG213/U ...............................................................90

Tabela 8 - Dados elétricos do para-raios MWK …............................................................ 91

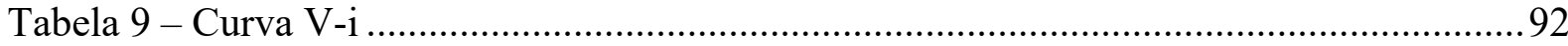




\section{LISTA DE SIGLAS}

ABB

ABNT

ATP

BIL

BSL

CIGRÉ

EMTP

IEEE

LCC

MOV

NBI

NBR

PSCAD

RLC

RRDS

STC

TACS

TRT
Asea Brown Boveri

Associação Brasileira de Normas Técnicas

Alternative Transient Program

Basic Insulation Level

Basic Switching Impulse Level

Conseil International des Grands Réseaux Électriques

Electromagnetics Transient Program

Institute of Electrical and Electronic Engineering

Line Constants and Cables

Metal Oxide Para-raios

Nível Básico de Isolamento a Impulso Atmosférico

Norma Brasileira

Power System Aided Design

Resistência, Indutância e Capacitância

Rate of Rise of Dielectric Strength

Saturable Transformer Component

Transient Analysis of Control Systems

Tensão de Restabelecimento Transitória 


\section{SUMÁRIO}

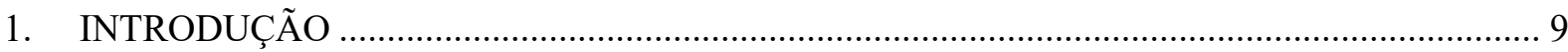

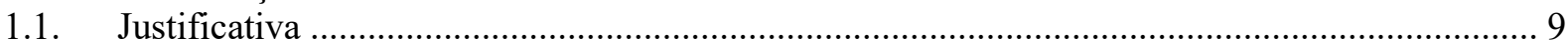

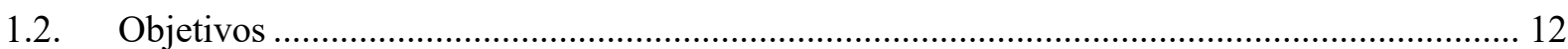

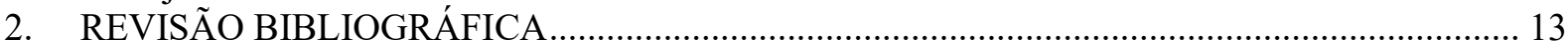

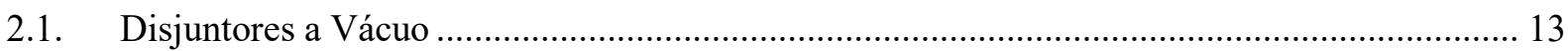

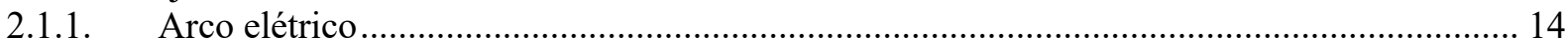

2.1.2. Ruptura dielétrica e capacidade de extinção de correntes de alta frequência........................ 17

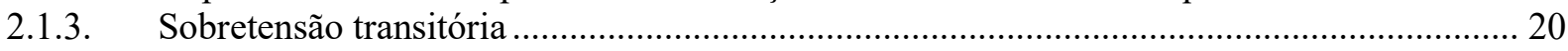

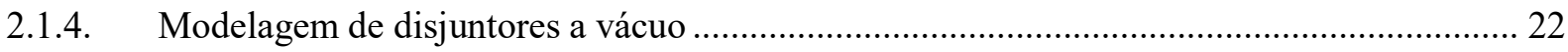

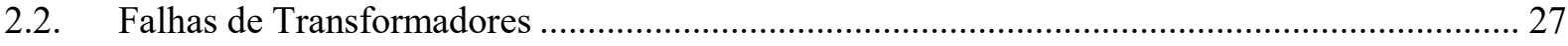

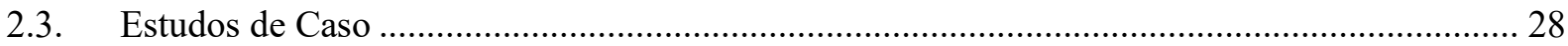

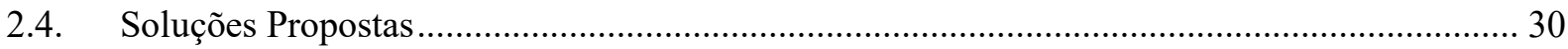

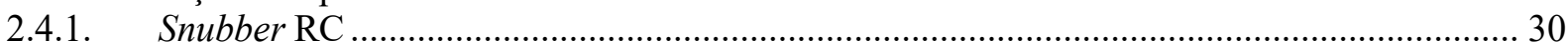

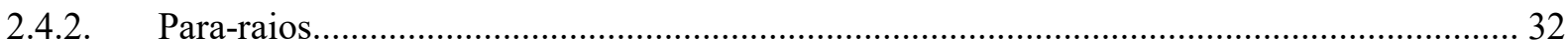

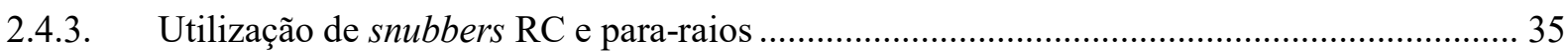

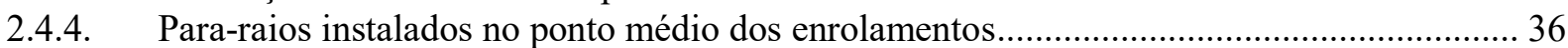

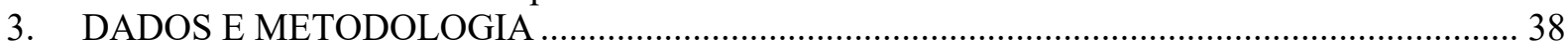

3.1. Análise Matemática de Transitórios Durante o Corte de Corrente .......................................... 38

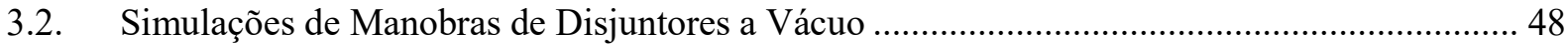

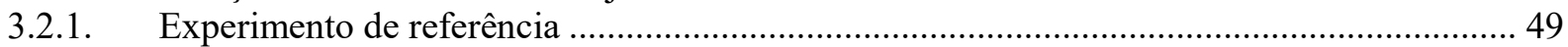

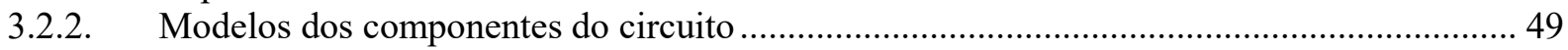

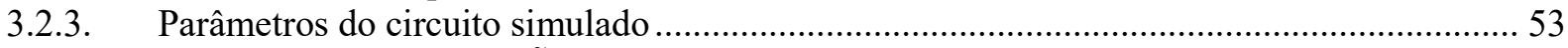

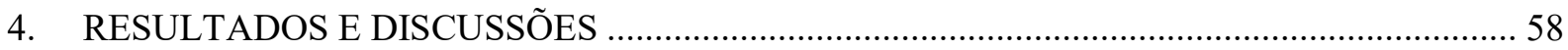

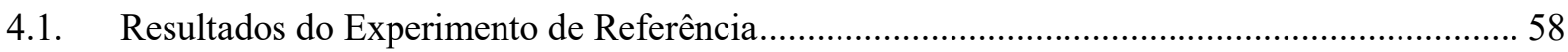

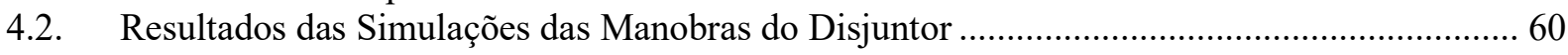

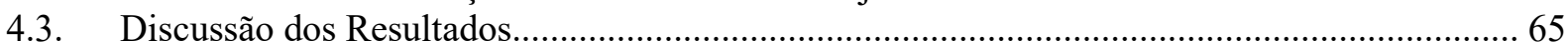

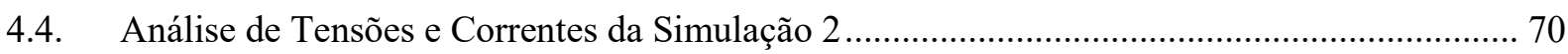

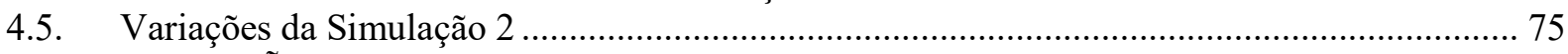

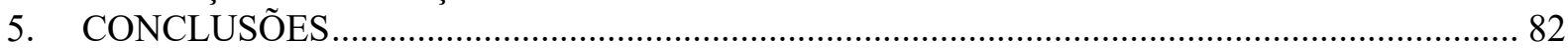

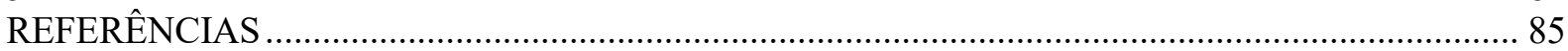

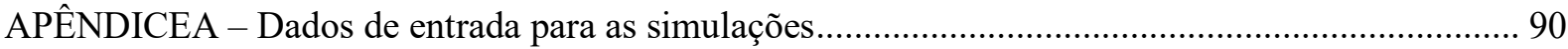




\section{INTRODUÇÃO}

Com o avanço da tecnologia, os disjuntores a vácuo passaram a ser utilizados em média tensão (faixa de tensão entre $1 \mathrm{kV}$ e $36,2 \mathrm{kV}$ conforme definição da Associação Brasileira de Normas Técnicas - ABNT (2005)), substituindo os tradicionais disjuntores a óleo, a ar comprimido e magnéticos e competindo diretamente com os disjuntores a $\mathrm{SF}_{6}$. Os disjuntores a vácuo e os disjuntores a $\mathrm{SF}_{6}$ possuem vantagens com relação aos tipos de disjuntores tradicionais, como facilidade de manutenção, vida útil elevada, curto tempo de interrupção, tamanho reduzido, sendo os disjuntores a vácuo menores do que os disjuntores a $\mathrm{SF}_{6}$. Com relação ao custo, ambos são mais caros que os disjuntores tradicionais, porém o disjuntor a vácuo apresenta um custo inferior em relação aos disjuntores a SF6. Além disso, os disjuntores a vácuo não liberam gases durante a interrupção da corrente circulante entre seus terminais e nem necessitam ter sua pressão interior monitorada, devido ao fato de seu dielétrico ser o vácuo (SWINDLER, 1984).

A maior desvantagem encontrada nesses disjuntores é a introdução de transitórios de alta frequência na rede elétrica associada, durante o processo de interrupção do arco elétrico característico desses disjuntores. Esses transitórios podem causar danos tanto a esses dispositivos quanto aos equipamentos da rede elétrica, em virtude de sobretensões que atingem altos níveis ou à repetição de impulsos de tensão em uma frequência elevada. Em disjuntores a $\mathrm{SF}_{6}$, pode-se observar sobretensões durante a interrupção de correntes, entretanto os impulsos de tensão não são tão repetitivos quanto os ocorridos nos disjuntores a vácuo, graças à diferença no fenômeno físico relacionado à interrupção de corrente (SWINDLER, 1984).

Vários transitórios em operações de disjuntores a vácuo foram observados, sendo esse fenômeno alvo de diversas publicações na literatura mundial, as quais buscam compreender os seus motivos e formas de mitigação.

\subsection{Justificativa}

Em diversos locais do mundo, diversos incidentes causados pela abertura ou fechamento de disjuntores a vácuo, ocasionando transitórios de alta frequência, levaram a falhas de equipamentos envolvidos. Esses incidentes motivaram vários pesquisadores a buscarem o motivo desse fenômeno, por meio de simulações e experimentos de campo. A explicação encontrada é que uma combinação de fatores cria as condições para altos níveis de sobretensões transitórias durante a manobra desses disjuntores, como a presença de disjuntores a vácuo e de 
transformadores a seco, o chaveamento de correntes indutivas (comumente encontradas nos circuitos elétricos), curta distância do disjuntor para a carga, entre outros.

Por meio do Quadro 1, pode-se ver alguns exemplos de incidentes dessa natureza, juntamente com os motivos e agravantes para ocorrência.

Quadro 1 - Casos de falhas devido a manobras de disjuntores

(continua)

\begin{tabular}{|c|c|c|c|c|}
\hline Instalação & Caso & Agravantes & Manobra & Referência \\
\hline Hidroelétrica & $\begin{array}{l}\text { Falha da isolação do } \\
\text { enrolamento primário } \\
\text { de um transformador } \\
\text { seco, cujo nível básico } \\
\text { de isolamento era igual } \\
\text { a } 50 \mathrm{kV} \text {. }\end{array}$ & $\begin{array}{c}\text { Substituição de } \\
\text { disjuntores a óleo por } \\
\text { disjuntores a vácuo; curta } \\
\text { distância entre o disjuntor } \\
\text { e o transformador. }\end{array}$ & Fechamento & $\begin{array}{c}\text { Shipp et al. } \\
\text { (2011) }\end{array}$ \\
\hline $\begin{array}{l}\text { Estrada de } \\
\text { ferro }\end{array}$ & $\begin{array}{l}\text { Falha da porção central } \\
\text { do enrolamento } \\
\text { primário de um } \\
\text { transformador imerso } \\
\text { em óleo, cujo nível } \\
\text { básico de isolamento } \\
\text { era igual a } 150 \mathrm{kV} \text {. }\end{array}$ & $\begin{array}{c}\text { Disjuntor a vácuo, } \\
\text { Ressonância interna, } \\
\text { devido à combinação do } \\
\text { valor da capacitância e } \\
\text { indutância de um } \\
\text { retificador CC e da } \\
\text { indutância do } \\
\text { transformador. }\end{array}$ & Abertura & $\begin{array}{c}\text { Shipp et al. } \\
\text { (2011) }\end{array}$ \\
\hline $\begin{array}{l}\text { Fornos } \\
\text { arco }\end{array}$ & $\begin{array}{c}\text { Falha da isolação dos } \\
\text { enrolamentos de alta } \\
\text { tensão de } \\
\text { transformadores. }\end{array}$ & $\begin{array}{c}\text { Circuito } \\
\text { predominantemente } \\
\text { indutivo, com presença de } \\
\text { fornos a arco. }\end{array}$ & $\begin{array}{l}\text { Abertura / } \\
\text { Fechamento }\end{array}$ & $\begin{array}{c}\text { Panek e } \\
\text { Fehrle } \\
(1975)\end{array}$ \\
\hline $\begin{array}{l}\text { Centros de } \\
\text { Dados }\end{array}$ & $\begin{array}{l}\text { Falha da isolação do } \\
\text { enrolamento primário } \\
\text { de dois } \\
\text { transformadores a seco } \\
\text { entre seis, cujos níveis } \\
\text { básicos de isolamento } \\
\text { eram iguais a } 150 \mathrm{kV} .\end{array}$ & $\begin{array}{c}\text { Cabos curtos entre } \\
\text { disjuntores e } \\
\text { transformadores; } \\
\text { chaveamento frequente; } \\
\text { densidade de energia } \\
\text { elevada. }\end{array}$ & $\begin{array}{c}\text { Abertura / } \\
\text { Fechamento } \\
\text { (Um } \\
\text { incidente em } \\
\text { cada } \\
\text { manobra) }\end{array}$ & $\begin{array}{l}\text { Shipp et al. } \\
\text { (2011) } \\
\text { Shipp e } \\
\text { Dionisie, } \\
(2016)\end{array}$ \\
\hline
\end{tabular}


Quadro 1 - Casos de falhas devido a manobras de disjuntores

(conclusão)

\begin{tabular}{|c|c|c|c|c|}
\hline Instalação & Caso & Agravantes & Manobra & Referência \\
\hline $\begin{array}{l}\text { Usina eólica } \\
\text { offshore }\end{array}$ & $\begin{array}{l}\text { Falhas nos isolamentos } \\
\text { de transformadores a } \\
\text { seco da usina eólica } \\
\text { Middelgrunden }\end{array}$ & $\begin{array}{l}\text { Uso de disjuntores a } \\
\text { vácuo e cabos para } \\
\text { transmissão }\end{array}$ & Não definido. & $\begin{array}{l}\text { Liljestrand et } \\
\text { al. (2008) e } \\
\text { Larsen et al. } \\
\text { (2005) }\end{array}$ \\
\hline
\end{tabular}

Fonte: Autor

Observa-se no Quadro 1, incidentes decorrentes da utilização de disjuntores a vácuo podem ocorrer em aplicações de fornos a arco, de centros de dados e outras aplicações industriais, contendo, principalmente, transformadores de distribuição a seco. Por meio da Figura 1, ilustra-se um caso de falha do isolamento entre fases de um transformador a seco causada por manobras de disjuntores a vácuo.

Figura 1 - Falha de enrolamento de transformador
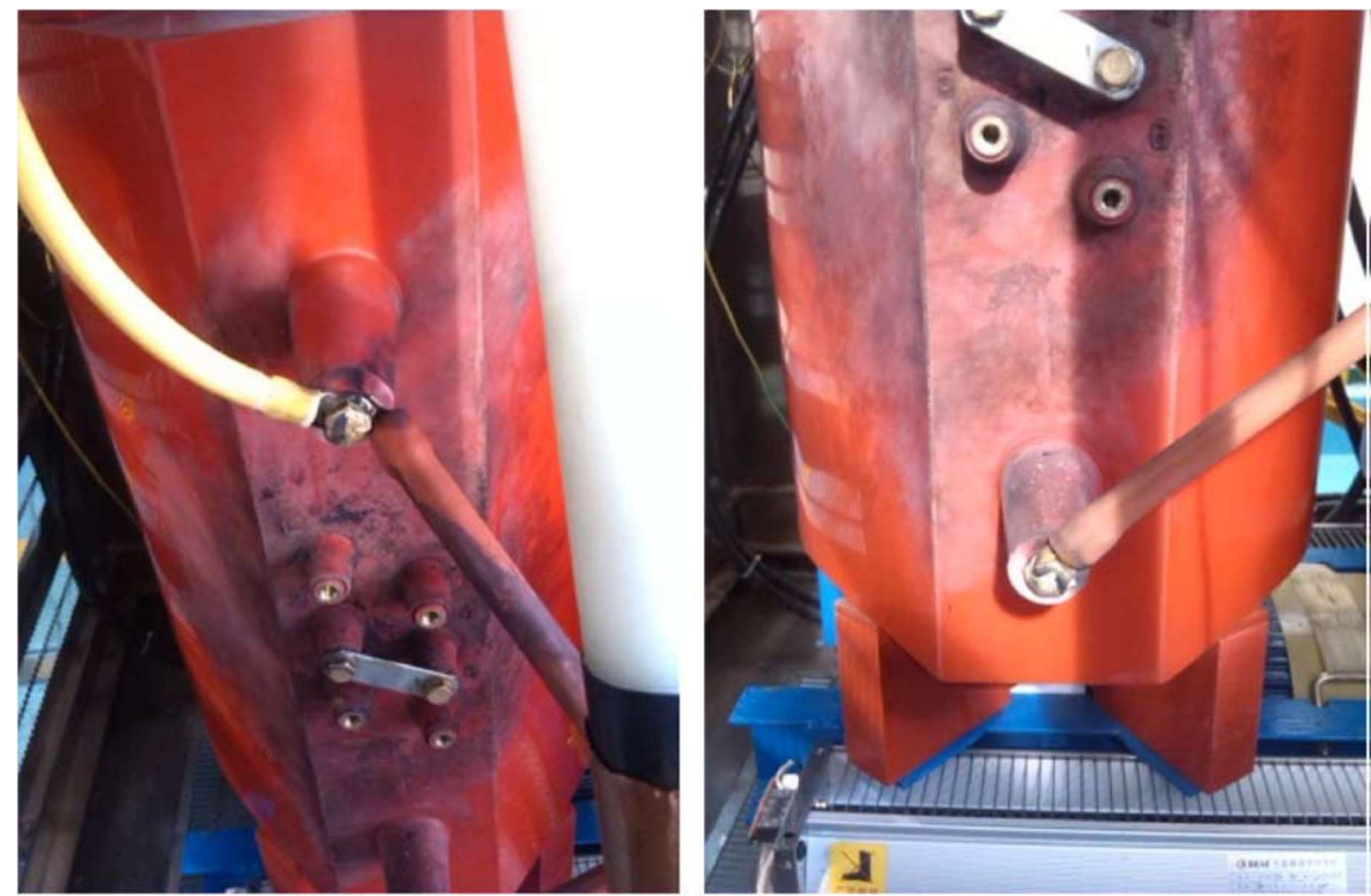

Fonte: Yang et al. (2016). 
Tais tipos de incidentes poderiam ter sido evitados, caso o fenômeno tivesse sido identificado em etapas preliminares do projeto da instalação afetada, eventualmente por meio de simulações. Isso acarretaria em redução de gastos, pois, com os incidentes evitados, não haveria necessidade de manutenção corretiva ou ainda a troca dos equipamentos danificados. Além disso, a disponibilidade de modelos de componentes elétricos, especificamente de disjuntores a vácuo, que pudessem contribuir para simulações dessas configurações poderia sugerir soluções que pudessem ser integradas no circuito, melhorando sua resposta e comportamento.

Além dos disjuntores, existem modelos para componentes da rede como transformadores e capacitores que podem impactar substancialmente nos resultados apresentados. Os modelos existentes não foram formulados para representação de fenômenos de alta frequência e sofrem uma adaptação para que sua resposta em alta frequência seja possível. Essa adaptação impacta os resultados, portanto, há também a necessidade de analisar a utilização de diferentes modelos de componentes elétricos nos resultados de simulações de transitórias durante chaveamentos de disjuntores a vácuo.

\subsection{Objetivos}

Os objetivos deste trabalho são apresentar inicialmente um histórico de incidentes devido ao chaveamento de disjuntores a vácuo, assim como descrever as características operacionais dos disjuntores a vácuo responsáveis pelos fenômenos de sobretensões durante o chaveamento de cargas predominantemente indutivas e apresentar formas de reduzir essas sobretensões. Em seguida, realizar uma análise matemática dos transitórios causados pela interrupção de correntes devido à manobra de disjuntores para um circuito predominantemente indutivo. A partir das características dos disjuntores a vácuo apresentadas, desenvolver um algoritmo que possa servir como modelo de seu comportamento para utilização em simulações de transitórios. Para ajuste dos seus parâmetros e análise de sua performance, identificar na literatura resultados de experimentos que pudessem servir como referência. A partir dessa referência, comparar os resultados dos transitórios encontrados nas simulações com o resultado real, alterando os modelos dos componentes elétricos conectados aos disjuntores a vácuo.

Por fim, analisar as causas de transitórios mais danosos aos equipamentos e incorporar nas simulações as soluções empregadas para esse tipo de incidente para verificar suas influências no transitório. 


\section{REVISÃO BIBLIOGRÁFICA}

O presente capítulo apresenta as principais características dos disjuntores a vácuo e os fenômenos relacionados às sobretensões transitórias, formas de modelagem dos disjuntores a vácuo para simulações e estudos realizados na literatura internacional sobre o tema. Adicionalmente são apresentados motivos que levam à falha da isolação de transformadores durante manobras de disjuntores a vácuo e soluções empregadas para esse tipo de problemática.

\subsection{Disjuntores a Vácuo}

Os disjuntores a vácuo consistem de dois contatos, um fixo e outro móvel dentro de um ambiente a vácuo (SWINDLER, 1984), sendo utilizados em aplicações de média tensão, concorrendo neste mercado principalmente com os disjuntores a $\mathrm{SF}_{6}$.

Tais disjuntores utilizam o vácuo como dielétrico para extinção do arco elétrico. Essa utilização decorre do fato de que, como o vácuo possui uma rigidez dielétrica elevada, no seu interior não ocorrem colisões inelásticas entre moléculas, não havendo, portanto, um mecanismo de avalanche para rompimento do dielétrico (GARZON, 2002). Além disso, ele possui uma elevada taxa de recuperação da suportabilidade dielétrica (SWINDLER, 1984), portanto logo após a interrupção da corrente, o dielétrico volta a recompor suas características originais. Esse tipo de disjuntor possui uma rigidez dielétrica de pelo menos $200 \mathrm{kV} / \mathrm{cm}$ em condições normais de temperatura e pressão (valor que varia em função das características construtivas e dos materiais dos contatos), enquanto os disjuntores a $\mathrm{SF}_{6}$ possuem rigidez dielétrica em torno de $80 \mathrm{kV} / \mathrm{cm}$ nas mesmas condições (FEHR, 2016).

As maiores vantagens operacionais desse tipo de disjuntor são sua vida útil e a baixa necessidade de manutenção durante sua utilização (FLURSCHEIM, 1985). A maior desvantagem é que, para situações específicas, dependendo das características do circuito protegido e devido a fenômenos que ocorrem durante suas manobras, sobretensões transitórias irão ocorrer no sistema podendo causar a falha dos equipamentos conectados a esse disjuntor.

O Quadro 2 sumariza as características principais dos disjuntores a vácuo: 
Quadro 2 - Características gerais de disjuntores a vácuo

\begin{tabular}{|c|c|}
\hline Parâmetro & Disjuntores a vácuo \\
\hline Aplicações & Média tensão (tensão de distribuição entre $1 \mathrm{kV}$ e $36,2 \mathrm{kV})$ \\
\hline $\begin{array}{c}\text { Taxa de recuperação das características } \\
\text { dielétricas }\end{array}$ & $\begin{array}{c}\text { Possui uma taxa elevada de restabelecimento das características } \\
\text { originais do dielétricos após uma interrupção de corrente. }\end{array}$ \\
\hline Velocidade de interrupção & Três ciclos \\
\hline Manutenção & 10 mil na corrente nominal e 20 interrompendo faltas \\
\hline Operações & 50 mil a 20 milhões \\
\hline Operações em controle de motores & $10^{-6}$ a $10^{-8}$ torr, aproximadamente de $10^{-8}$ a $10^{-9}$ bar \\
\hline Pressão interna & Dida útil \\
\hline
\end{tabular}

Fonte: Swindler (1984)

\subsubsection{Arco elétrico}

Como esse disjuntores possuem o vácuo como dielétrico não haveria a possibilidade de formação de um arco em seu interior, devido à inexistência de moléculas. Assim, o arco elétrico, nesse tipo de disjuntor, é caracterizado por uma descarga elétrica autossustentável entre dois eletrodos, mantendo o fluxo de corrente pelo vapor metálico e pelos portadores de cargas derivados de um ou de ambos os eletrodos (GREENWOOD, 2007).

O processo de formação do arco elétrico em disjuntores a vácuo começa a partir da abertura dos contatos, quando a temperatura de pontos dos contatos se iguala à temperatura de derretimento de seus componentes metálicos, levando ao surgimento de uma ponte de material derretido entre os contatos. Com a abertura do disjuntor em andamento, essa ponte fica instável e se rompe, liberando vapor metálico no espaçamento (gap) com alta densidade em um ambiente com alta temperatura. Logo após a ruptura da ponte, um plasma ionizado se forma, devido à alta densidade do vapor metálico, sendo o meio por onde a corrente pode fluir entre os contatos do disjuntor. Nesse instante, os elétrons são fornecidos pelo contato com polo negativo (cátodo) (SLADE, 2008).

Com a expansão dos vapores metálicos no interior do disjuntor, o arco elétrico adquire uma forma mais estável, sendo o cátodo responsável por fornecer elétrons e vapores metálicos para mantê-lo. Esse fornecimento se deve à fusão do material do contato e da extração de elétrons devido ao campo elétrico aplicado ao cátodo. Os elétrons interagem com os vapores metálicos resultando em um processo de ionização capaz de produzir e manter o plasma ionizado no interior do disjuntor e garantindo que a corrente flua por ele (SLADE, 2008). 
Com o aumento da corrente, o arco elétrico passa a ser conhecido como arco difuso. Pela literatura, sabe-se que, nesse modo, existe a presença de pontos brilhantes em constante movimento no cátodo, pelos quais são ejetados elétrons e vapores metálicos, responsáveis por manter o plasma ionizado e pelo fluxo de corrente. Esses pontos catódicos se repelem, devido à mesma polarização, e possuem diâmetro aproximado de 40 a $100 \mu \mathrm{m}$ com uma vida útil de $100 \mu$ s. O nível de corrente que flui sobre esses pontos catódicos depende do tipo de material utilizado, como por exemplo no caso de contatos de cobre, onde uma corrente de aproximadamente 100A pode fluir. Os elétrons emitidos pelos pontos catódicos fluem pelo plasma e são coletados pelo ânodo, onde o plasma se concentra nos pontos catódicos e banha o ânodo. Dessa forma, verifica-se a presença de arcos paralelos no interior do disjuntor. Após o arco difuso ser cessado, constatam-se erosões na superfície do cátodo e uma aparência fosca no ânodo (SLADE, 2008) (GREENWOOD, 2007). A Figura 2 apresenta um disjuntor a vácuo conduzindo o arco elétrico no modo difuso, sendo possível observar o plasma em forma de névoa entre o ânodo e o cátodo e a presença dos pontos catódicos.

Figura 2 - Arco elétrico no modo difuso

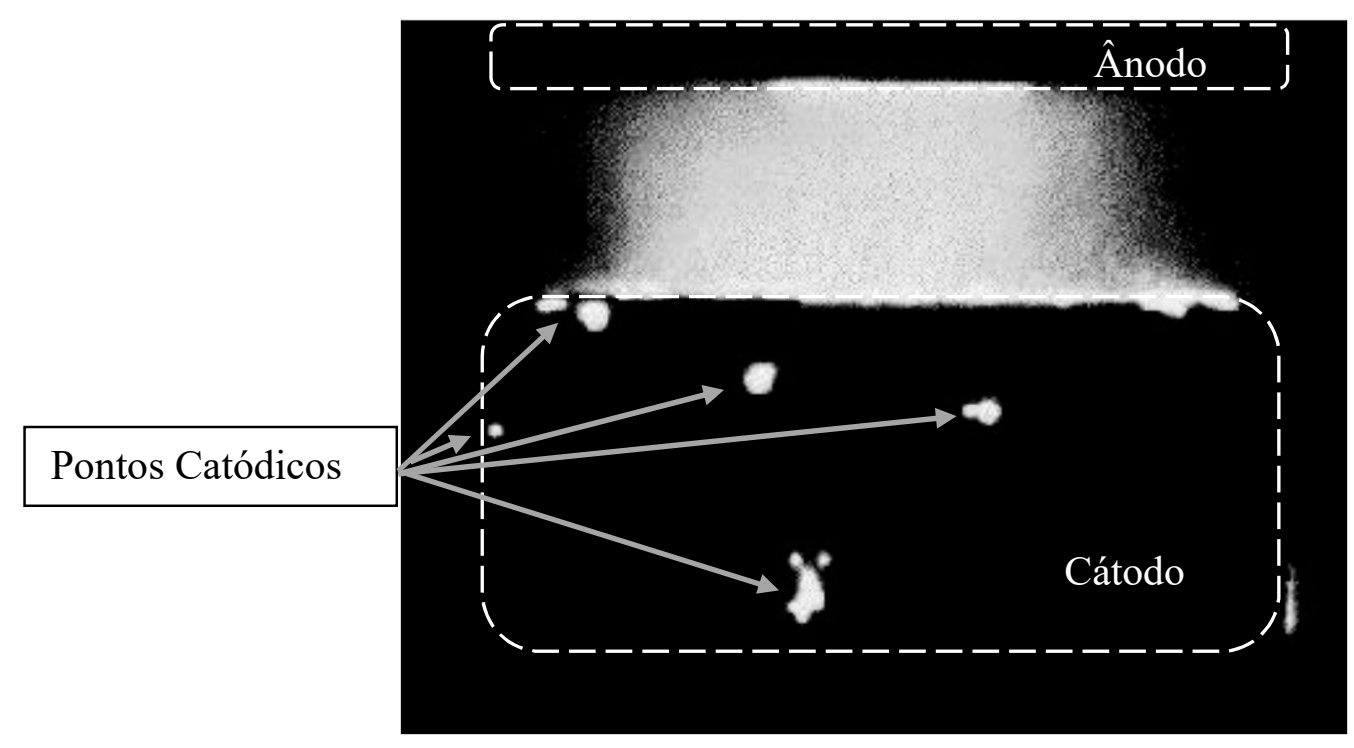

Fonte: Adaptado de Slade (2008)

Com o aumento da corrente, o plasma passa a se concentrar em uma área do ânodo, chegando ao modo constrito. Nesse modo, pela literatura, nota-se a presença de um ponto anódico e de um ponto catódico, oriundo do agrupamento dos pontos catódicos do modo difuso. Sendo assim, ambos os contatos participam ativamente da descarga de vapores metálicos e o arco adquire a aparência de uma coluna. Após o término desse modo, nota-se erosão dos dois 
contatos (GREENWOOD, 2007). Na prática, tenta-se evitar esse modo por meio de escolhas no projeto dos contatos dos disjuntores, especificamente em relação à sua geometria (SLADE, 2008). A Figura 3 apresenta um disjuntor a vácuo conduzindo arco elétrico no modo constrito, sendo possível observar que o arco elétrico se concentra em uma única coluna.

Figura 3 - Arco elétrico no modo constrito

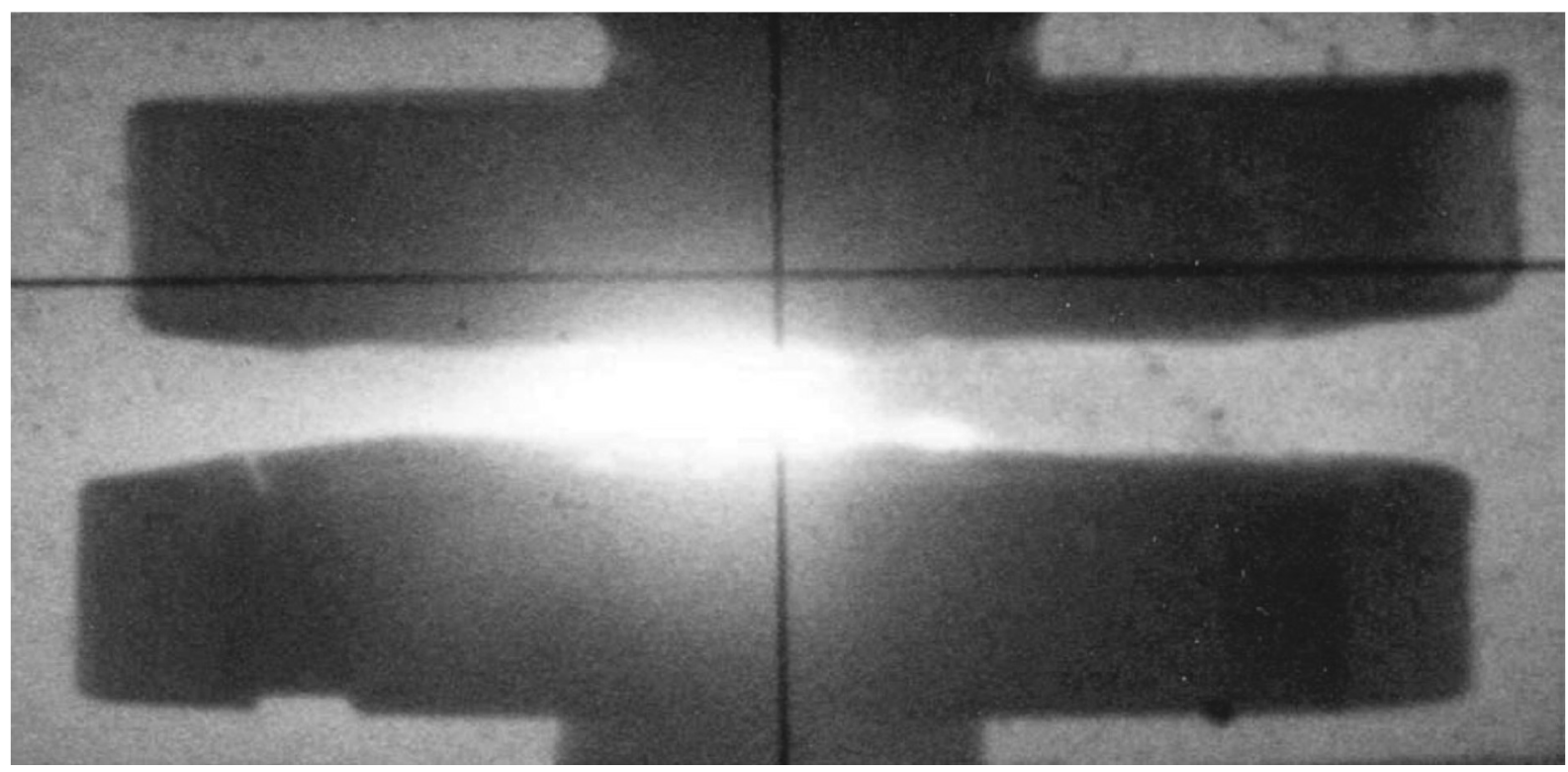

Fonte: Slade (2008)

Para se realizar a interrupção do arco no interior do disjuntor, é preferível que o mesmo esteja no modo difuso. Quando no modo difuso, havendo a redução da corrente se observa a diminuição dos pontos catódicos. Ao se extinguir um ponto catódico, há uma redução na temperatura em seus arredores e uma redução de emissão de elétrons e vapores metálicos, reduzindo a ionização do plasma. Consequentemente, em um determinado instante o plasma não consegue se manter, havendo a interrupção da corrente. A corrente pode ser cessada antes de atingir o valor de zero amperes dependendo do material utilizado nos contatos; sendo que seu valor diminui conforme maior for a pressão de vapor do material do contato, menor for a condutividade térmica e maior for o potencial de ionização, pois a extinção total dos pontos catódicos torna-se mais difícil. Esse valor de corrente de corte (current chopping) não possui um valor fixo, mas sim uma distribuição estatística (SLADE, 2008).

Assim, existem dois pontos críticos em projetos de disjuntores a vácuo. O primeiro é a escolha dos materiais dos seus contatos, pois dependendo da escolha, pode-se gerar um nível de corrosão elevado, fragilidade mecânica e um valor elevado de corrente de corte (SLADE, 2008). Nos desenvolvimentos iniciais desse tipo de disjuntor, os contatos eram de cobre, porém 
foi observado que eles se soldavam para altos valores de corrente. Com isso, ligas metálicas passaram a ser utilizadas para desenvolvimentos dos contatos. A liga metálica de CobreBismuto $(\mathrm{Cu}-\mathrm{Bi})$ trouxe melhores resultados operacionais, como a não soldagem dos contatos para altos valores de correntes e a ocorrência do corte de corrente em 21A. Entretanto, com o avanço das pesquisas, verificou-se que a liga metálica de Cobre-Cromo $(\mathrm{Cu}-\mathrm{Cr})$ trazia maiores vantagens, como uma maior suportabilidade a elevados valores de tensões, reduzindo as chances de reignições após abertura; menor erosão dos contatos levando a uma recuperação mais rápida da suportabilidade dielétrica, pois menos partículas iriam existir no interior do plasma após a interrupção da corrente; e corte de corrente em no máximo 5A (SLADE, 2008) (TELANDER, WILHEIM e STUMP, 1987).

O segundo ponto crítico é a definição da geometria dos contatos. A forma do contato influencia diretamente na redução do aquecimento do contato durante a circulação de corrente e na maximização do tempo no qual o arco se mantém na forma difusa. Existem três tipos de formatos: $a$ ) contatos em forma de disco, b) contatos que fazem com que as colunas de arcos se movam na sua superfície e $c$ ) contatos que forçam a formação de um arco no modo difuso para altos valores de corrente. Os contatos em forma de disco são os mais simples de serem fabricados, porém devem ser utilizados em aplicações onde o arco elétrico se mantenha no modo difuso, ou seja, em aplicação por onde circulem correntes de até 10kA. Para interrupção de valores de correntes elevados, acima de 10kA, os contatos dos tipos $b$ e $c$ são mais funcionais e atuam nas componentes do campo magnético transversal e axial, respectivamente, presentes no interior dos disjuntores (SLADE, 2008).

\subsubsection{Ruptura dielétrica e capacidade de extinção de correntes de alta frequência}

Com a popularização dos disjuntores a vácuo, o comportamento do seu dielétrico passou a ser estudado amplamente por diversos autores. Roguski (1989) realizou diversos experimentos em disjuntores a vácuo com tensão nominal de $15 \mathrm{kV}$ e $7,2 \mathrm{kV}$ procurando obter os níveis de tensão em que os fenômenos citados anteriormente venham a ocorrer e proporcionem a formação do arco elétrico e, dessa forma, delimitar uma curva de tensão de ruptura do dielétrico. O resultado desses experimentos pode ser observado na Figura 4. 
Figura 4 - Composição de tensões de ruptura dielétrica em uma série de testes completa para disjuntor de $7,2 \mathrm{kV}$ para tensão igual a $45 \mathrm{kV}$ e resistência do circuito de teste igual a $339 \mathrm{k} \Omega$

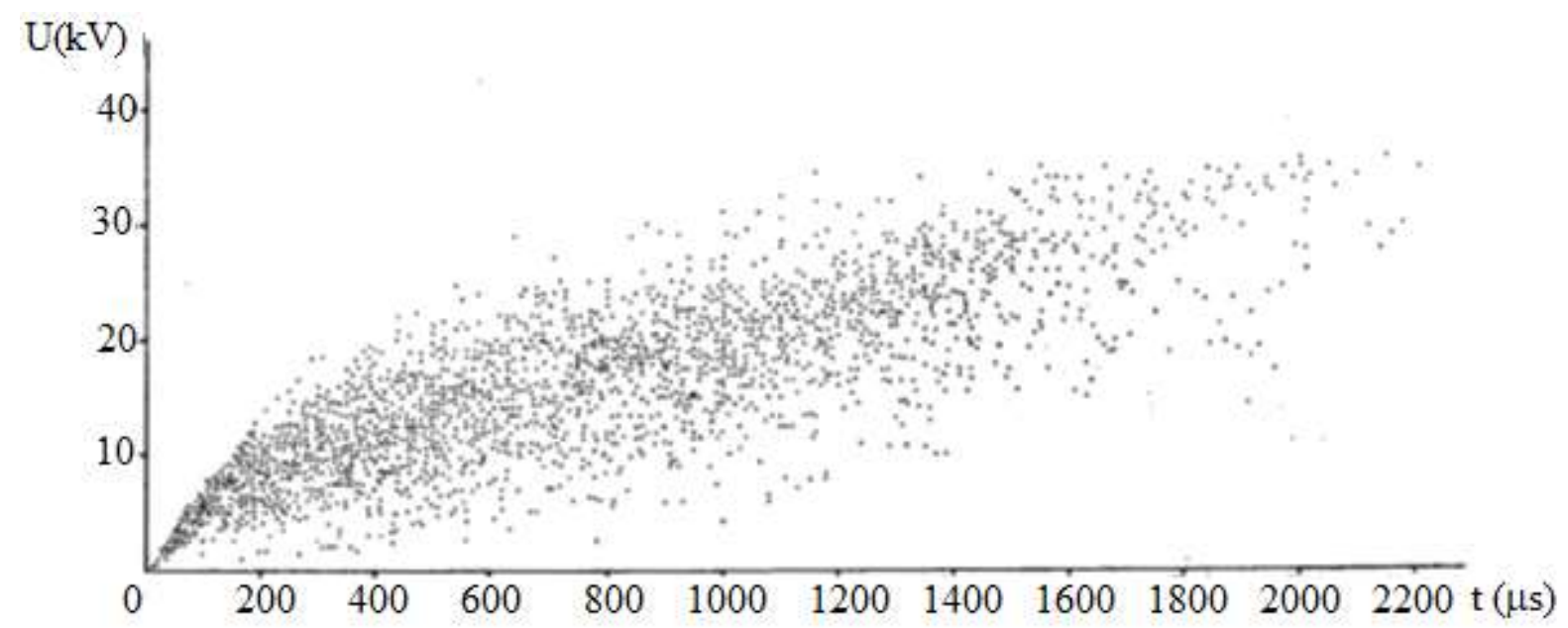

Fonte: Adaptado de Roguski (1989)

Conforme pode ser notado, o nível de tensão de ruptura dielétrica aumenta em função do tempo de sua abertura, consequentemente, esse crescimento é diretamente proporcional à distância entre os contatos. Ressalta-se que existe um componente probabilístico no valor da tensão disruptiva.

A Figura 5 apresenta um comparativo da tensão de ruptura dielétrica suportada pelo disjuntor em função da distância entre seus contatos para os principais tipos de disjuntores utilizados nas instalações elétricas. 
Figura 5 - Comparativo do valor da tensão de ruptura dielétrica em função da distância entre os contatos

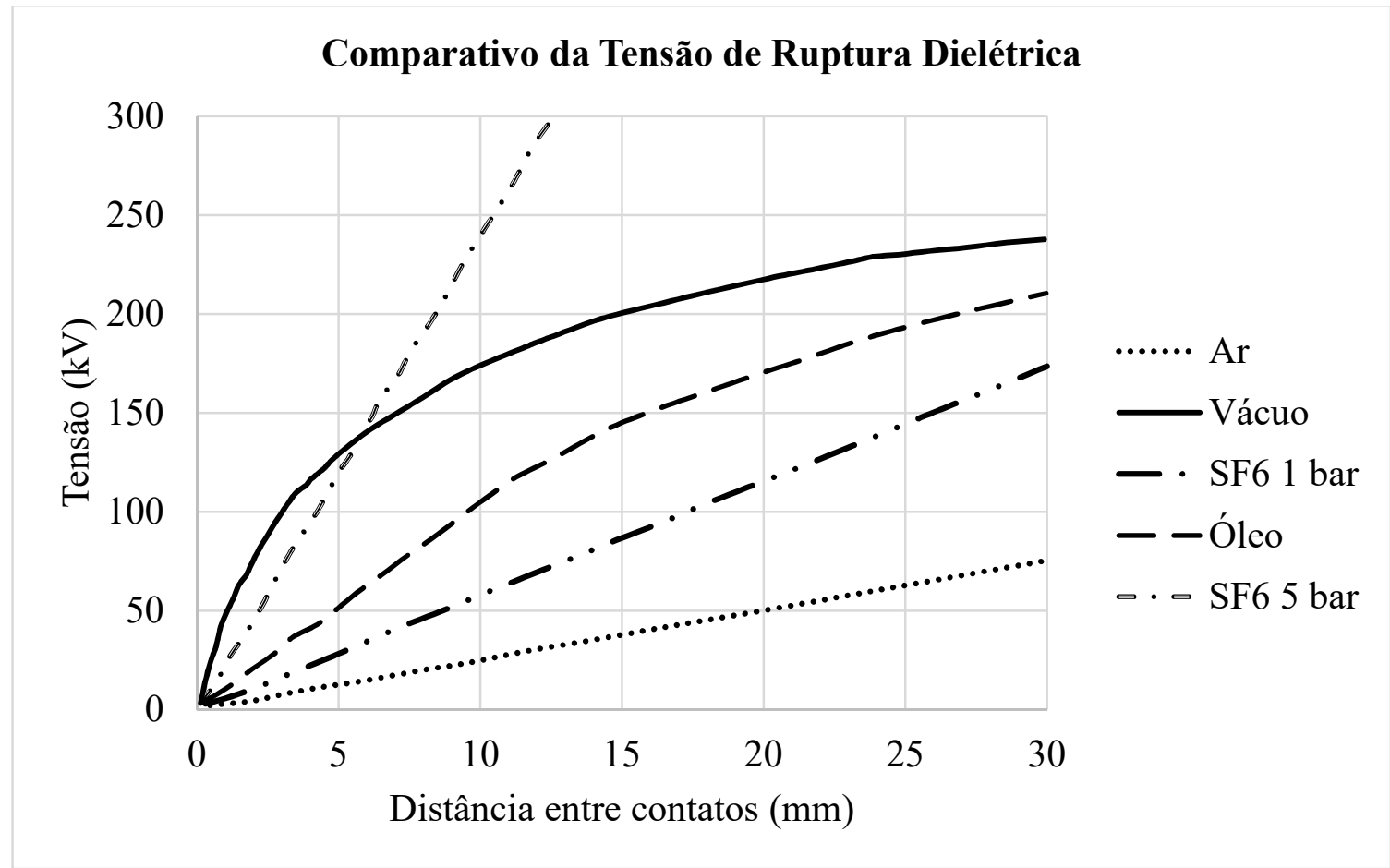

Fonte: Adaptado de Girodet

Pode-se observar que o valor da tensão de ruptura dielétrica dos disjuntores a $\mathrm{SF}_{6}$ pressurizados internamente a 5 bar varia linearmente em função da distância entre seus contatos, suportando um alto valor de tensão em um curto período de tempo.

Os disjuntores a vácuo também são caracterizados por suportar um elevado nível de tensão entre seus terminais, sendo o valor suportado maior do que dos disjuntores a $\mathrm{SF}_{6}$ pressurizados a 5 bar nos primeiros milímetros da separação dos contatos. Sua curva de ruptura possui um comportamento não-linear, podendo ser aproximada por duas retas em modelos matemáticos.

Outra característica importante dos disjuntores a vácuo é sua capacidade mais elevada de extinção de correntes de alta frequência quando comparados com outros disjuntores. A capacidade de extinção de correntes de alta frequência está associada com o espaçamento entre os contatos, ou seja, uma abordagem similar ao comportamento da tensão de ruptura dielétrica do disjuntor (ABDULAHOVIC et al., 2014). 


\subsubsection{Sobretensão transitória}

Fenômenos elétricos podem ocorrer em manobras de disjuntores associados à variação abrupta do nível de corrente. Durante a abertura, observam-se os fenômenos de reignição com escalada de tensão e corte de corrente virtual; já no fechamento observa-se a pré-ignição (SHIPP et al., 2011).

\subsubsection{Reignições com (amplificação) escalada de tensão (Reignitions with voltage scalade)}

A reignição é caracterizada pela recondução de corrente no disjuntor após a sua interrupção. Ela está associada ao fenômeno do corte de corrente e à Tensão de Restabelecimento Transitória (TRT), a qual é igual a diferença entre as tensões dos seus terminais após a interrupção da corrente. Essa tensão é composta de uma parcela inicial transitória, amortecida e em alta frequência, resultante das características do circuito, sobreposta à parcela da frequência nominal do sistema (COLOMBO, 1990).

De acordo com Telander, Wilheim e Stump (1987), o mecanismo de múltiplas reignições para cargas predominantemente indutivas começa quando o disjuntor inicia a se abrir e o arco se estabelece entre seus contatos. Quando a corrente atinge o valor de corte, o arco é interrompido e um certo nível de energia fica armazenado nos componentes do circuito. A partir desse momento, o dielétrico passa a suportar o valor da tensão entre os terminais do disjuntor, existindo em seu interior um plasma remanescente, formado durante a condução do arco elétrico interrompido, e se observando uma temperatura em partes dos contatos suficiente para produzir vapor metálico (GREENWOOD, 2007).

Se em algum momento, a tensão entre os terminais superar a tensão de ruptura dielétrica, aliado à produção de vapores metálicos e a presença do plasma remanescente, a recondução de corrente ou reignição pode ocorrer e o arco se restabelece. Devido às indutâncias e capacitâncias do sistema e à instabilidade do arco, a corrente que flui nessa reignição possui uma componente harmônica de alta frequência, que pode ser interrompida devido à grande capacidade de extinção de correntes de alta frequência dos disjuntores a vácuo.

Essa interrupção ocorre no momento em que essa componente de alta frequência da corrente atingir o valor de corte, desde que a capacidade de extinção de alta frequência do disjuntor seja maior do que a taxa de variação da corrente no tempo. Caso a corrente seja extinta, o dielétrico deve suportar a tensão entre seus terminais, e os componentes do circuito passam a 
trocar energia novamente. Essa sequência pode ocorrer várias vezes, sendo que com o aumento do espaçamento entre os terminais do disjuntor, o nível de tensão entre seus contatos tende a aumentar a cada reignição.

De acordo com Perkins (1982), esse mecanismo acaba quando a corrente de alta frequência é cortada e o dielétrico suporta a próxima tensão transitória de restabelecimento associada à frequência nominal do sistema.

\subsubsection{Corte de corrente virtual (Virtual current chopping)}

Em sistemas trifásicos utilizando disjuntores a vácuo com três polos, no momento em que um polo interrompe a corrente, ela não será extinta simultaneamente nos outros polos. Se reignições ocorrerem durante esse período na fase onde o polo foi aberto, correntes de alta frequência podem fluir para as outras fases por meio do acoplamento capacitivo entre elas. Essas correntes de alta frequência sobrepostas com a corrente de frequência nominal podem atingir o valor de corte e se a capacidade de extinção de correntes de alta frequência do disjuntor for maior do que a derivada da corrente em relação ao tempo, o arco é cessado (SWINDLER, 1984). Nesse instante, a corrente de frequência nominal pode estar numa amplitude elevada e gerar sobretensões (LINDELL e LILJESTRAND, 2016).

\subsubsection{Pré-ignição (Prestrike)}

O fenômeno de reignição acontece durante a abertura dos disjuntores, porém existe um fenômeno similar no fechamento de disjuntores: a pré-ignição. Durante uma manobra de fechamento, com a proximidade dos contatos, o gradiente de potencial aplicado sobre o dielétrico pode ser grande o suficiente para rompê-lo e permitir a condução de uma corrente momentânea de alta frequência, dependente dos parâmetros do circuito. Essa condução de corrente é conhecida como pré-ignição.

Quando essa corrente chega ao valor de corte, ela pode ser interrompida e ocasionar sobretensões. Com a aproximação maior dos contatos, outras pré-ignições podem ocorrer, entretanto com amplitude de tensão reduzida entre os contatos do disjuntor. 


\subsubsection{Modelagem de disjuntores a vácuo}

Devido à natureza complexa das sobretensões transitórias oriundos de manobras de disjuntores a vácuo, há a necessidade de representar seu comportamento por meio de um modelo equivalente a ser utilizado em simulações numéricas. Diversos autores na literatura buscaram desenvolver um modelo para disjuntores a vácuo, sendo consideradas algumas características principais.

Primeiramente, Helmer e Lindmayer (1996), Abdulahovic et al. (2014), Yang et al. (2016) e Zhou et al. (2016) utilizaram um circuito com resistência, induntância e capacitância (RLC) série em paralelo com a chave dos disjuntores para simular seus componentes parasitas. Slade (2008) utilizou uma abordagem diferente, simulando os efeitos capacitivos dos disjuntores por meio de uma capacitância entre seus contatos e uma capacitância entre cada terminal e o terra.

Adicionalmente, algumas características do dielétrico devem ser incluídas no modelo. Com relação à tensão de ruptura dielétrica dos disjuntores, Budzisz e Wróblewski (2016) indicam que ela é influenciada principalmente pelas características de projeto, como o material dos contatos, suas dimensões e formato geométrico (vide Figura 6).

Figura 6 - Tensão de ruptura dielétrica em função da distância entre contatos e diâmetro dos contatos

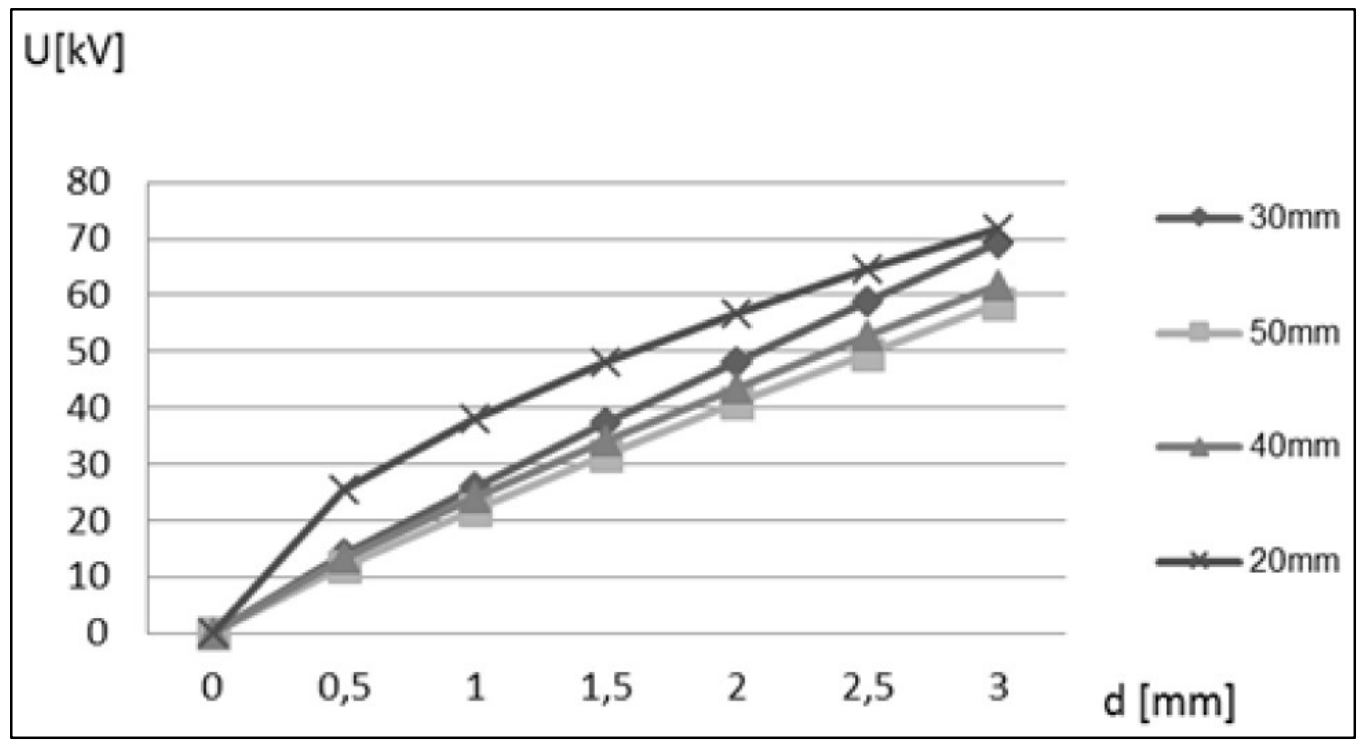

Fonte: Budzisz e Wróblewski (2016)

Conforme pode ser analisado na Figura 6, a tensão de ruptura dielétrica máxima entre os contatos no vácuo muda de acordo com seu diâmetro e a distância entre eles, sendo que o 
maior valor encontrado é para o disjuntor com contatos de diâmetro igual a $20 \mathrm{~mm}$ e distância entre ambos de $3 \mathrm{~mm}$. Essa característica do disjuntor é governada pela equação (1) (BUDZISZ e WRÓBLEWSKI, 2016):

$$
U_{D M}=A_{1} \times d^{b}
$$

sendo $U_{D M}$ a tensão de ruptura dielétrica máxima [V], $A_{1}$ e $b$ coeficientes que dependem do material dos contatos, onde $b$ é adimensional e a unidade de $A_{1}$ é $[\mathrm{V} / \mathrm{mm}]$, e $d$ a distância entre os contatos $[\mathrm{mm}]$.

Para que Budzisz e Wróblewski desenvolvessem um modelo no software Alternative Transient Program (ATP), experimentos foram realizados com disjuntores a vácuo para determinar os valores de tensão suportados pelo dielétrico em função do tempo a partir da interrupção do arco entre seus contatos, ou seja, a curva de tensão de ruptura dielétrica conforme Figura 7, sendo essa curva implementada no ATP.

Figura 7 - Tensão de ruptura dielétrica em função do tempo após abertura com contatos de cobre e diâmetro igual a $30 \mathrm{~mm}$

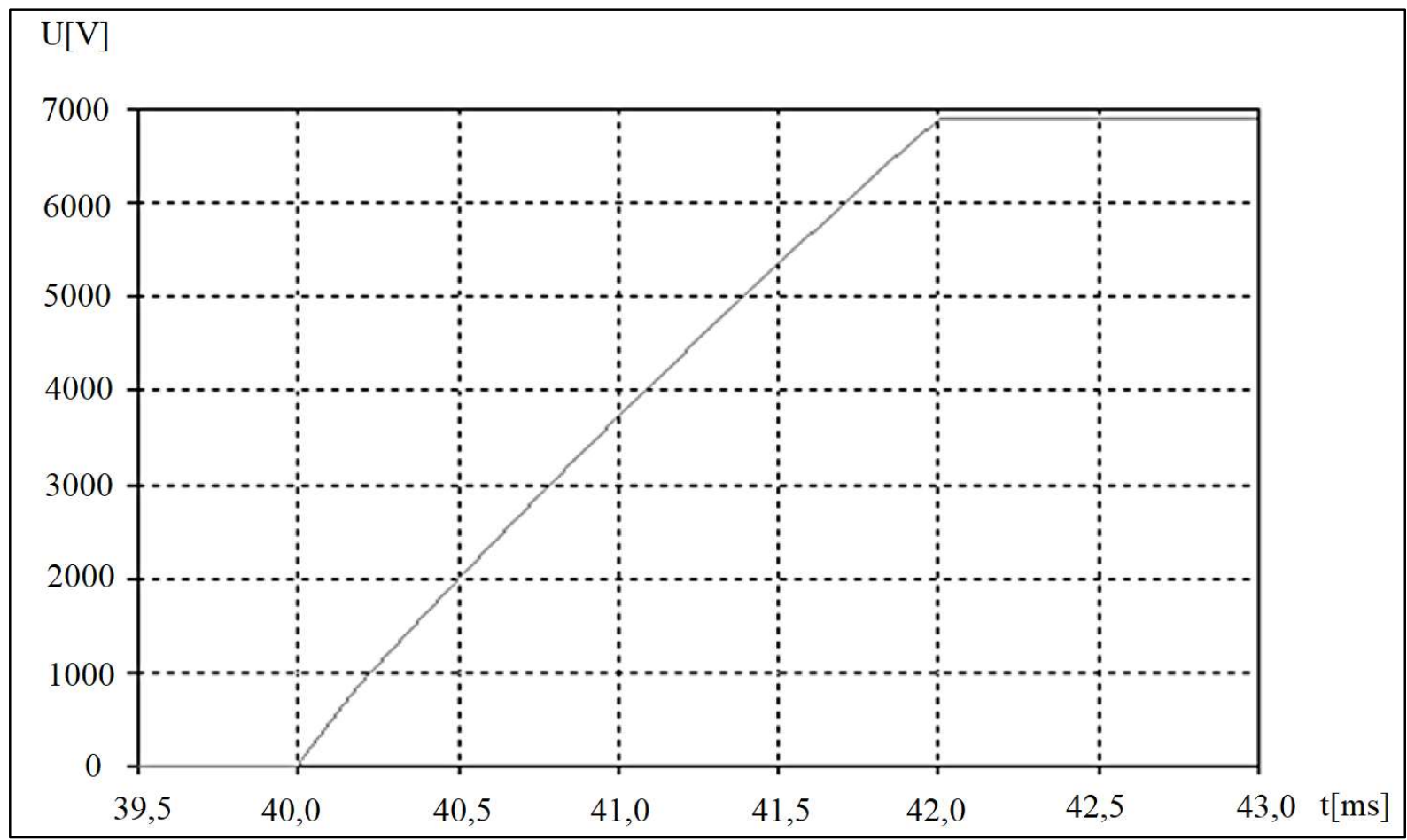

Fonte: Adaptado de Budzisz e Wróblewski (2016)

Constata-se pela Figura 7 que a curva de tensão de ruptura dielétrica após interrupção do arco elétrico pode ser aproximada por duas retas, sendo essa a forma mais popular de 
representação dessa propriedade do disjuntor. Para que essa curva seja expandida para diferentes tipos de disjuntores a vácuo, Popov (2002), Rao e Gajjar (2006), Yang et al. (2016) entre outros autores propuseram representar a curva da tensão de ruptura dielétrica em função do tempo de abertura, por meio da seguinte expressão:

$$
U_{D 1}=A\left(t-t_{A}\right)+B
$$

onde $\mathrm{U}_{\mathrm{D} 1}$ é a tensão de ruptura dielétrica [V], $\mathrm{t}_{\mathrm{A}}$ é o tempo de abertura [s] e $A$ e $B$ são constantes que dependem das características intrínsecas de cada disjuntor. A constante $A$ é definida experimentalmente e representa a taxa de recuperação da suportabilidade dielétrica (do inglês

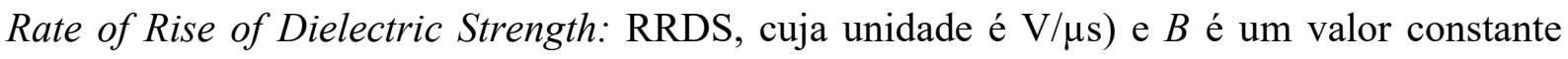
definido como a suportabilidade dielétrica inicial do disjuntor em [V] (YANG et al., 2016).

De acordo com Lerche (2009), os valores de $A$ variam de $2 \mathrm{~V} / \mu$ s até $50 \mathrm{~V} / \mu$ s. Já segundo Glinkowski, Gutierrez e Braun (1997), os valores de $A$ e $B$ são definidos em função de características típicas de rigidez dielétrica, conforme Tabela 1:

Tabela 1 - Valores de A e B

\begin{tabular}{cc}
\hline $\mathbf{A}(\mathbf{k V} / \mathbf{m s})$ & $\mathbf{B}(\mathbf{k V})$ \\
\hline 17 & 3,4 \\
\hline 13 & 0,69 \\
\hline 4,7 & 0,69 \\
\hline
\end{tabular}

Fonte: Glinkowski, Gutierrez e Braun (1997)

Apesar da maioria dos autores dessa área utilizarem o formato linear para representar essa características, outras abordagens são adotadas. Helmer e Lindmayer (1996) consideram que a tensão disruptiva do dielétrico varia linearmente com a distância entre os contatos, regida pela equação (3):

$$
U_{D 2}=A \times d+U_{0}
$$

sendo $A$ a RRDS com relação à distância entre os contatos $[\mathrm{kV} / \mathrm{mm}], U_{0}$ a suportabilidade dielétrica constante $[\mathrm{kV}]$ e $d$ a distância entre os contatos [mm]. Essa abordagem é muito similar com a anterior, pois a distância entre os contatos varia com o tempo.

Abdulahovic et al. (2014) contestam o modelo linear, pois em seus experimentos foi constatado que a velocidade de separação dos contatos aumenta durante a operação de abertura, 
portanto a curva do dielétrico não poderia variar linearmente. Dessa maneira, os referidos autores propõe uma modelagem mecânica do disjuntor, onde a distância entre os contatos depende de uma força que o acelera, representada a seguir:

$$
d=\frac{F}{m} t^{2}
$$

onde $F$ é a força que acelera os contatos $[\mathrm{N}], t$ é o tempo [s] e $m$ sua massa $[\mathrm{kg}]$. O valor da distância da equação (3) é substituída na equação (4) e chega-se a uma equação de segundo grau. O problema dessa modelagem é a dificuldade de obter os valores de $F$ e $m$, portanto Abdulahovic et al. (2014) optaram por modelar o comportamento da curva por uma equação de segunda ordem, com o intuito de se assemelhar com a equação (2). A equação está representada a seguir:

$$
U_{D 3}=A_{1}\left(t-t_{A}\right)^{2}+B_{1}\left(t-t_{A}\right)+C_{1}
$$

onde $C_{1}$ representa o mesmo que a constante $B$ apresentada para a equação (2), e $A_{1}$ e $B_{1}$ são constantes determinadas experimentalmente de acordo com a taxa de inclinação da reta no início e no final do transitório, cujas unidades são respectivamente $\left[\mathrm{V} / \mathrm{s}^{2}\right] \mathrm{e}[\mathrm{V} / \mathrm{s}]$.

Uma abordagem completamente diferente das demais é adotada por Mammadov, Lazimov e Imanov (2009). Em seu artigo é apresentada uma modelagem para o comportamento dielétrico pela seguinte expressão:

$$
U_{D 4}=\frac{1}{2} V_{M A X}\left\{1-\cos \left[\frac{\pi\left(t-t_{A}\right)}{T_{T A}}\right]\right\},
$$

Esse modelo leva em conta a inércia dos contatos e é coincidente com o comportamento real dos disjuntores. Segundo os mesmos autores a representação linear superestima as tensões, subestima a quantidade de reignições e possui um comportamento mais rígido quando comparado com a representação cosseinodal.

O modelo da equação (6) foi aprimorado no trabalho de Mammadov, Lazimov e Imanov (2009), levando em consideração a inconstância da rigidez dielétrica no vácuo. Assim, chegouse na seguinte expressão para caracterizar a curva de recuperação da tensão de ruptura dielétrica: 


$$
U_{D 5}=191,43 \log \left\{1+5,75 \mathrm{x}_{\mathrm{m}}\left\{1-\cos \left[\frac{\pi\left(t-t_{A}\right)}{T_{T A}}\right]\right\}\right\},
$$

sendo $\mathrm{x}_{\mathrm{m}}$ a maior distância entre os contatos. Esse modelo, segundo apresentado pelos autores, é muito próximo ao comportamento real, porém ele não é aplicável para qualquer faixa de tensão de disjuntores a vácuo e para qualquer tipo de formato de contatos, sendo necessário realizar adaptações.

Com relação à tensão máxima de rompimento do dielétrico, foi constatado por Slade (2008) que seu valor é diretamente proporcional à distância entre os contatos para distâncias de até $0,4 \mathrm{~mm}$, já para distâncias maiores a tensão é proporcional a distância elevada a um fator que varia de acordo com a distância $(0,58$ para distâncias entre $0,4 \mathrm{~mm}$ e $40 \mathrm{~mm}$ e 0,34 para distâncias entre 40 e 100mm). Acima de 100mm, observa-se uma limitação do valor máximo. $\mathrm{O}$ disjuntor com terminais com a liga $\mathrm{Cu}-\mathrm{Cr}$ pode atingir uma tensão de ruptura do dielétrico igual a $400 \mathrm{kV}$.

A capacidade de extinção de correntes de alta frequência desse tipo de disjuntor pode ser definida como um valor constante entre $100 \mathrm{~A} / \mu \mathrm{s}$ e $600 \mathrm{~A} / \mu \mathrm{s}$ ou pode-se adotar uma abordagem similar da curva de tensão de ruptura dielétrica, ou seja, uma equação linear com o seguinte formato (ABDULAHOVIC et al., 2014):

$$
\frac{d i}{d t}=C\left(t-t_{A}\right)+D
$$

onde $C$ e $D$ são valores que podem ser determinados por meio de experimentos em disjuntores, sendo valores típicos para tais constantes são definidos na Tabela 2.

Tabela 2 - Valores de C e D

\begin{tabular}{cc}
\hline $\mathbf{C}\left(\mathbf{A} / \boldsymbol{\mu} \mathbf{s}^{2}\right)$ & $\mathbf{D}(\mathbf{A} / \boldsymbol{\mu} \mathbf{s})$ \\
\hline$-0,034$ & 255 \\
\hline 0,32 & 155 \\
\hline 1 & 190 \\
\hline
\end{tabular}

Fonte: Glinkowski, Gutierrez e Braun (1997)

Por fim, a corrente de corte, como já apresentado no Capítulo 2.1.1, varia de acordo com o material utilizado nos terminais dos disjuntores a vácuo. Kosmac e Zunko (1995) apontam 
que a corrente de corte possui uma natureza probabilística, portanto, determina-se o valor da corrente de corte a partir de um valor médio, adicionando ou subtraindo um valor de desvio padrão.

Yang et al. (2016) estabelecem a equação (9) para o cálculo do valor médio da corrente de corte:

$$
\overline{I_{\text {CORTE_MÉDIO }}}=(\omega . i \cdot \alpha \cdot \beta)^{q},
$$

onde $\omega$ é a frequência da fonte em $\mathrm{rad} / \mathrm{s}, i$ é a amplitude da corrente na frequência nominal, $\alpha$ vale $6,2.10^{-16}, \beta$ vale 14,3 e $q$ é igual a $(1-\beta)^{-1}$.

\subsection{Falhas de Transformadores}

Como apresentado no Quadro 1 do subcapítulo 1.1, transformadores em diversas instalações tiveram falha de seu isolamento devido às tensões transitórias oriundas de manobras de disjuntores a vácuo.

Conforme apresentado pelo Institute of Electrical and Electronic Engineering (IEEE) (2011), o isolamento é um dos elementos construtivos mais importantes de um transformador, com a função de confinar a corrente em seu caminho usual, onde qualquer fragilidade pode causar uma falha do transformador.

Testes de impulso são necessários para verificar a suportabilidade do isolamento frente a impulsos atmosféricos e de manobra por parte do fabricante, sendo que eventualmente o comprador realiza testes para aceitação final do produto. Conforme estabelecido pelo IEEE (2011) e pela ABNT (2008), as formas de ondas utilizadas para testar a suportabilidade do isolamento do transformador frente a impulsos são conhecidas como impulso pleno (full wave), impulso cortado (chopped wave), frente de onda (front-of-wave) e impulso de manobra (switching impulse wave).

O nível máximo de tensão que o isolamento do transformador deve suportar em testes de impulso atmosférico é conhecido como tensão nominal suportável a surto atmosférico, cujo termo utilizado em normas americanas é Basic Insulation Level (BIL), traduzido para nível básico de isolamento a impulso atmosférico (NBI). Já para os ensaios de manobra, o valor máximo de tensão é conhecido como tensão nominal suportável a surto de manobra (do inglês Basic Switching Impulse Level - BSL), sendo esse último valor igual a aproximadamente 83\% 
do NBI. Os ensaios de manobras são realizados em um nível elevado de tensão (acima de $300 \mathrm{kV})$.

As formas de onda das sobretensões encontradas nas manobras de disjuntores a vácuo são muito diferentes daquelas dos ensaios padronizados, e apesar dos ensaios realizados, falhas no isolamento de transformadores podem ocorrer durante manobras de disjuntores a vácuo face aos seguintes fatores:

- Elevada taxa de crescimento da tensão em relação ao tempo excitando ressonâncias internas (LILJESTRAND et al., 2013);

- Impulsos de tensão aplicados repetidamente. Quando vários impulsos de tensão são aplicados repetidas vezes no transformador pode ocorrer a falha do isolamento, mesmo que sejam observados valores de tensão menores do que seu NBI. Isso ocorre devido ao desgaste acumulativo em pontos internos do enrolamento. Estudos realizados apontam que o valor da ruptura dielétrica é inversamente proporcional ao número de impulsos, sendo desenvolvido pelo Grupo de Trabalho C4.302 do Conseil International des Grands Réseaux Électriques (CIGRÉ) ou em português Conselho Internacional de Grandes Sistemas Elétricos, uma curva característica de tensão/número (V-N) para estudar esse tipo de característica do transformador (BALAJI et al., 2011), levando em conta fatores relativos à forma da onda dos impulsos aplicados e ao valor mínimo de tensão que causa ruptura dielétrica associado a esse impulso (BALAJI e USA, 2013). Tais estudos foram realizados para transformadores a óleo, sendo necessário expandi-los para tratar do caso de transformadores a seco; ou

- De acordo com Liljestrand et al. (2013), podem ocorrer sobretensões que ultrapassam o NBI dos equipamentos. No entanto, durante manobras de disjuntores a vácuo, pode-se admitir que níveis elevados de sobretensões a ponto de superar o NBI dos equipamentos raramente ocorrem, podendo-se considerar as duas causas apresentadas anteriormente como principais causas de falhas de isolamento de transformadores durante manobras de disjuntores a vácuo.

\subsection{Estudos de Caso}

Kuczek (2015) e Kuczek, Florkowski e Piasecki (2016) analisaram os impactos de sobretensões em usinas fotovoltaicas e a influência do filtro LC conectado ao conversor $\mathrm{CC} / \mathrm{CA}$ 
na redução do nível de sobretensões nos transitórios causados pelo fechamento e abertura de um disjuntor a vácuo. Para tal, realizaram experimentos e simulações no software ATP analisando a parte em corrente alternada de um circuito conectado a uma planta fotovoltaica. $\mathrm{O}$ circuito experimentado era composto de um painel solar conectado a um conversor CC-CC em cascata a um conversor CC-CA, ligado a um transformador de média tensão por meio dos filtros LC e que, por fim, era interligado à rede elétrica. A rede elétrica era composta por uma fonte, cabos elétricos, um autotransformador e um transformador de baixa tensão. Como o comportamento do chaveamento dos conversores não fazia parte do escopo, o circuito da Figura 8 foi preparado no laboratório:

Figura 8 - Circuito experimentado

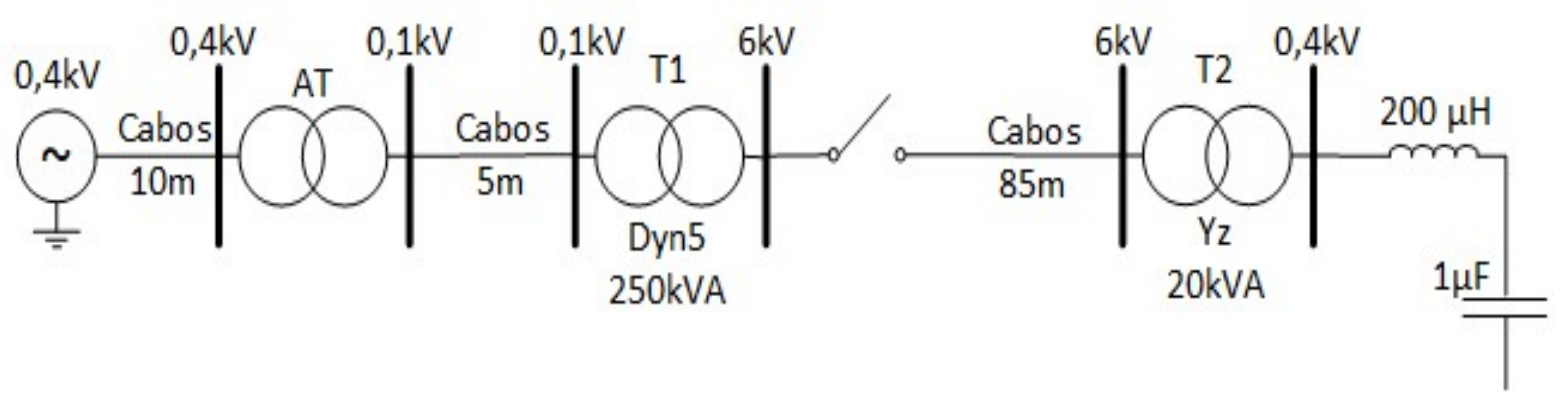

Fonte: Adaptado de Kuczek, Florkowski e Piasecki (2016)

Yang et al. (2016) avaliaram os resultados de experimentos realizados em uma subestação de $220 \mathrm{kV}$, contendo um transformador $(220 / 10 \mathrm{kV})$ conectado a um barramento de $10 \mathrm{kV}$. O barramento era conectado a três circuitos, sendo o primeiro composto por um disjuntor a vácuo, uma linha de transmissão e reatores shunt; o segundo composto por capacitores shunt; e o terceiro composto de uma linha de transmissão e um transformador. Foi observada a influência dos reatores shunt nas sobretensões.

Ghafourian et al. (2016) examinaram as sobretensões em aerogerados causadas por préignições em usinas eólicas offshore, onde os resultados foram coletados in loco e simulados no software ATP. A usina eólica estudada se localizava em Liverpool (Inglaterra) e consistia de 25 geradores eólicos. $\mathrm{Na}$ base de cada gerador, se localizava um transformador 34/0,69kV de 4MVA, que se conectava aos cabos agregadores submarinos por meio de um disjuntor a vácuo. Esses cabos se agrupavam em três barramentos submarinos que, por fim, se conectavam à subestação em terra. A partir da subestação era feita a conexão ao sistema elétrico por meio de cabos aéreos ou subterrâneos. 
Finalmente, Zhou et al (2016) também estudaram reignições em parques eólicos por meio de simulações no software ATP. O parque eólico objeto do estudo era composto de 20 geradores eólicos de 3MW, onde cada qual possuía um transformador $35 / 0.69 \mathrm{kV}$ em sua base. Dois grupos de dez geradores eram conectados entre si e a um cabo submarino, o qual era conectado a um disjuntor a vácuo e à rede elétrica. No experimento, a tensão no lado de $35 \mathrm{kV}$ do primeiro transformador de um dos grupos de geradores foi medida.

\subsection{Soluções Propostas}

Autores abordam soluções para se reduzir as sobretensões transitórias oriundas de manobras de disjuntores a vácuo e evitar danos aos equipamentos do circuito protegido, sendo que Lindell e Liljestrand (2016) as condensam em seu trabalho. As soluções propostas são as seguintes:

1. Utilização de snubber RC;

2. Conexão de para-raios fase-terra (F-T);

3. Conexão de para-raios F-T e fase-fase (F-F);

4. Combinação de snubber RC e para-raios F-T;

5. Conexão de para-raios F-T e ao ponto médio dos enrolamentos de transformadores.

\subsubsection{Snubber $\mathrm{RC}$}

A primeira solução é a instalação de um snubber $\mathrm{RC}$, o qual atua como filtro de alta frequência, nos terminais primários de transformadores para a terra (Figura 9). 
Figura 9 - Instalação de snubbers RC

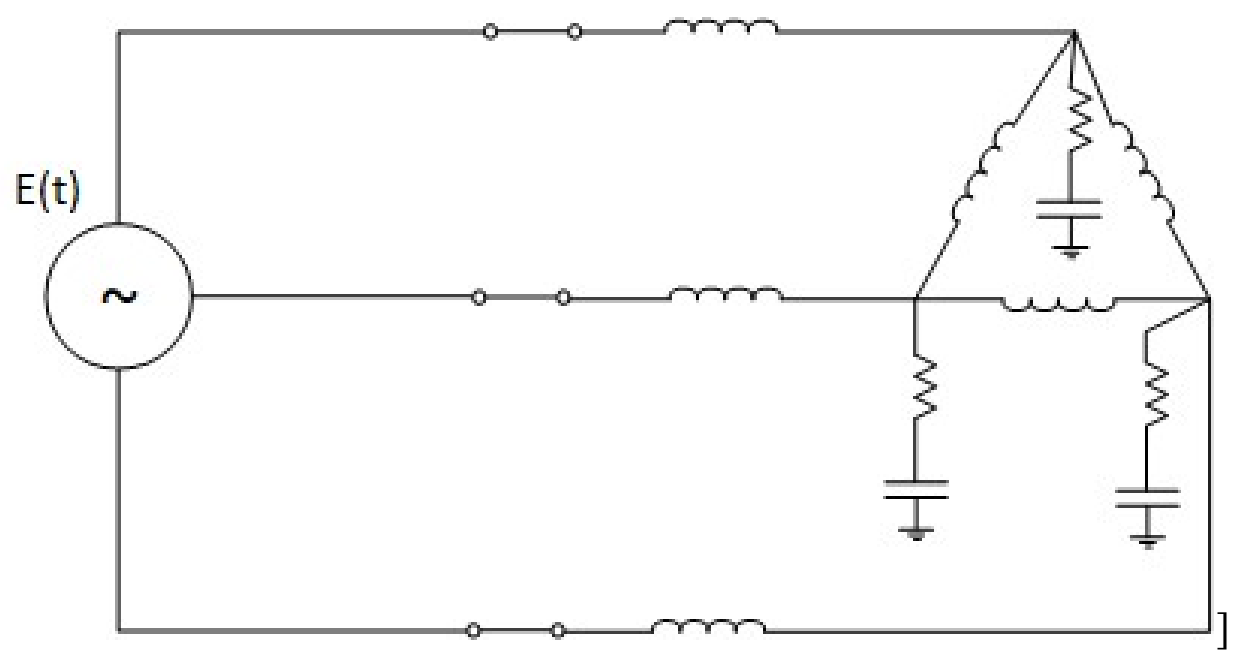

Fonte: Autor

De acordo com Lindell e Liljestrand (2016), a instalação de snubbers RC nos terminais do transformador atua no sistema aumentando o valor da capacitância no circuito e consequentemente criando um caminho para dissipar a energia acumulada na indutância e, consequentemente, diminuindo o valor da magnitude da sobretensão causada pela manobra do disjuntor. Além disso, os capacitores impedem uma variação brusca da tensão no terminal do disjuntor. Conforme apresentado, uma diminuição da tensão reduz o número de reignições, pois a tensão suportada pelo dielétrico não é superada nesses casos. Adicionalmente, o snubber desloca os valores da frequência de oscilação e pode prevenir que amplificações da tensão nas frequências naturais do transformador protegido venham a ocorrer.

Mardegan et al. (2016) apresentaram um guia para determinação dos valores dos componentes do snubber a partir de suas experiências em instalação desse tipo de equipamento:

a) Capacitor: Os capacitores devem ser escolhidos de forma a limitar as sobretensões e a frequência de oscilação e possuir um NBI similar ao NBI do transformador. Além do mais, sua capacitância deve ser selecionada de modo a manter os picos de correntes e tensão abaixo do seu máximo suportável e deve valer entre 0,1 e $0,5 \mu \mathrm{F}$;

b) Resistor: O valor da resistência deve ser próximo ao valor da impedância de surto do cabo localizado entre o transformador e o disjuntor a vácuo, de forma a evitar reflexão de ondas. A potência do resistor deve ser o dobro da potência dissipada para a corrente nominal do circuito snubber. Por fim, para o resistor não queimar durante transitórios, seu limite de energia térmica deve ser determinado para um determinado período típico de $4 \mathrm{~ms}$. 
Esse tipo de instalação ocupa um grande espaço físico e seu custo é elevado.

\subsubsection{Para-raios}

Os para-raios possuem a característica de limitar a tensão devido à resistência não linear do materiais utilizados na sua composição: os óxidos metálicos. Esses para-raios de óxido metálico (Metal Oxide Varistor - MOV) possuem preponderância de óxido de zinco $(\mathrm{ZnO})$ e são também conhecidos pelo nome desse óxido. A curva da resistência não linear desses pararaios é apresentada na Figura 10:

Figura 10 - Curva V-i para-raio

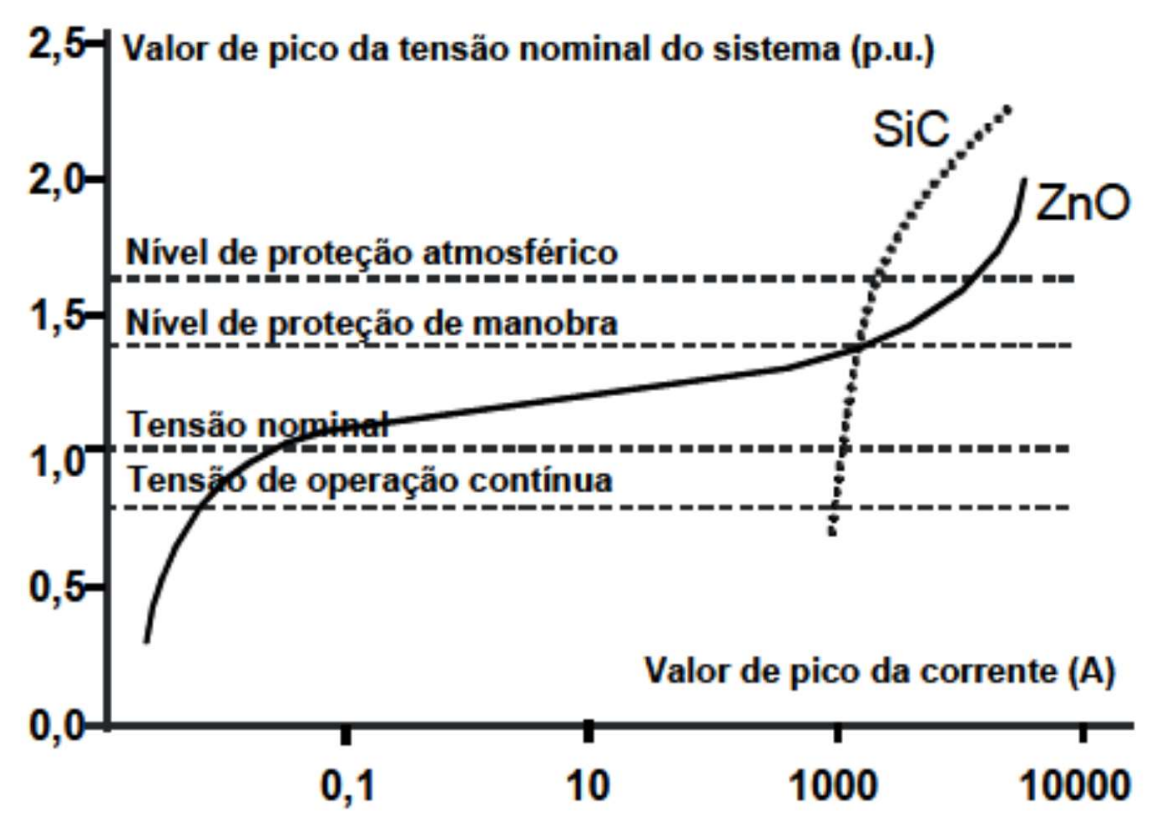

Fonte: Marcarini (2012)

Pode-se observar que em determinada região da curva, a corrente aumenta e a tensão praticamente se mantém constante. O para-raios limita amplitudes de sobretensões de alta frequência durante as reignições e pré-ignições e durante o corte de corrente.

Durante as reignições e pré-ignições, quando o disjuntor está conduzindo, maiores valores de sobretensão são limitados, sendo que um alto valor de corrente circula pelo pararaios nesses instantes. Nesse caso, o para-raios atua como na sua aplicação contra sobretensões oriundas de descargas atmosféricas em linhas aéreas. 
Já durante o corte de corrente, quando o disjuntor deixa de conduzir, uma sobretensão pode ocorrer devido às energias magnéticas armazenadas nas indutâncias do circuito. Nesse caso, a corrente oriunda dessa energia circula pela capacitância do circuito. A instalação de um para-raios cria um caminho alternativo para essa corrente, permitindo que essa corrente de pequena amplitude continue a fluir mesmo com o disjuntor aberto, absorvendo a energia magnética e limitando a tensão em uma amplitude baixa (LINDELL e LILJESTRAND, 2016).

Uma primeira solução utilizando para-raios é instalação F-T desses equipamentos nos terminais primários do transformador conforme Figura 11.

Figura 11 - Instalação de para-raios F-T

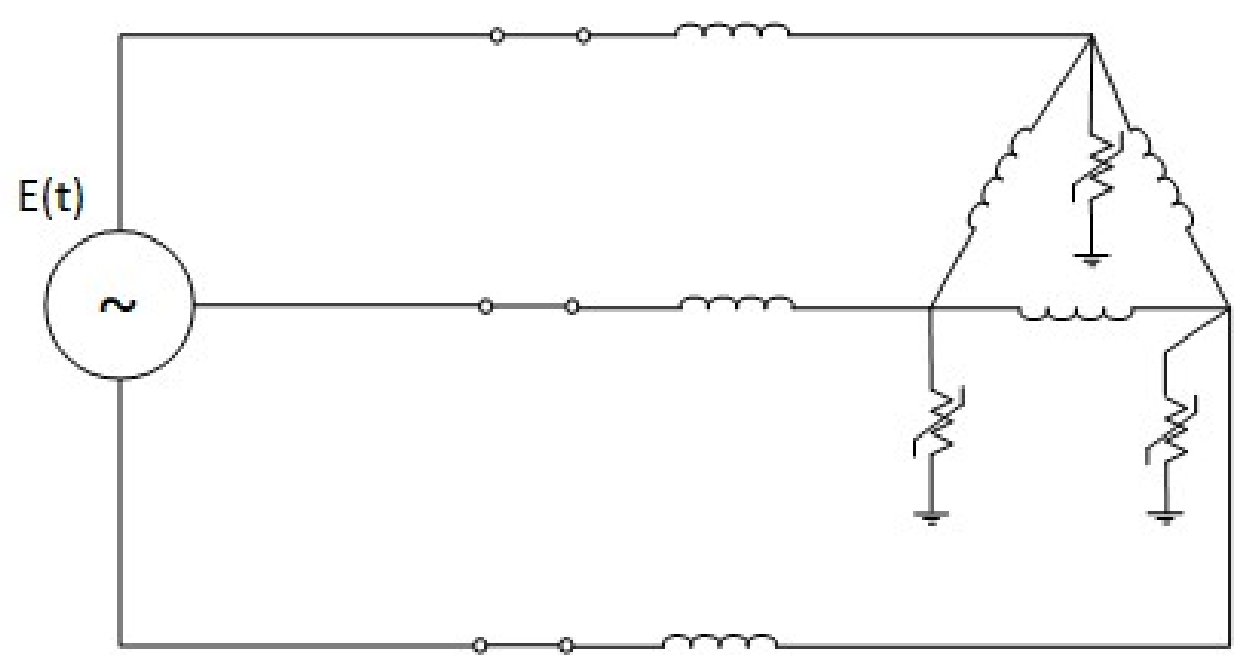

Fonte: Autor

Nesse caso, no momento de abertura do disjuntor, a tensão sobre os enrolamentos fica limitada à soma da tensão fase-terra em dois para-raios.

Uma segunda opção de solução utilizando para-raios é sua instalação F-T e F-F, conforme apresentado na Figura 12. 
Figura 12 - Instalação de para-raios F-T e F-F

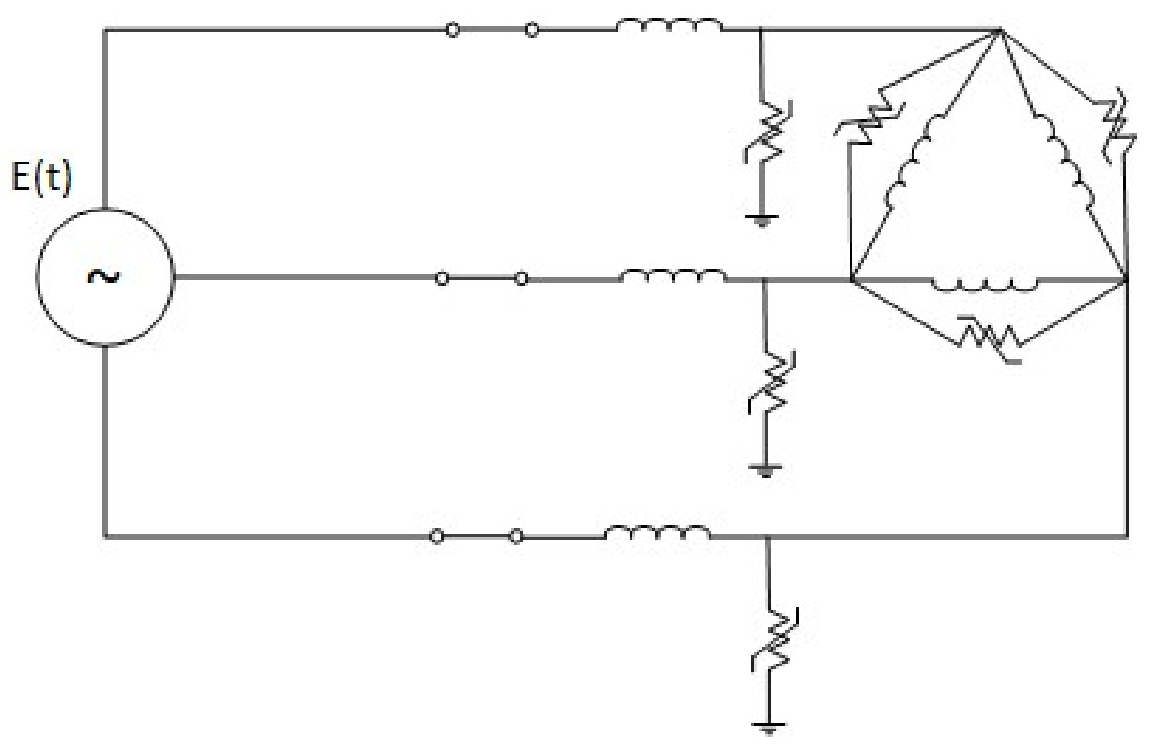

Fonte: Autor

Nessa instalação, observa-se uma atuação mais eficiente dos para-raios F-F em relação aos F-T, e a tensão aplicada sobre os enrolamentos é igual à tensão de linha, sendo menor do que na configuração anterior (duas vezes a tensão fase terra). Segundo Lindell e Liljestrand (2016), a necessidade de se utilizarem os para-raios F-T é que, caso eles sejam removidos, uma tensão offset $\mathrm{CC}$ pode aparecer nos terminais do transformador.

Além disso, com relação à instalação dos para-raios, há a necessidade de reservar espaço suficiente na planta, porém esse espaço é menor quando comparado ao ocupado pelos snubbers. 


\subsubsection{Utilização de snubbers RC e para-raios}

Lindell e Liljestrand (2016) e Mardegan et al. (2016) sugerem a utilização conjunta das soluções apresentadas anteriormente, conforme Figura 13.

Figura 13 - Instalação de para-raios e snubbers RC

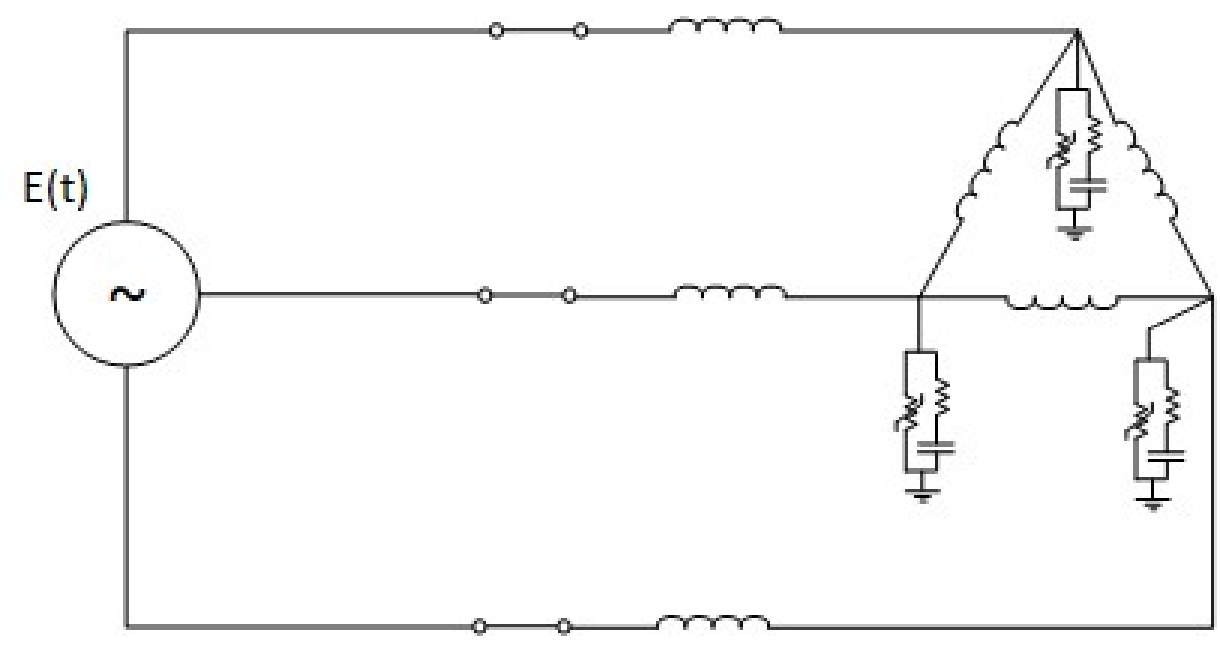

Fonte: Autor

Essa solução reúne as vantagens das soluções anteriores, ou seja, uma redução do número de reignições devido ao snubber RC e uma limitação na sobretensão devido aos pararaios.

A instalação de snubbers RC e para-raios requer um espaço considerável na planta, pois segundo Mardegan et al. (2016) o arranjo consiste em instalar os para-raios no topo e os capacitores logo abaixo para então conectar ao transformador, conforme a Figura 14. 
Figura 14 - Arranjo de snubbers RC e para-raios

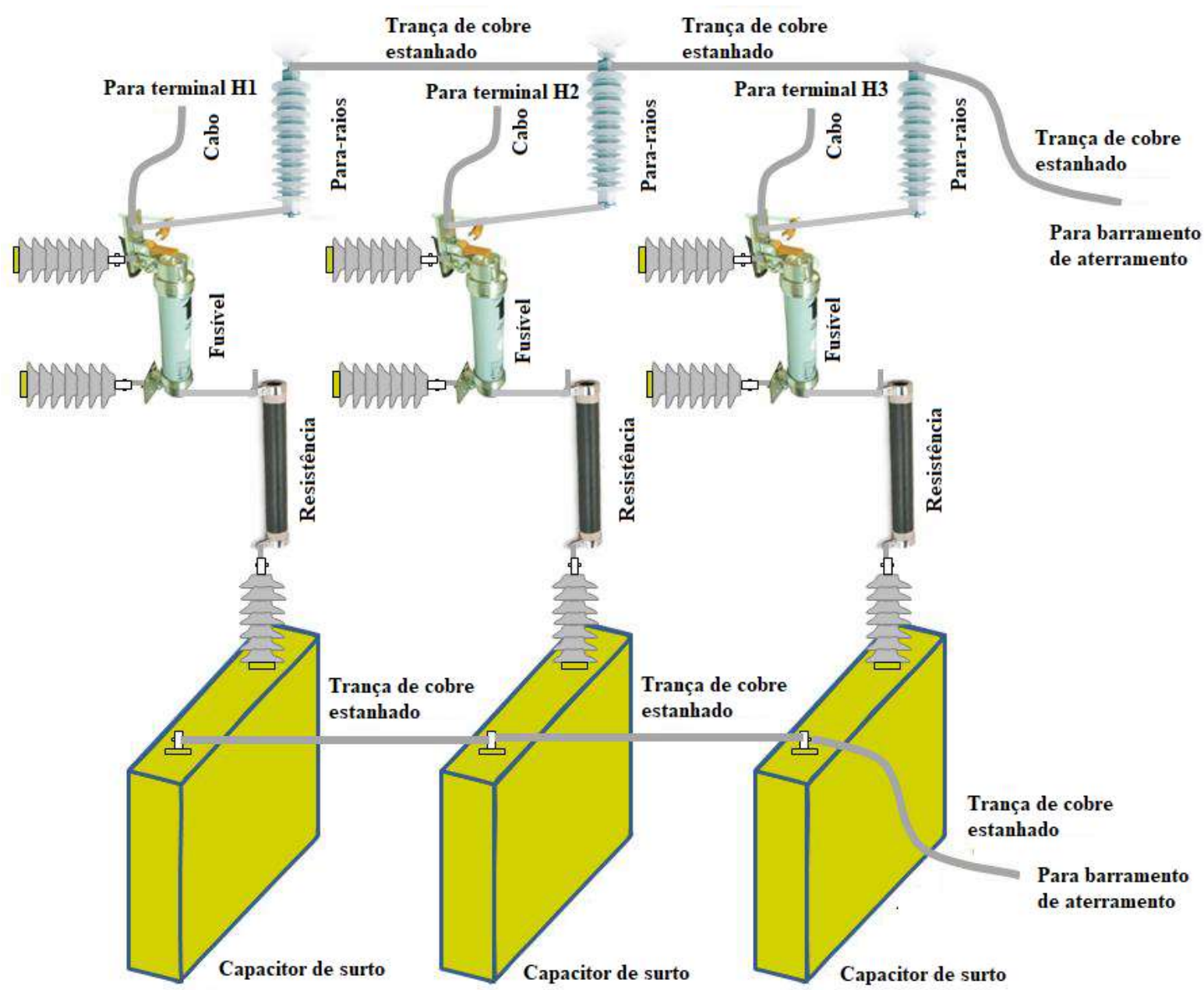

Fonte: Adaptado de Mardegan et al. (2016)

\subsubsection{Para-raios instalados no ponto médio dos enrolamentos}

A ultima solução proposta é a instalação de dois para-raios em série por enrolamento, sendo o ponto médio dessa conexão conectado ao ponto médio do enrolamento, conforme Figura 15. Além desses para-raios, os para-raios F-T são instalados. A instalação dos para-raios conectados ao ponto médio dos enrolamentos tem a função de reduzir os efeitos da amplificação das ressonâncias internas no transformador, amortecendo as ressonâncias de ordem ímpar (LINDELL e LILJESTRAND, 2016). 
Figura 15 - Para-raios F-T e no ponto médio dos enrolamentos dos transformadores

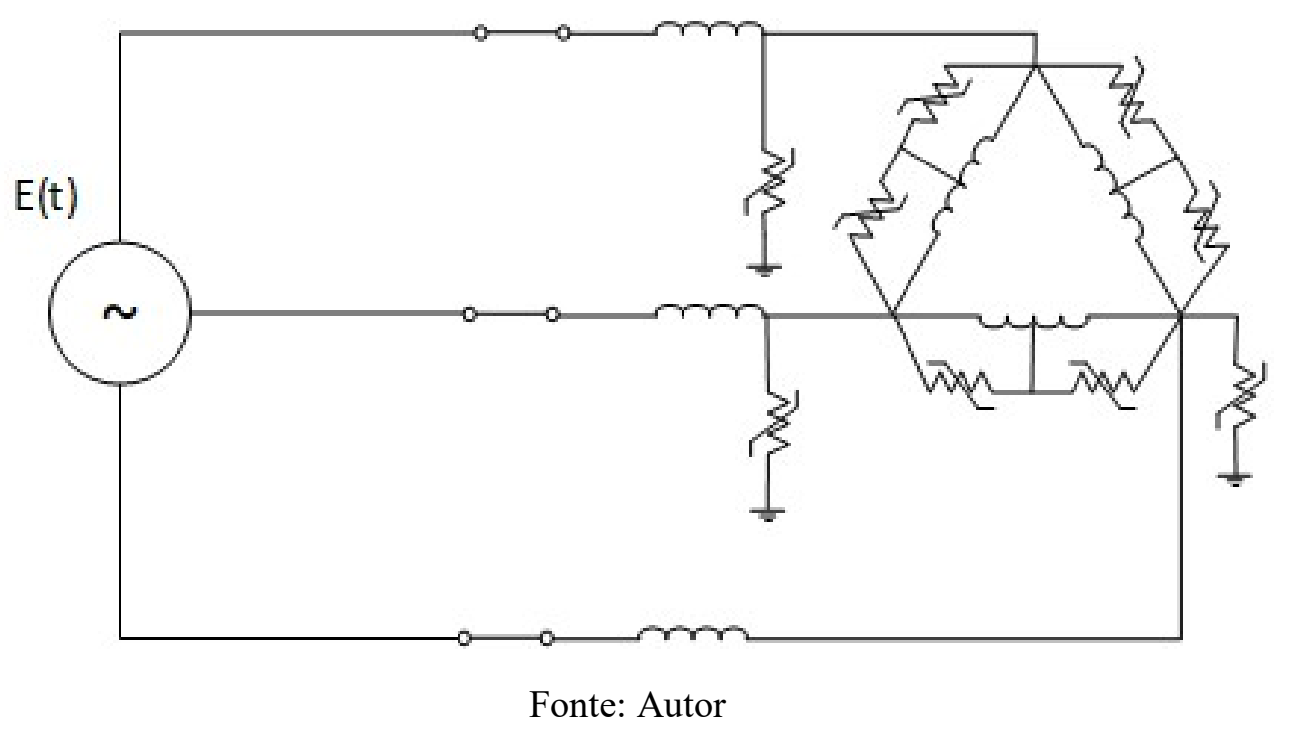

Os para-raios conectados ao ponto médio dos enrolamentos precisam ser instalados durante a fabricação dos transformadores, pois se encontram dentro de suas carcaças. Portanto, com relação ao espaço físico, não trazem consequências tão notáveis quanto às demais soluções apresentadas. 


\section{DADOS E METODOLOGIA}

Nesse capítulo é realizada uma análise matemática das tensões de restabelecimento transitória causadas após a interrupção de corrente em um circuito oscilatório LC. Tal análise tem o intuito de se verificar a influência do valor da corrente interrompida na TRT. Devido à natureza complexa do problema de sobretensões oriundas de manobras de disjuntores a vácuo, uma metodologia para simulações é apresentada, tomando como base um experimento de referência, o qual é utilizado para ajuste dos modelos dos componentes utilizados (cabos, disjuntor a vácuo e transformadores).

\subsection{Análise Matemática de Transitórios Durante o Corte de Corrente}

Em circuitos elétricos predominantemente indutivos, considerando apenas componentes com parâmetros concentrados, sabe-se que a corrente não pode variar instantaneamente, portanto o melhor momento para abertura do disjuntor, e consequente extinção da corrente alternada, é quando a mesma atinge o valor zero.

Devido às características operacionais dos disjuntores a vácuo já apresentadas, sabe-se que eles podem interromper correntes com valores diferentes de zero, fato esse que causa sobretensões transitórias entre seus terminais em circuitos predominantemente indutivos. Portanto, especialmente para disjuntores a vácuo, é de extrema importância estudar o comportamento da TRT.

Com o intuito de se investigar os transitórios em um circuito oscilatório causados pela interrupção de corrente para valores igual e diferente de zero em um determinado circuito LC, tem-se o circuito apresentado na Figura 16. Esse circuito é monofásico, composto por uma fonte ideal cossenoidal $E(t)$, por um indutor $L$ e por um capacitor $C$, desconsiderando suas perdas.

Figura 16 - Circuito LC

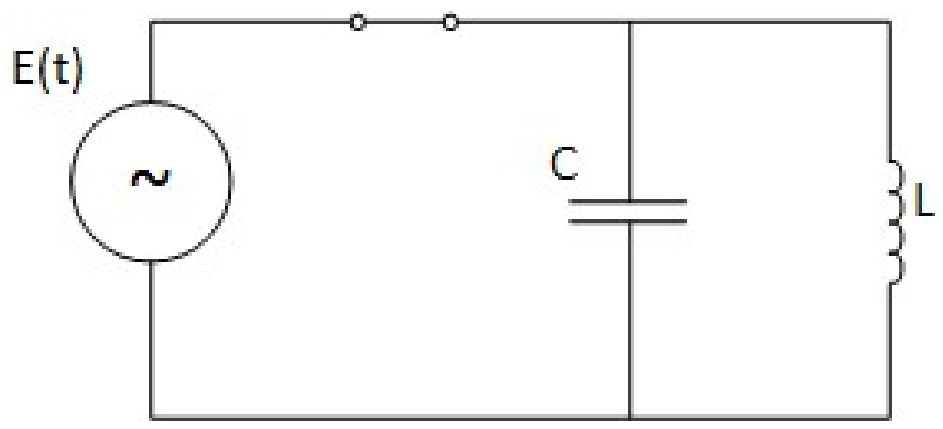

Fonte: Autor 
A fonte cossenoidal $E(t)$ é representada pela seguinte expressão:

$$
E(t)=E_{0} \cos (\omega t+\theta)
$$

sendo $E_{0}$ o valor da amplitude da fonte, $\theta$ o valor do deslocamento angular e $\omega$ o valor da frequência da fonte, onde:

$$
\omega=2 \pi f \text {. }
$$

A TRT pode ser determinada por meio do método de injeção de correntes e pelo princípio da superposição. No método de injeção de correntes, considera-se que, no momento de abertura do disjuntor, uma fonte de corrente contrária à corrente que está circulando no circuito é inserida, levando a corrente do circuito ao valor de zero amperes. A partir desse método, pode-se aplicar o príncipio da superposição, com o qual pode-se analisar a resposta da rede estudada com e sem a fonte de corrente, para em seguida efetuar a superposição de ambas as respostas (ZANETTA, 2003).

Conforme apresentado por Zanetta (2003), considera-se que a distribuição de tensões com o disjuntor fechado se mantém a mesma com sua substituição por um gerador de corrente $i(t)$ com o mesmo valor da corrente existente no circuito. Para o caso do circuito LC, verificase que a onda da corrente está em quadratura com relação ao sinal de tensão, portanto possui um formato senoidal e, assim:

$$
i(t)=I_{0} \operatorname{sen}(\omega t+\theta)
$$

sendo $\mathrm{I}_{0}$ a amplitude da fonte de corrente determinada a partir do valor da impedância equivalente do circuito e da amplitude $E_{0}$ da fonte de tensão. A impedância equivalente da rede é igual a:

$$
Z_{E Q}=\frac{j \omega L \times 1 / j \omega C}{j \omega L+1 / j \omega C}=\frac{j \omega L}{\left(-\omega^{2} L C+1\right)}=\frac{\omega}{C\left(-\omega^{2}+\omega_{0}^{2}\right)} \angle 90^{\circ},
$$

onde $\omega_{0}$ é o valor da frequência natural do circuito, sendo: 


$$
\omega_{0}^{2}=\frac{1}{L C}
$$

A partir da impedância equivalente do circuito, pode-se determinar o valor da amplitude da corrente $\left(I_{0}\right)$ :

$$
I_{0}=\frac{E_{0}}{Z_{E Q}}=\frac{E_{0}}{\frac{\omega}{C\left(-\omega^{2}+\omega_{0}^{2}\right)}}=\frac{E_{0}\left(-\omega^{2}+\omega_{0}^{2}\right) C}{\omega}
$$

A abertura do disjuntor é equivalente à introdução do gerador de corrente $-i(t)$. Dessa forma, no momento em que se deseja abrir o disjuntor, insere-se uma fonte de corrente com sentido oposto à corrente existente no sistema, ou seja, -i(t), conforme a Figura 17.

Figura 17 - Inserção do gerador de corrente $-i(t)$

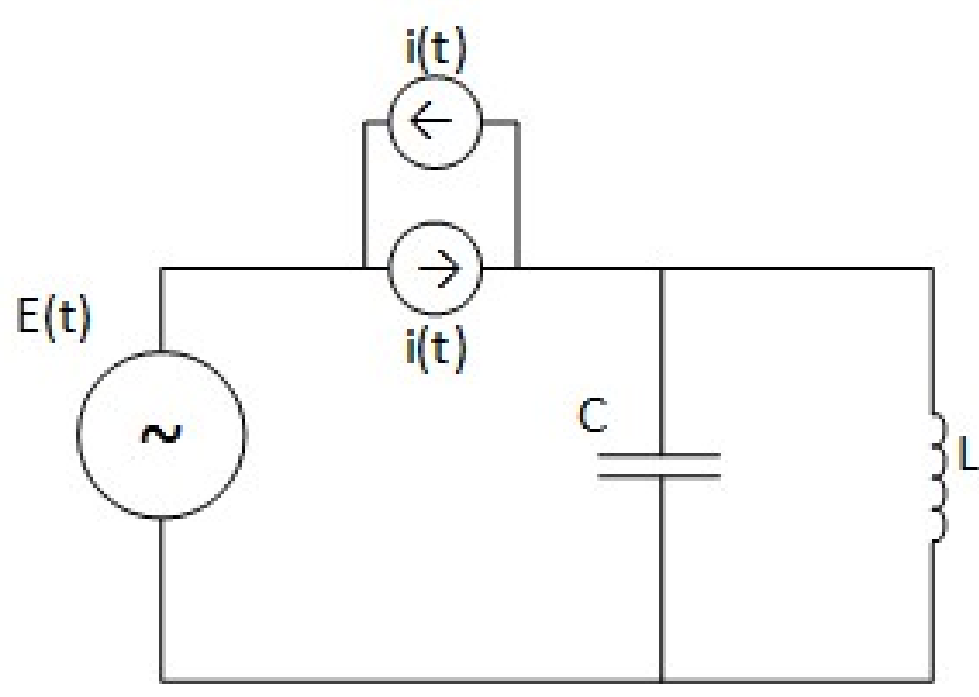

Fonte: Autor

A partir desse circuito, pode-se aplicar o princípio da superposição para se determinar a tensão entre os terminais do disjuntor. Primeiramente se considera o circuito sem o gerador de corrente $-i(t)$. Em seguida, considera-se o circuito apenas com o gerador de corrente $-i(t) \mathrm{e}$ somam-se os resultados para determinar o valor da TRT, conforme a Figura 18. 
Figura 18 - Princípio da superposição

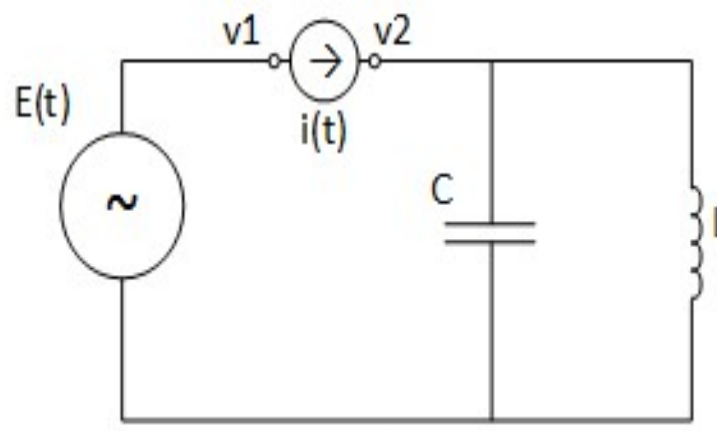

A)

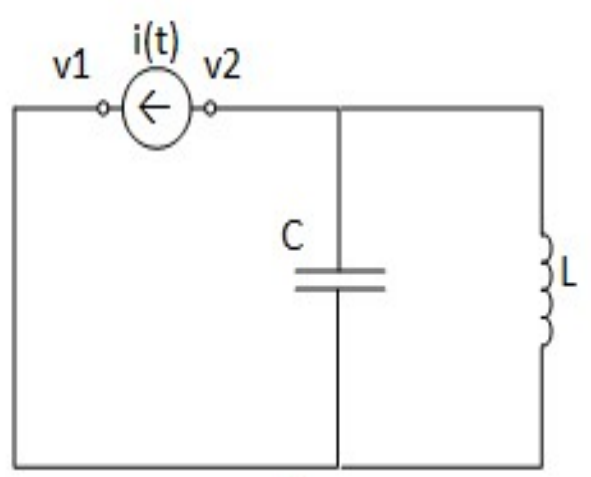

B)

Fonte: Autor

No circuito A), percebe-se que a contribuição para a TRT é nula, pois v1 é igual a v2. No circuito B), a TRT é a tensão existente sobre o capacitor e o indutor. Ou seja, apenas com o uso do circuito B) é possível determinar o valor da diferença de potencial sobre os terminais do disjuntor. Para determinação da TRT, após a interrupção da corrente, o circuito da Figura 19 é analisado.

Figura 19 - TRT após interrupção da corrente

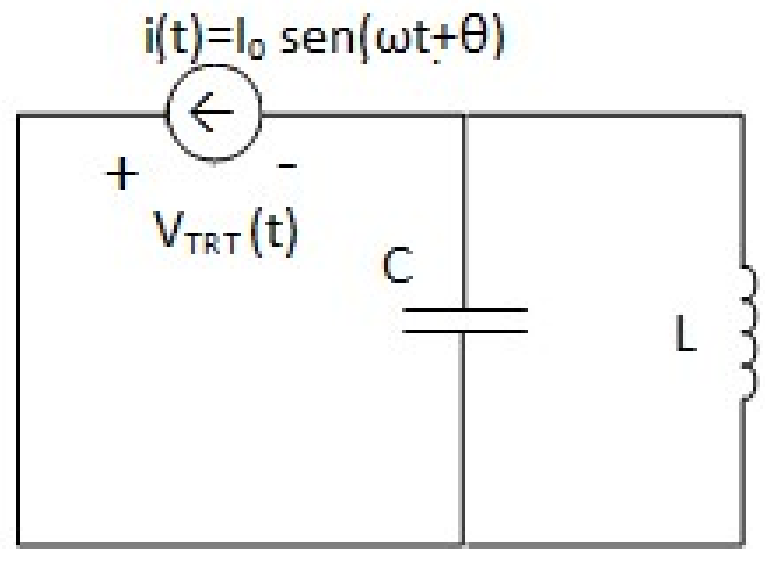

Fonte: Autor

Com o intuito de se analisar o comportamento da tensão de restabelecimento transitória, deve-se determinar o valor de $\mathrm{V}_{\mathrm{TRT}}$ no domínio complexo. Por meio de relações trigonométricas, sabe-se que:

$$
\operatorname{sen}(A+B)=\operatorname{sen}(A) \cos (B)+\cos (A) \operatorname{sen}(B) .
$$


Assim, a partir da transformada de Laplace do seno e da impedância equivalente definida em (13), o valor da TRT no campo complexo vale:

$$
\begin{aligned}
& V_{T R T}(s)=\frac{I_{0}(\omega \times \cos (\theta)+s \times \operatorname{sen}(\theta))}{s^{2}+\omega^{2}} \frac{s}{C\left(s^{2}+\omega_{0}^{2}\right)} \\
& =\frac{I_{0}}{C}\left[\frac{\omega \times \cos (\theta) \times s}{\left(s^{2}+\omega^{2}\right)\left(s^{2}+\omega_{0}^{2}\right)}+\frac{s^{2} \times \operatorname{sen}(\theta)}{\left(s^{2}+\omega^{2}\right)\left(s^{2}+\omega_{0}^{2}\right)}\right] .
\end{aligned}
$$

Pode-se resolver essa equação, a expandindo em frações parciais. O primeiro termo da equação pode ser igualado a:

$$
\frac{I_{0} \omega \cos (\theta)}{C} \frac{s}{\left(s^{2}+\omega^{2}\right)\left(s^{2}+\omega_{0}^{2}\right)}=\frac{K_{1}}{s-j \omega}+\frac{\dot{K}_{1}}{s+j \omega}+\frac{K_{2}}{s-j \omega_{0}}+\frac{\dot{K}_{2}}{s+j \omega_{0}}
$$

Como os polos das equações do denominador são complexos conjugados, os seus respectivos resíduos serão complexos conjugados, bastando o cálculo de um deles. $K_{l}$ pode ser encontrado multiplicando a equação por $\frac{s-j \omega}{s-j \omega}$ e igualando $s$ a $j \omega$, dessa forma encontra-se:

$$
\begin{gathered}
K_{1}=\frac{I_{0} \omega \cos (\theta)}{C} \frac{s}{(s+j \omega)\left(s^{2}+\omega_{0}^{2}\right)}=\frac{I_{0} \omega \cos (\theta)}{C} \frac{j \omega}{(2 j \omega)\left(-\omega^{2}+\omega_{0}^{2}\right)} \\
=\frac{I_{0} \omega \cos (\theta)}{2 C\left(-\omega^{2}+\omega_{0}^{2}\right)} .
\end{gathered}
$$

$K_{2}$ é determinado de forma similar, realizando o mesmo mostrado para $K_{1}$, entretanto considerando $s$ igual a $j \omega_{0}$, portanto:

$$
K_{2}=\frac{I_{0} \omega \cos (\theta)}{2 C\left(-\omega_{0}^{2}+\omega^{2}\right)}
$$

Portanto pode-se determinar a transformada inversa de Laplace da equação (18) diretamente, considerando-se os valores de $K_{1}$ e $K_{2}$ : 


$$
\begin{aligned}
& \frac{I_{0} \omega \cos (\theta)}{2 C\left(-\omega^{2}+\omega_{0}^{2}\right)} e^{\omega t}+\frac{I_{0} \omega \cos (\theta)}{2 C\left(-\omega^{2}+\omega_{0}^{2}\right)} e^{-\omega t}+\frac{I_{0} \omega}{2 C\left(-\omega_{0}^{2}+\omega^{2}\right)} e^{\omega_{0} t} \\
& \quad+\frac{I_{0} \omega}{2 C\left(-\omega_{0}^{2}+\omega^{2}\right)} e^{-\omega_{0} t} \\
& \quad=\frac{I_{0} \omega \cos (\theta)}{2 C\left(-\omega^{2}+\omega_{0}^{2}\right)}\left(e^{\omega t}+e^{-\omega t}\right)+\frac{I_{0} \omega}{2 C\left(-\omega_{0}^{2}+\omega^{2}\right)}\left(e^{\omega_{0} t}+e^{-\omega_{0} t}\right) .
\end{aligned}
$$

Considerando a relação de Euler, tem-se finalmente para o primeiro termo:

$$
\begin{aligned}
& \frac{I_{0} \omega \cos (\theta)}{C\left(-\omega^{2}+\omega_{0}^{2}\right)} \cos (\omega t)+\frac{I_{0} \omega \cos (\theta)}{C\left(-\omega_{0}^{2}+\omega^{2}\right)} \cos \left(\omega_{0} t\right) \\
= & \frac{I_{0} \omega \cos (\theta)}{C\left(-\omega^{2}+\omega_{0}^{2}\right)}\left[\cos (\omega t)-\cos \left(\omega_{0} t\right)\right] .
\end{aligned}
$$

O segundo termo pode ser resolvido expandindo a equação em frações parciais:

$$
\frac{I_{0} \operatorname{sen}(\theta)}{C} \frac{s^{2}}{\left(s^{2}+\omega^{2}\right)\left(s^{2}+\omega_{0}^{2}\right)}=\frac{K_{3}}{s-j \omega}+\frac{\dot{K}_{3}}{s+j \omega}+\frac{K_{4}}{s-j \omega_{0}}+\frac{\dot{K}_{4}}{s+j \omega_{0}} .
$$

$K_{3}$ pode ser encontrado multiplicando a equação por $\frac{s-j \omega}{s-j \omega}$ e igualando $s$ a $j \omega$, assim:

$$
\begin{gathered}
K_{3}=\frac{I_{0} \operatorname{sen}(\theta)}{C} \frac{s^{2}}{(s+j \omega)\left(s^{2}+\omega_{0}^{2}\right)}=\frac{I_{0} \operatorname{sen}(\theta)}{C} \frac{-\omega^{2}}{(2 j \omega)\left(-\omega^{2}+\omega_{0}^{2}\right)} \\
=-\frac{I_{0} \operatorname{sen}(\theta) \omega}{2 C\left(-\omega^{2}+\omega_{0}^{2}\right)} \angle-90^{\circ} .
\end{gathered}
$$

$K_{4}$ é determinado de forma similar, realizando o mesmo mostrado para $K_{3}$, entretanto considerando $s$ igual a $j \omega_{0}$, portanto:

$$
K_{4}=-\frac{I_{0} \operatorname{sen}(\theta) \omega_{0}}{2 C\left(\omega^{2}-\omega_{0}^{2}\right)}<-90^{\circ} .
$$

Dessa forma, pode-se determinar a expressão no domínio do tempo do segundo termo utilizando o mesmo método aplicado na equação (21). Assim, a seguinte equação é obtida: 


$$
\begin{gathered}
V_{T R T}(t)=\frac{I_{0} \omega \cos (\theta)}{C\left(-\omega^{2}+\omega_{0}^{2}\right)}\left[\cos (\omega t)-\cos \left(\omega_{0} t\right)\right]-\frac{I_{0} \operatorname{sen}(\theta) \omega}{C\left(-\omega^{2}+\omega_{0}^{2}\right)} \cos \left(\omega t-90^{\circ}\right) \\
-\frac{I_{0} \operatorname{sen}(\theta) \omega_{0}}{C\left(\omega^{2}-\omega_{0}{ }^{2}\right)} \cos \left(\omega_{0} t-90^{\circ}\right) .
\end{gathered}
$$

Portanto:

$$
\begin{aligned}
& V_{T R T}(t)=\frac{I_{0} \omega \cos (\theta)}{C\left(-\omega^{2}+\omega_{0}^{2}\right)} \cos (\theta)\left[\cos (\omega t)-\cos \left(\omega_{0} t\right)\right] \\
& +\frac{I_{0} \operatorname{sen}(\theta)}{C\left(-\omega^{2}+\omega_{0}^{2}\right)}\left[-\omega \cos \left(\omega t-90^{\circ}\right)+\omega_{0} \cos \left(\omega_{0} t-90^{\circ}\right)\right] .
\end{aligned}
$$

Substituindo $I_{0}$, tem-se:

$$
\begin{aligned}
V_{T R T}(t) & =E_{0} \cos (\theta)\left[\cos (\omega t)-\cos \left(\omega_{0} t\right)\right]+\frac{E_{0} \operatorname{sen}(\theta)}{\omega}[-\omega \sin (\omega t) \\
& \left.+\omega_{0} \sin \left(\omega_{0} t\right)\right] .
\end{aligned}
$$

Pode-se simplificar a equação (28) agrupando-se os termos cossenóides:

$$
\begin{aligned}
V_{T R T}(t) & =E_{0} \cos (\theta) \cos (\omega t)-E_{0} \operatorname{sen}(\theta) \sin (\omega t)-E_{0} \cos (\theta) \cos \left(\omega_{0} t\right) \\
& \left.+\frac{E_{0} \operatorname{sen}(\theta)}{\omega} \omega_{0} \sin \left(\omega_{0} t\right)\right] .
\end{aligned}
$$

Para os dois primeiros termos da equação (29), utiliza-se a seguinte relação trigonométrica:

$$
\cos (A+B)=\cos (A) \cos (B)+\operatorname{sen}(A) \operatorname{sen}(B) .
$$

Consequentemente:

$$
\left.V_{T R T}(t)=E_{0} \cos (\omega t+\theta)-E_{0} \cos (\theta) \cos \left(\omega_{0} t\right)+\frac{E_{0} \operatorname{sen}(\theta)}{\omega} \omega_{0} \sin \left(\omega_{0} t\right)\right] .
$$


Para os dois últimos termos, pode-se utilizar do artifício:

$$
M=\sqrt{\cos ^{2}(\theta)+\left(\frac{\omega_{0}}{\omega}\right)^{2} \sin ^{2}(\theta)}
$$

Multiplicando-se e dividindo-se a equação (31) por M e considerando:

$$
\begin{aligned}
& \sin (\varphi)=\frac{\frac{\omega_{0}}{\omega} \sin (\theta)}{M} \\
& \cos (\varphi)=\frac{\cos (\theta)}{M} \\
& \operatorname{tg}(\varphi)=\frac{\frac{\omega_{0}}{\omega} \sin (\theta)}{\cos (\theta)}
\end{aligned}
$$

tem-se que a equação (31) é equivalente a:

$$
V_{T R T}(t)=E_{0} \cos (\omega t+\theta)-\mathrm{M} E_{0}\left[\cos (\varphi) \cos \left(\omega_{0} t\right)-\operatorname{sen}(\varphi) \operatorname{sen}\left(\omega_{0} t\right)\right] .
$$

Finalmente,

$$
V_{T R T}(t)=E_{0} \cos (\omega t+\theta)-\mathrm{M} E_{0} \cos \left(\omega_{0} t+\varphi\right) .
$$

Para o caso onde a interrupção da corrente ocorre quando seu valor é igual a zero, temse, para o tempo igual a zero, $\theta$ igual a zero. Assim a equação (37), se resume a:

$$
v_{T R T}(t)=E_{0}\left[\cos (\omega t)-\cos \left(\omega_{0} t\right)\right]
$$

Os resultados dessas expressões podem ser comparados com resultados obtidos através de simulações no software ATP, considerando uma fonte com amplitude igual a $10 \mathrm{kV}$, indutor com uma indutância de $3,65 \mathrm{mH}$ e um capacitor com capacitância igual a 200nF. No ATP, o circuito da Figura 20 é simulado, realizando os ajustes necessários para que a abertura do disjuntor somente ocorresse quando o valor da corrente fosse igual a $0 \mathrm{~A}$. 
Figura 20 - Circuito simulado via ATP

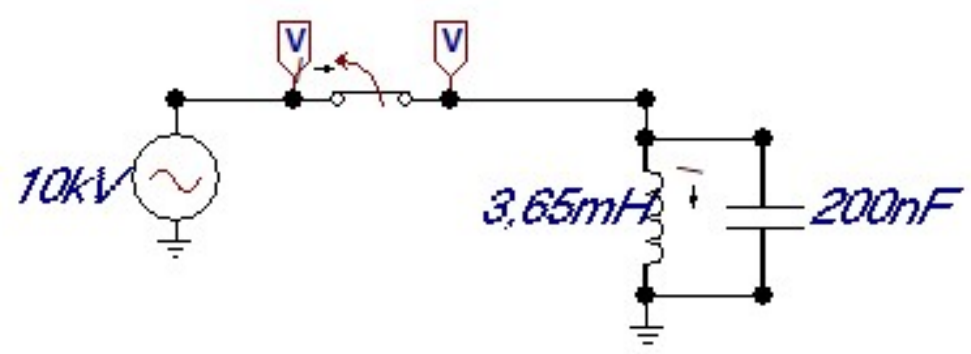

Fonte: Autor

Dessa forma, simulando para 35ms com um degrau de integração de $0,1 \mu \mathrm{s}$, a Figura 21 para tensão entre os terminais do disjuntor é encontrada:

Figura 21 - Tensão entre os terminais do disjuntor (corrente igual a zero no momento de abertura)

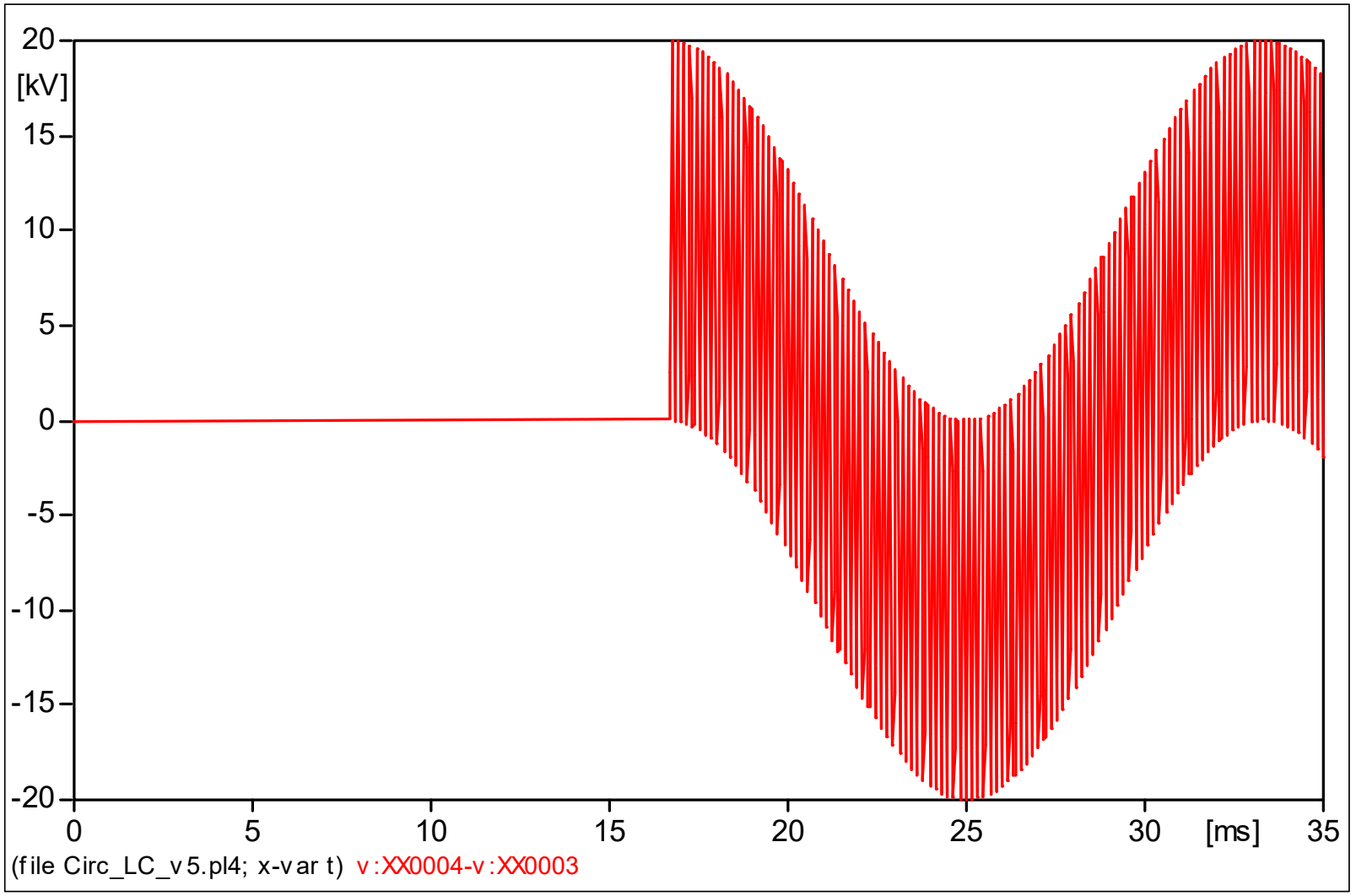

Fonte: Autor

Observa-se que até o instante da interrupção da corrente a tensão é nula e após a abertura do disjuntor ocorre um transitório, cuja amplitude é de $20 \mathrm{kV}$.

A fim de validar a equação (38), a mesma foi reproduzida no software Matlab utilizando os valores do circuito estudado. Além disso, os dados simulados do ATP foram exportados para 
o Matlab e os dois gráficos foram sobrepostos e comparados na Figura 22 para os primeiros $5 \mathrm{~ms}$ da simulação:

Figura 22 - Comparação entre resultados do ATP e Matlab

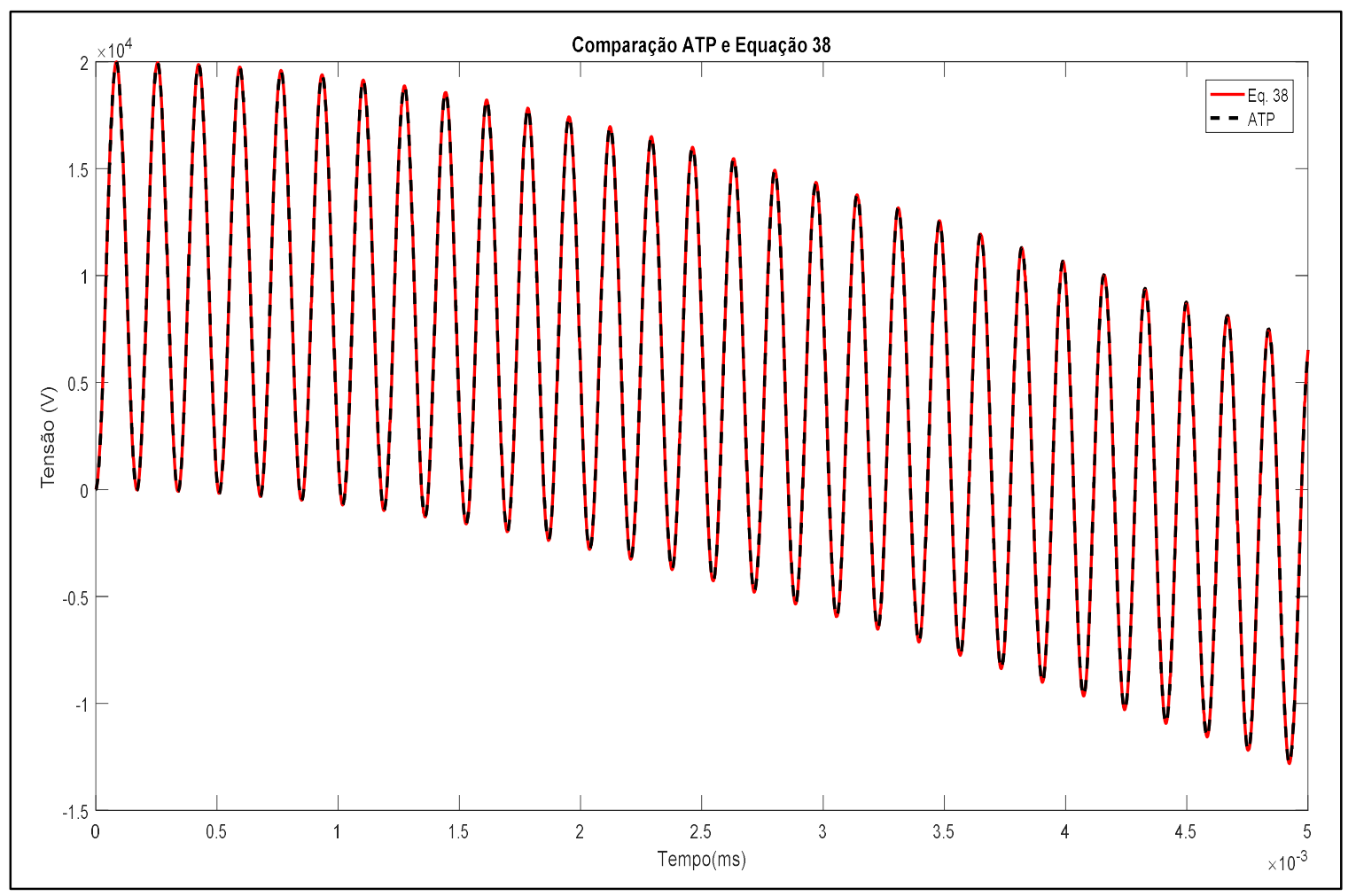

Fonte: Autor

Pode-se observar a concordância entre os resultados, validando a expressão da equação (38). Para se comprovar a influência do valor da corrente interrompida nas sobretensões, o gráfico da Figura 23 foi criado. O gráfico apresenta a variação da TRT obtida na equação. (37) em função das variáveis $\theta$ e tempo, considerando os mesmos parâmetros utilizados no circuito da Figura 20.

No caso, pôde-se constatar que os maiores valores de sobretensão ocorrem quando a interrupção de corrente se dá nos ângulos $\theta$ iguais a $90^{\circ}$ e a $270^{\circ}$ com sinais invertidos, com valor igual a aproximadamente $980 \mathrm{kV}$ e $-980 \mathrm{kV}$, respectivamente. Para esses ângulos, observam-se os maiores valores de corrente interrompidas $\left(7266 \mathrm{~A}\right.$ para $90^{\circ}$ e $-7266 \mathrm{~A}$ para $270^{\circ}$ ), corroborando o fato de que quanto a maior a corrente interrompida, maiores as sobretensões observadas em circuitos oscilatórios predominantemente indutivos. 
Figura 23 - TRT em função de $\theta$ e tempo

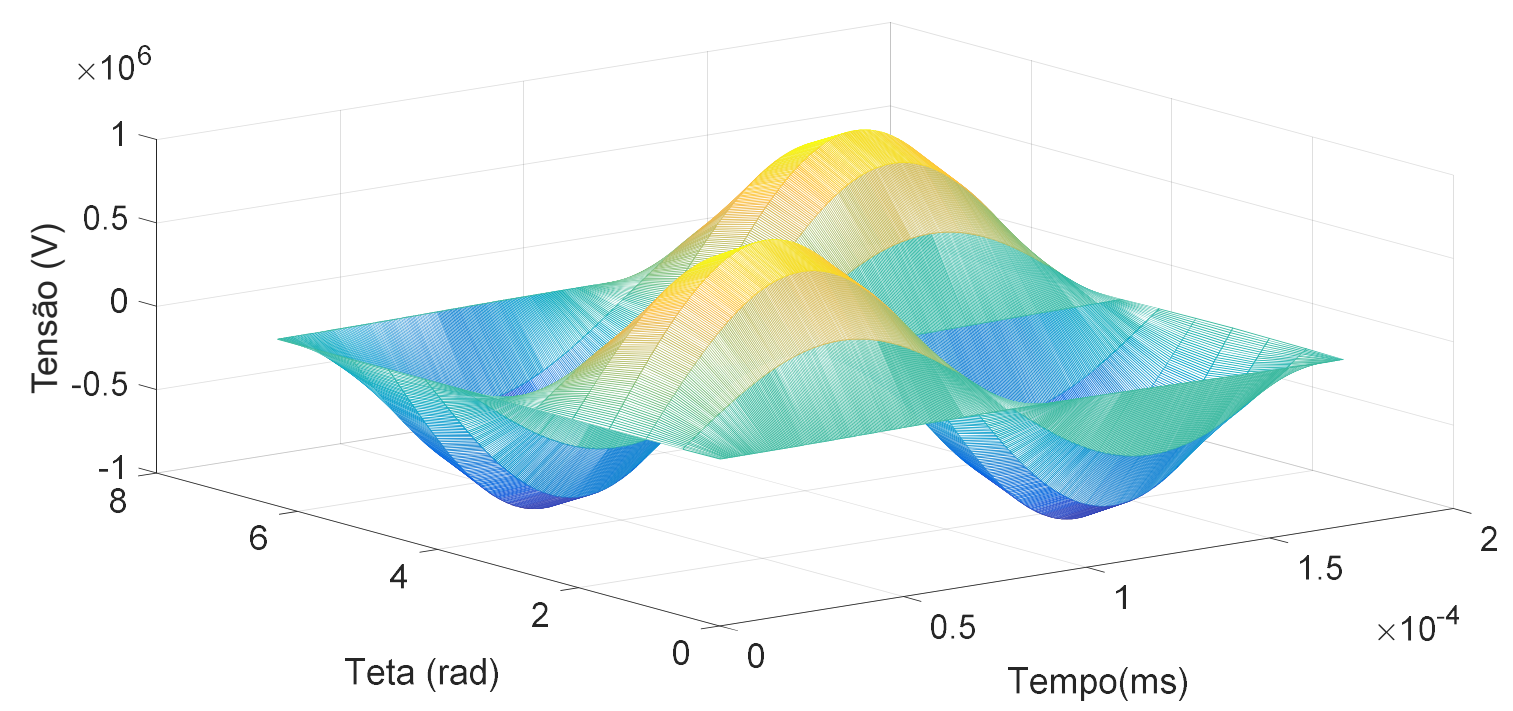

Fonte: Autor

\subsection{Simulações de Manobras de Disjuntores a Vácuo}

Devido à natureza complexa e aleatória de tensões transitórias oriundas de manobras de disjuntores a vácuo em circuitos trifásicos, existe a necessidade do desenvolvimento de ferramentas que reproduzam os fenômenos associados às características operacionais dos disjuntores a vácuo, permitindo uma análise completa do problema no domínio do tempo.

Para se estudar esse problema no presente trabalho, um modelo de disjuntor a vácuo foi desenvolvido. Este modelo foi ajustado baseado em dados de um experimento de referência. A partir da preparação do modelo, foi possível aplicá-lo em um software de cálculo de transitórios, o ATP, e analisar o comportamento dos principais componentes elétricos, como transformadores e cabos, cujos tipos de modelagens e respectivos méritos e deficiências são discutidos. A partir dessa premissa, buscou-se portanto resultados que pudessem ser mais representativos para validação do modelo. Em seguida, buscou-se simular situações mais danosas aos componentes do circuito e incorporar as soluções de modo a analisar seus impactos.

O programa ATP é uma versão derivada do programa de transitórios eletromagnéticos (do inglês Electromagnetic Transients Program - EMTP) e é utilizado para simulação de fenômenos transitórios de um sistema elétrico. O ATP possui licença gratuita e é difundido principalmente no meio acadêmico para o estudo de transitórios em geral. $O$ programa ATPDraw é uma interface gráfica para o ATP e é usado para criar e editar circuitos. A saída dessa interface é um arquivo texto, que é utilizado como entrada para execução no ATP. 


\subsubsection{Experimento de referência}

O experimento de referência escolhido para ser modelado e simulado foi realizado por Kuczek (2015), sendo novamente avaliado por Kuczek, Florkowski e Piasecki (2016). O experimento está descrito no primeiro estudo de caso do capítulo 2.3. Ele foi selecionado devido ao acesso aos dados dos componentes do circuito. O circuito de referência com suas características principais está apresentado na Figura 8. No caso experimentado e simulado, o filtro LC foi retirado. Kuczek, Florkowski e Piasecki (2016) realizaram medições no primário do transformador 2 durante a abertura e fechamento do disjuntor a vácuo. Os dados específicos dos componentes do circuito podem ser encontrados no Apêndice A.

\subsubsection{Modelos dos componentes do circuito}

Para realização das simulações, foi necessário desenvolver um modelo de disjuntor a vácuo e definir os demais modelos para os componentes elétricos do circuito.

a) Disjuntor a vácuo

O disjuntor foi modelado com o componente TACS (Transient Analysis of Control Systems, em português Análise de Transitórios de Sistemas de Controle) switch, sendo necessário replicá-lo para cada fase em um sistema trifásico. O componente TACS switch permite seu acionamento por meio de comandos provenientes de um código computacional do próprio ATP, conhecido como MODELS.

Para modelagem do comportamento dos disjuntores a vácuo, um código computacional foi desenvolvido a partir dos modelos desenvolvidos por Abdulahovic et al. (2014) e Popov (2002). O algoritmo desenvolvido segue o fluxograma da Figura 24: 
Figura 24 - Fluxograma disjuntor a vácuo

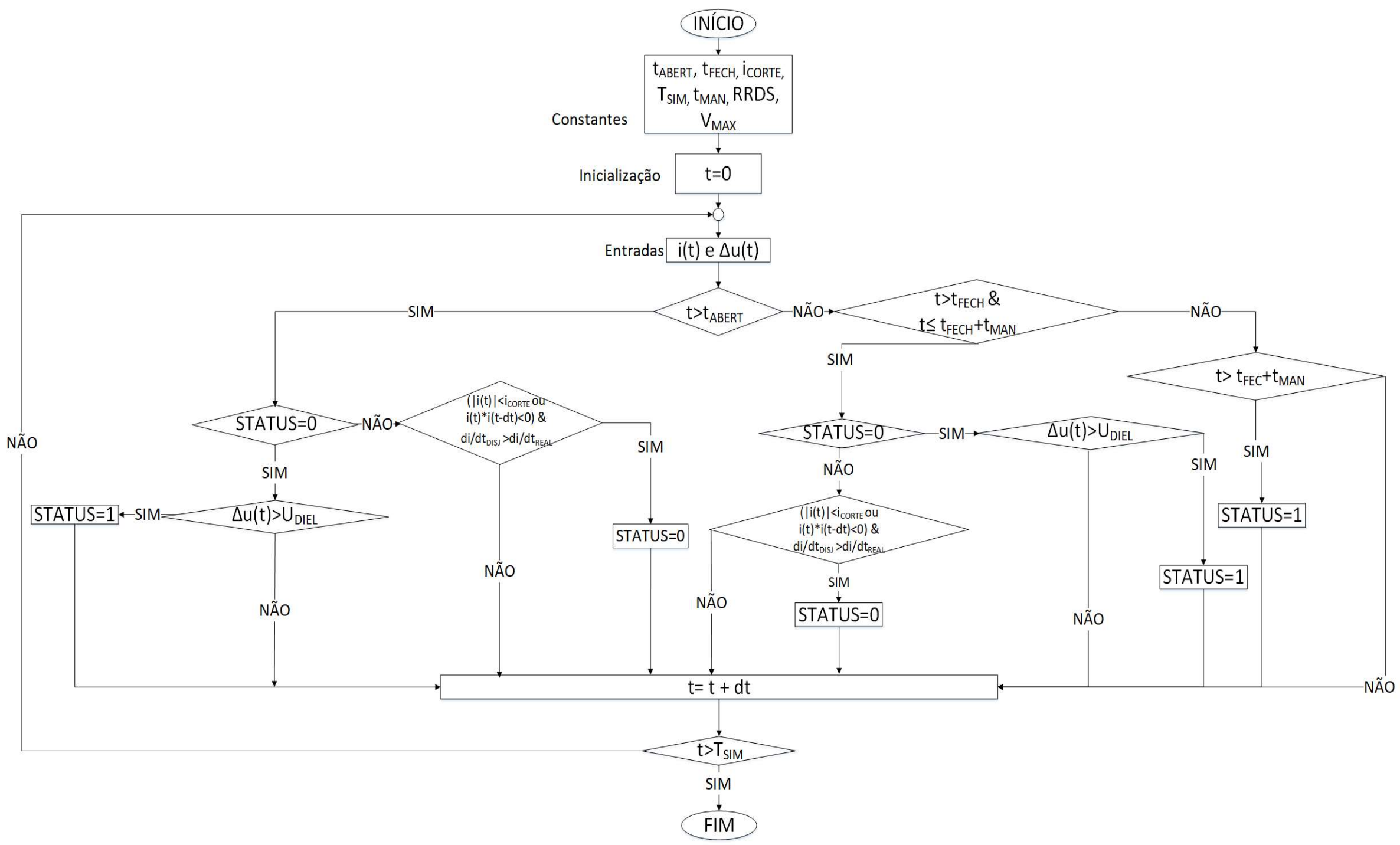

Fonte: Autor 
O fluxograma se caracteriza pelos seguintes passos:

1. Definição das constantes por meio de uma interface gráfica:

a. iCORTE: Corrente de corte do disjuntor $[\mathrm{A}]$;

b. taBertura: Tempo em que o disjuntor é aberto [s];

c. t t

d. RRDS: taxa de recuperação do dielétrico [V/s];

e. VMAX: valor máximo de tensão suportado pelo dielétrico [V];

f. tTERM: Tempo total que os contatos do disjuntor demoram para abrir ou fechar [s]; e

g. Tsimulação: Tempo total de simulação [s], definido diretamente no software ATP;

2. Início da contagem do tempo;

3. Aquisição de dados da simulação:

a. $\Delta \mathrm{u}(\mathrm{t})$ : Tensão entre os terminais do disjuntor [V]; e

b. $\mathrm{i}(\mathrm{t})$ : Corrente fluindo pelo disjuntor $[\mathrm{A}]$;

4. Início das comparações para definição do novo estado do disjuntor;

5. Caso o tempo da simulação for maior do que o tempo de abertura estipulado na entrada do programa ou se tempo da simulação for maior do que o tempo de fechamento estipulado na entrada do programa, mas menor e igual a esse tempo de fechamento mais o tempo total de manobra:

a. O disjuntor irá abrir (ou o arco elétrico será interrompido) se o teste de abertura for satisfeito;

b. Caso o disjuntor esteja aberto, ele passará a conduzir se o teste de fechamento for satisfeito;

No teste de fechamento é verificado se o disjuntor está aberto e se a tensão entre seus terminais é superior à tensão suportada pelo dielétrico. Durante uma manobra de abertura, a tensão suportada pelo dielétrico do disjuntor é calculada a cada iteração por meio da equação (2). Já durante a manobra de fechamento, a tensão suportada pelo disjuntor é dada por:

$$
U_{D}=V_{M}-\left[A\left(t-t_{F}\right)+B\right]
$$


onde $\mathrm{V}_{\mathrm{M}}$ é a tensão máxima suportada pelo dielétrico [V], A e B são constantes definidas por experimentos, como já apresentado no capítulo 2.1.4, e t é o tempo que se inicia a manobra de fechamento [s].

No teste de abertura é verificado se a corrente é menor do que a corrente de corte ou se a corrente trocou de sinal, e se a capacidade de extinção de correntes de alta frequência do disjuntor é maior que a variação temporal da corrente para o instante simulado. Para a manobra de abertura, a capacidade de extinção de correntes de alta frequência do disjuntor para o instante de abertura é calculada pela equação (8). Já para o fechamento a capacidade de extinção de correntes de alta frequência é calculada por:

$$
\frac{d i}{d t}=E-\left(C\left(t-t_{F}\right)+D\right)
$$

onde C e D são as mesmas constantes apresentadas no capítulo 2.1.4 e E é uma constante determinada a partir do máximo valor de capacidade de extinção de correntes de alta frequência $[\mathrm{A} / \mathrm{s}]$.

b) Cabos Elétricos

Com o intuito de se realizar um estudo comparativo dos modelos de cabos, optou-se por realizar simulações com diferentes modelos presentes no ATP. Devido à falta de informações, os cabos de baixa tensão forma modelados da mesma maneira que os cabos de média tensão, considerando as diferenças de comprimento.

Para as simulações iniciais, os cabos foram modelados com o componente LINEZT_3, o qual representa os cabos por meio de parâmetros distribuídos e necessita apenas do valor da resistência por metro, a velocidade de propagação de onda e a impedância de surto.

Para as simulações seguintes as linhas foram modeladas com o componente Line Constants and Cables (LCC) template, utilizando o modelo de JMarti. Nesse modelo é necessário fornecer maiores detalhes para a rotina, como o número de cabos, suas posições físicas, características de suas camadas, a quantidade de pontos para realizar a adequação das funções da impedância característica e de propagação, a frequência na qual a matriz de 
transformação modal é gerada e características da resistividade do solo. Os dados da Tabela 7 foram utilizados como base para modelagem dos cabos.

Por fim, a adequação das funções da impedância característica e de propagação foi realizada no software PSCAD (Power System Computer Aided Design) e os resultados foram importados para o ATP.

c) Transformadores

As simulações tomaram como base dois modelos de transformadores. O primeiro modelo considera componentes especificados para a frequência nominal da rede, utilizando a mesma abordagem de Kuczek, Florkowski e Piasecki (2016). Dessa forma, os transformadores foram modelados por meio do componente BCTRAN, o qual apenas necessita dos resultados dos ensaios de curto-circuito e de circuito aberto de transformadores e uma complementação com a inserção de capacitores entre enrolamentos e entre fases para simular seu comportamento para altas frequências.

O segundo modelo é denominado Hybrid e possui um comportamento de alta frequência intrínseco. Neste caso, os dados da Tabela 6 presente no Apêndice A precisam ser inseridos na interface, sendo que para o núcleo foi assumido que o jugo possui um comprimento de 2,8 vezes o comprimento da perna do transformador, tomando como referência um transformador de potência similar ao experimentado. Além disso, é possível considerar que os valores das resistências e das indutâncias são variáveis em função da frequência.

\subsubsection{Parâmetros do circuito simulado}

Para as simulações de abertura e de fechamento do disjuntor, adotou-se tempos totais de simulação iguais a $20 \mathrm{~ms}$ e a $5 \mathrm{~ms}$, respectivamente, com um passo de integração igual a $10 \mathrm{~ns}$. Foi utilizada uma fonte de tensão de $600 \mathrm{~V} / 50 \mathrm{~Hz}$ e defasagem angular de $0^{\circ}$ para a abertura e de $235^{\circ}$ para o fechamento, para se garantir um transitório similar ao experimento.

Para o comportamento do dielétrico do disjuntor, a equação (2) foi utilizada para a abertura, sendo valor da RRDS (incógnita A da equação (2)) obtido experimentalmente por Kuczek (2015) e Kuczek, Florkowiski e Piasecki (2016) igual a 4,5kV/ms, o valor de B foi definido como $0 \mathrm{~V}$, para se garantir o pior caso e a tensão máxima suportada pelo disjuntor 
como $100 \mathrm{kV}$. Já para o fechamento utilizou-se a equação (39), mantendo-se os valores de A e B e igualando a tensão máxima em $10 \mathrm{kV}$, de forma a se garantir que o tempo das simulações tivessem a mesma referência de tempo observada no experimento. Para ambas as manobras, seus tempos totais foram definidos como $60 \mathrm{~ms}$.

A capacidade de extinção de correntes de alta frequência é simulada, no momento da abertura, pela equação (8), onde $\mathrm{C}$ foi definido como $0,32.10^{12} \mathrm{~A} / \mathrm{s}^{2}$ e $\mathrm{D}$ como $155.10^{6} \mathrm{~A} / \mathrm{s}$, sendo esses valores extraídos da Tabela 2. Para o fechamento, com o intuito de se manter a mesma referência de tempo observada no experimento de referência, a equação (40) foi utilizada, mantendo os mesmos valores para $\mathrm{C}$ e $\mathrm{D}$ e definindo $\mathrm{E}$ como 0,865 A/s. A corrente de corte foi definida como 3 A. Assim, as seguintes simulações foram realizadas:

a) Simulação 1: O mesmo circuito modelado por Kuczek, Florkowski e Piasecki (2016) foi utilizado. Como já apresentado, os transformadores foram modelados por meio do modelo BCTRAN com uma adaptação para simular seu comportamento de alta frequência e os cabos foram modelados com o componente LINEZT_3;

b) Simulação 2: Os transformadores 1 e 2 e suas capacitâncias foram substituídos pelo transformador modelo Hybrid. Já o autotransformador foi modelado da mesma forma que anteriormente.

c) Simulação 3: Os cabos foram substituídos pelo componente LCC template, sendo o modelo JMarti escolhido para representar a variação dos parâmetros dos cabos em função da frequência. Para adequação das funções de propagação e da impedância característica dos cabos elétricos, optou-se pela solução padrão do ATP. Os parâmetros dos cabos foram modelados para cinco décadas, com cinco pontos por década, a matriz de transformação foi calculada para $300 \mathrm{kHz}$, considerando a frequência inicial igual a $0,5 \mathrm{~Hz}$ e a frequência de regime permanente como $50 \mathrm{~Hz}$;

d) Simulação 4: Para comparação de resultados, o software PSCAD foi utilizado para realizar a adequação das funções da impedância característica do cabo e de propagação. Os valores dos polos e resíduos das funções foram gerados no PSCAD e inseridos em arquivos ".pch" do ATP. Dentro do arquivo ".pch" foi estipulado que o modelo do cabo é o de JMarti, já utilizado previamente; e 
e) Simulação 5: Os cabos da simulação 4 foram mantidos e o transformador foi substituído pelo modelo BCTRAN com uma adaptação para simular seu comportamento de alta frequência, como na simulação 1 .

A Figura 25 apresenta o circuito utilizado no software ATP para a simulação 1. Os circuitos utilizados para as demais simulações possuem o mesmo diagrama elétrico, apenas realizando as substituições dos respectivos modelos dos componentes elétricos do circuito. 
Figura 25 - Simulação 1

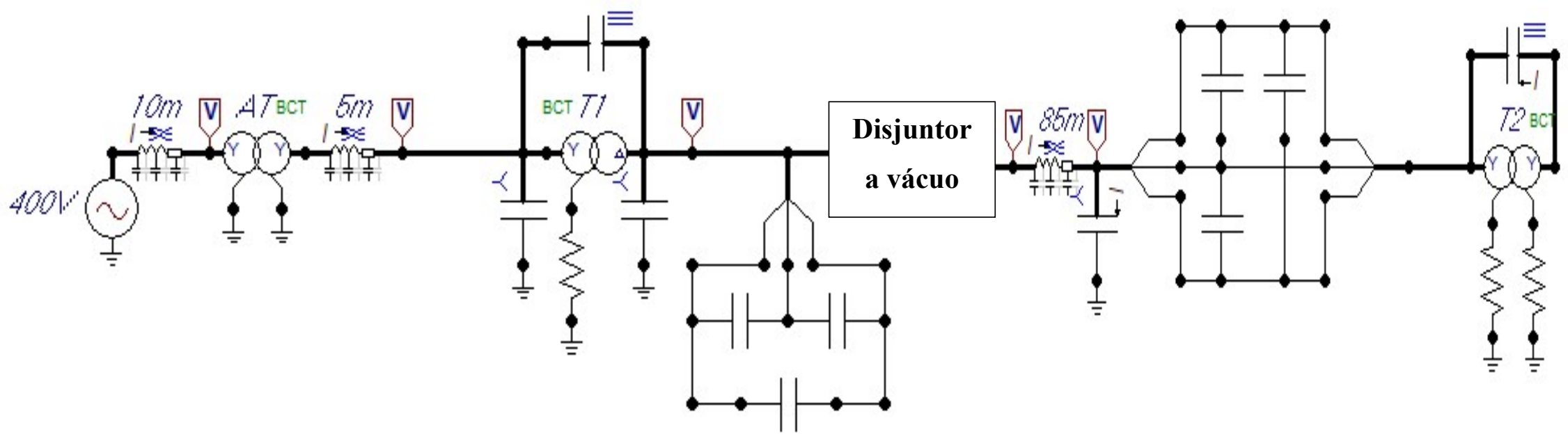

Fonte: Autor 
De forma ilustrativa, simulações similares foram realizadas, apresentando as configurações que levam a transitórios mais danosos aos equipamentos conectados ao sistema elétrico, isto é, por meio da redução do comprimento do cabo conectado entre o disjuntor e o transformador e da inclusão de uma carga indutiva. Nesse caso, tal carga foi definida com metade da potência do transformador em seu secundário (10kVA).

Para a situação com a carga indutiva e redução dos cabos, foram incluídas formas de reduzir as sobretensões transitórias, ou seja, com snubbers $\mathrm{RC}$ e para-raios $\mathrm{ZnO}$. Os capacitores e resistores de snubbers RC possuem valores típicos de $130 \mathrm{nF}$ e $30 \Omega$, respectivamente (LINDELL e LILJESTRAND, 2016). Conforme apresentado no subcapítulo 2.4.1, o valor da capacitância está dentro do usualmente utilizado. Entretanto para a resistência, como a impedância de surto do cabo era igual a $50 \Omega$, optou-se por mudar a resistência para esse valor.

Os para-raios foram modelados com o componente $R(t)$ type 99 . Ao se utilizar como referência os para-raios da família MWK da Asea Brown Boveri (ABB), definiu-se 7,5kV como tensão nominal para os para-raios F-T e F-F, utilizando o mesmo método de dimensionamento apresentado por Lindell e Liljestrand (2016), o qual considera a tensão nominal do sistema para determinar a tensão nominal dos para-raios. Dados específicos dos para-raios MWK da ABB podem ser encontrados no Apêndice A. 


\section{RESULTADOS E DISCUSSÕES}

Os resultados encontrados experimentalmente e nas simulações realizadas no software ATP são finalmente expostos e discutidos nos subcapítulos subsequentes.

\subsection{Resultados do Experimento de Referência}

No experimento de referência considerados para a avaliação, a tensão no primário do transformador de 20kVA (transformador 2) foi medida tanto para a manobra de abertura quanto para a de fechamento. Primeiramente foi realizada a abertura do disjuntor a vácuo estando o circuito em regime permanente, e no segundo momento foi realizado o fechamento do disjuntor com o circuito desenergizado. Assim, as formas de onda de tensões para abertura e fechamento estão apresentadas na Figura 26.

Figura 26 - Tensões no primário do transformador 2 a) Abertura b) Fechamento

a)

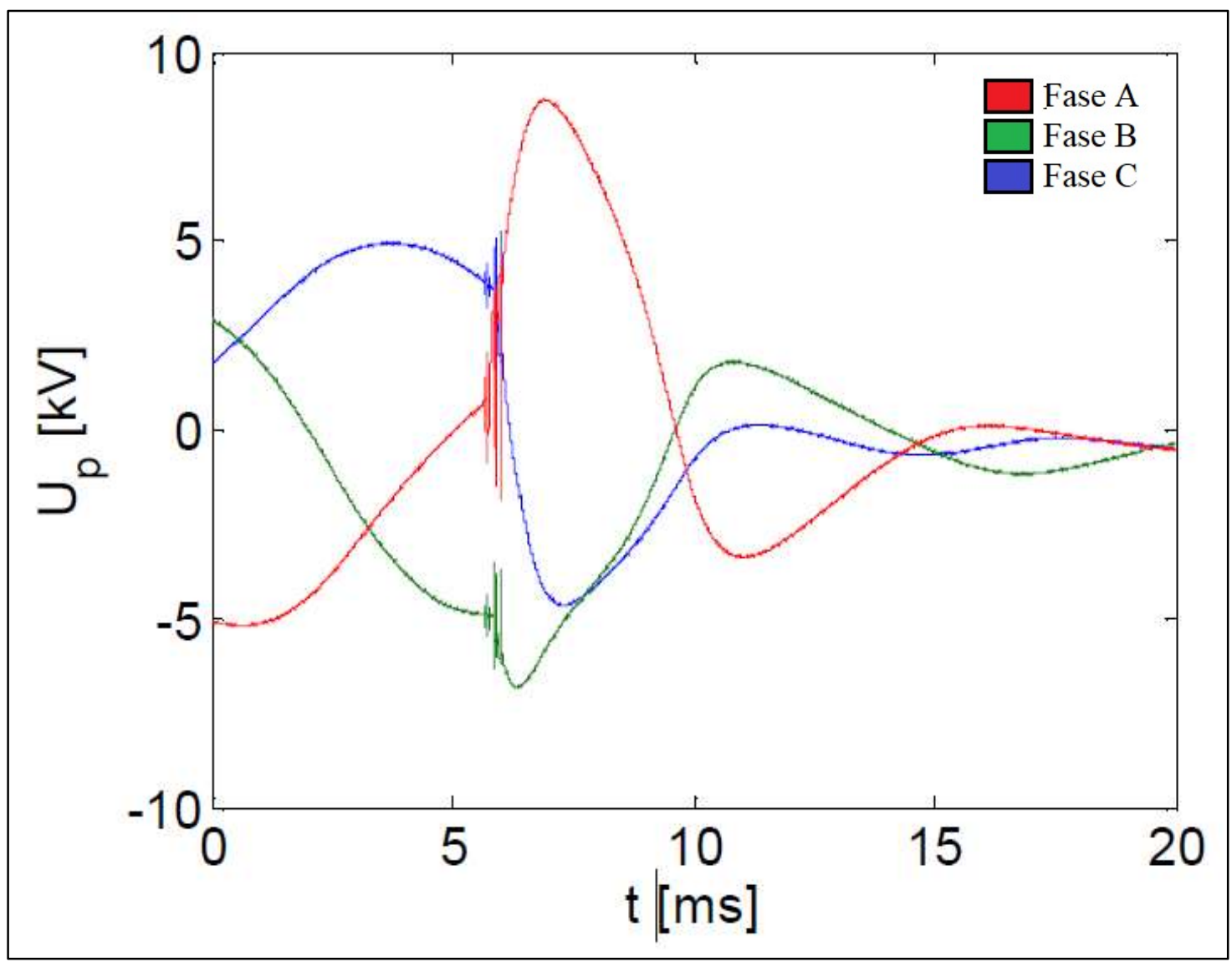


b)

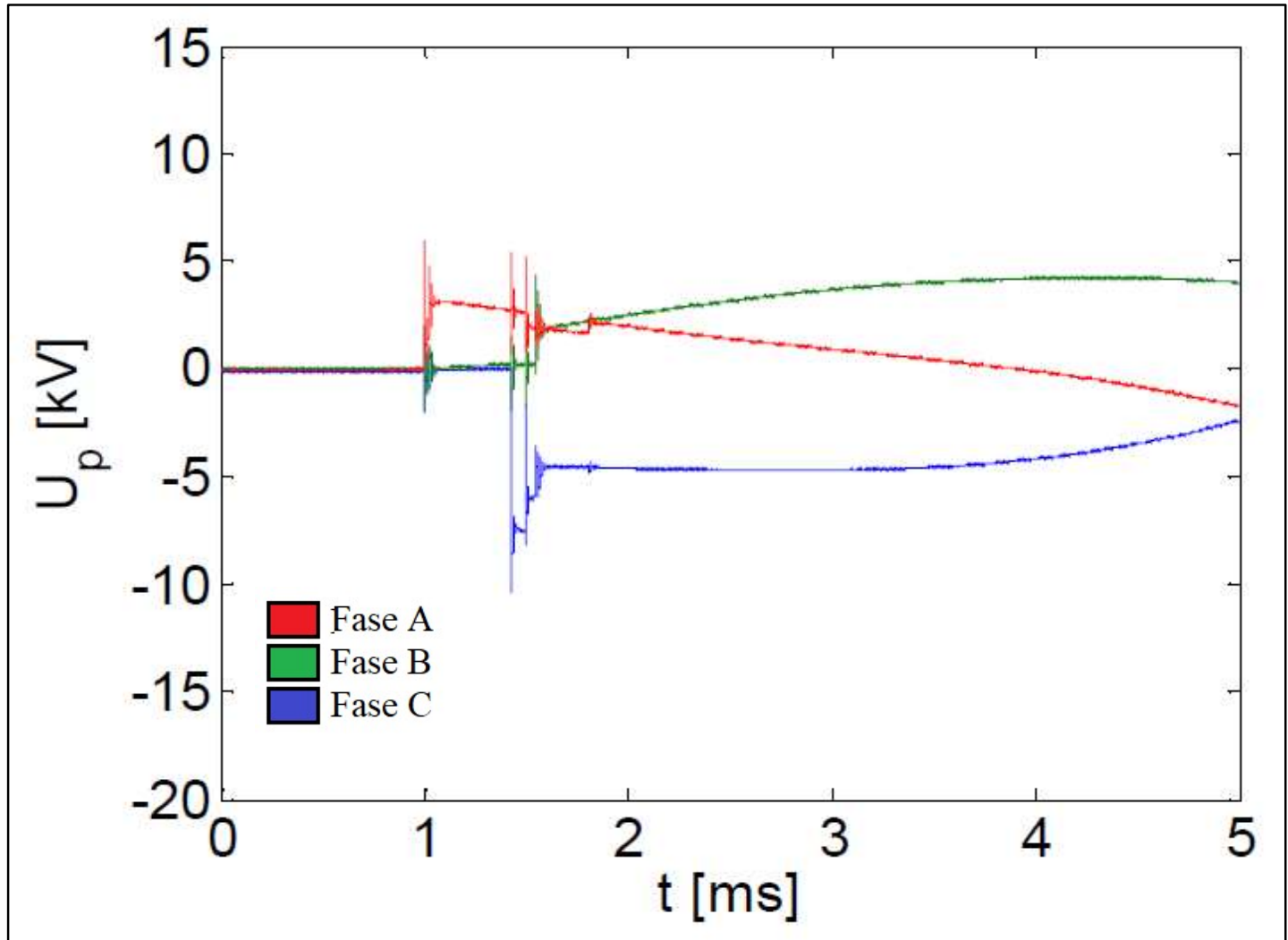

Fonte: Adaptado de Kuczek (2015)

Os resultados experimentais da tensão de pico entre as fases, variação de tensão no tempo e número de reignições por fase durante a abertura e durante o fechamento do disjuntor encontrados por Kuczek (2015) e Kuczek, Florwkowski e Piasecki (2016) estão tabulados em Kuczek, Florwkowski e Piasecki (2016) e apresentados na Tabela 3.

Tabela 3 - Resultados experimentais

\begin{tabular}{cccc}
\hline Manobras do disjuntor & Tensão de pico (kV) & $\begin{array}{c}\text { Variação de tensão } \\
\text { du/dt } \mathbf{( k V / \mu s )}\end{array}$ & $\begin{array}{c}\text { Número de reignições } \\
\text { por fase }\end{array}$ \\
\hline Abertura & 9,8 & 27 & 9 \\
\hline Fechamento & 10,3 & 24 & 6 \\
\hline
\end{tabular}

Fonte: Kuczek, Florkowski e Piasecki (2016)

Os transitórios durante as reignições para esses casos não causam níveis de tensão tão elevados a ponto de romper o dielétrico dos equipamentos conectados ao circuito, entretanto a repetição dos impulsos poderia levar à falha do isolamento. 
Pode-se observar que, para esse caso estudado, a tensão de pico durante o transitório foi maior durante o fechamento do disjuntor, já a taxa de variação de tensão e o número de reignições foi maior para o caso de abertura do disjuntor.

\subsection{Resultados das Simulações das Manobras do Disjuntor}

Para as simulações, as tensões no terminal primário do transformador 2 observadas para manobras de abertura e fechamento estão presentes na Figura 27 (simulação 1), Figura 28(simulação 2), Figura 29 (simulação 3), Figura 30 (simulação 4) e Figura 31 (simulação 5), sendo realizados os ajustes necessários para garantir que a simulação e o experimento tivessem a mesma base de tempo e que as correntes fossem interrompidas com aproximadamente a mesma amplitude em todas as simulações.

Figura 27 - Tensões no primário do transformador 2 observadas na simulação 1

a) Abertura b) Fechamento

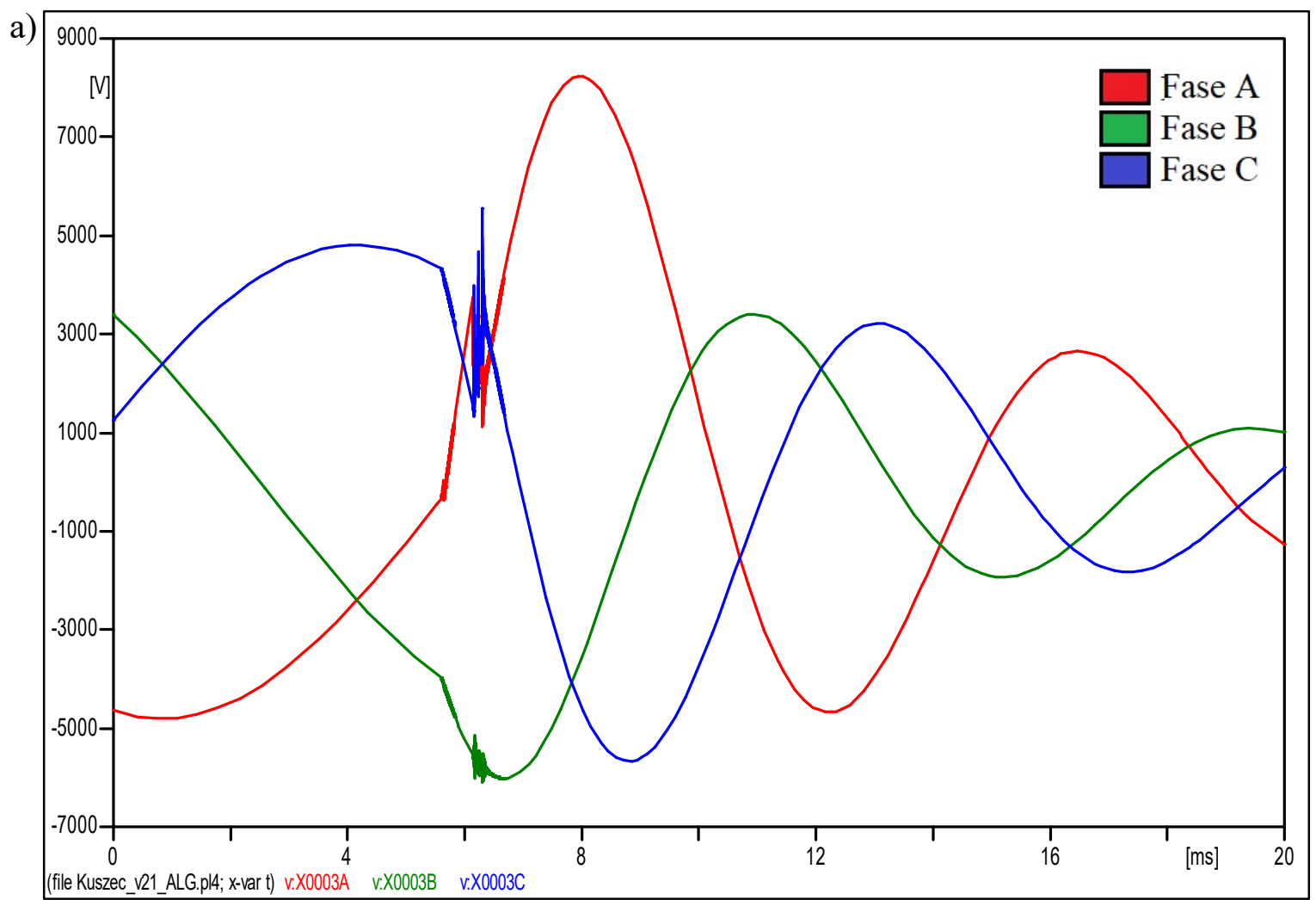


b)

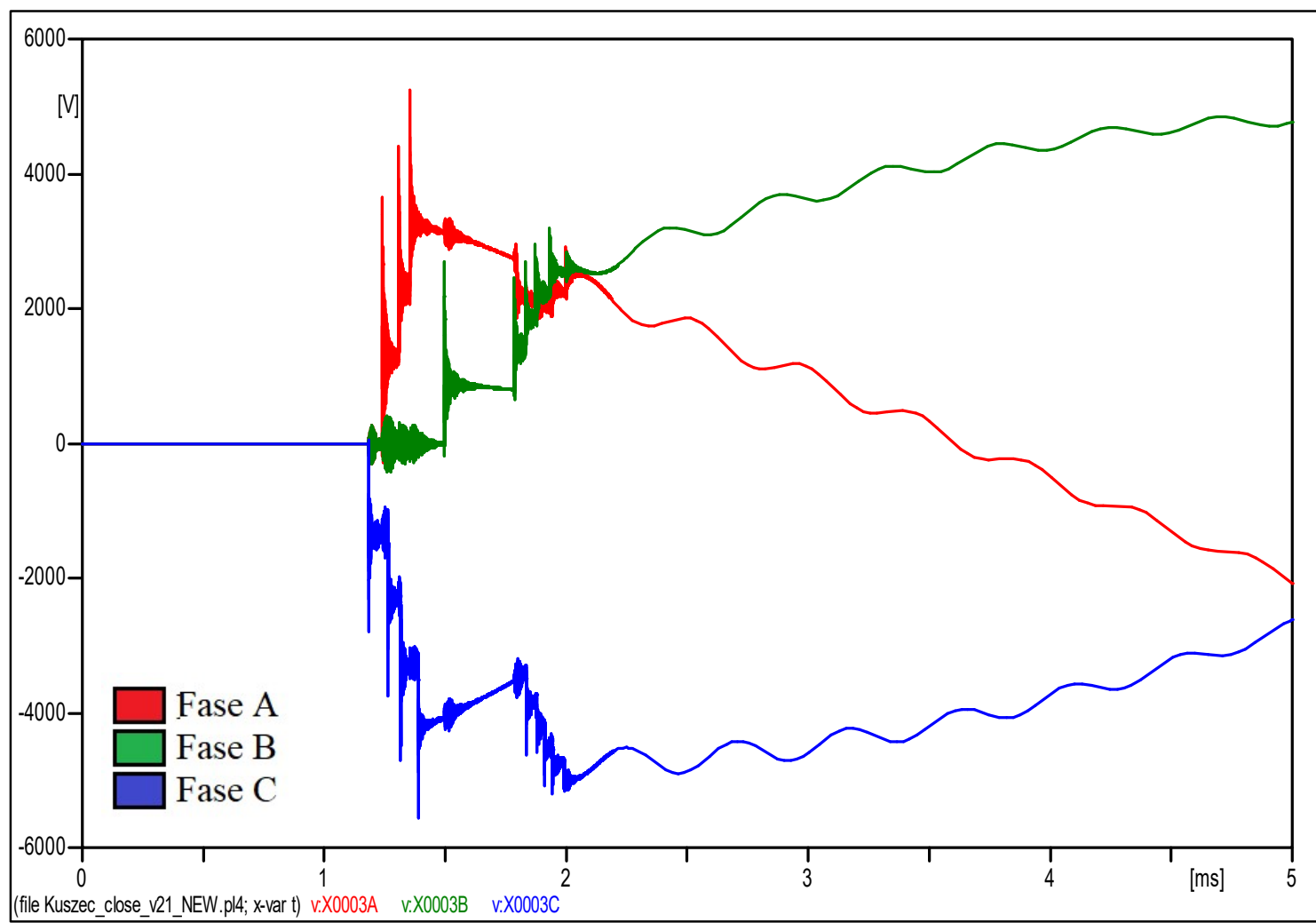

Fonte: Autor

Figura 28 - Tensões no primário do transformador 2 observadas na simulação 2

a) Abertura b) Fechamento

a)

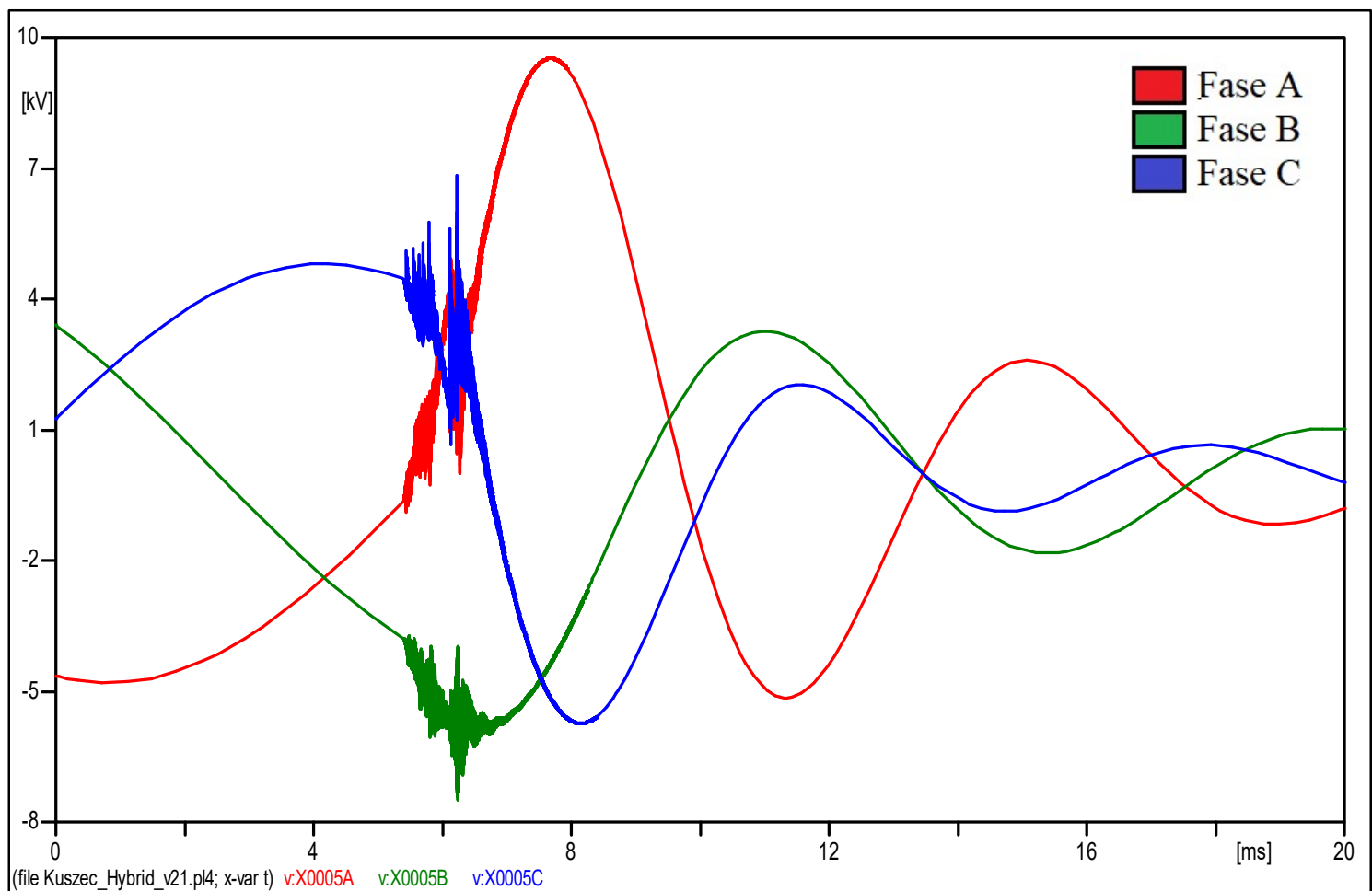


b)

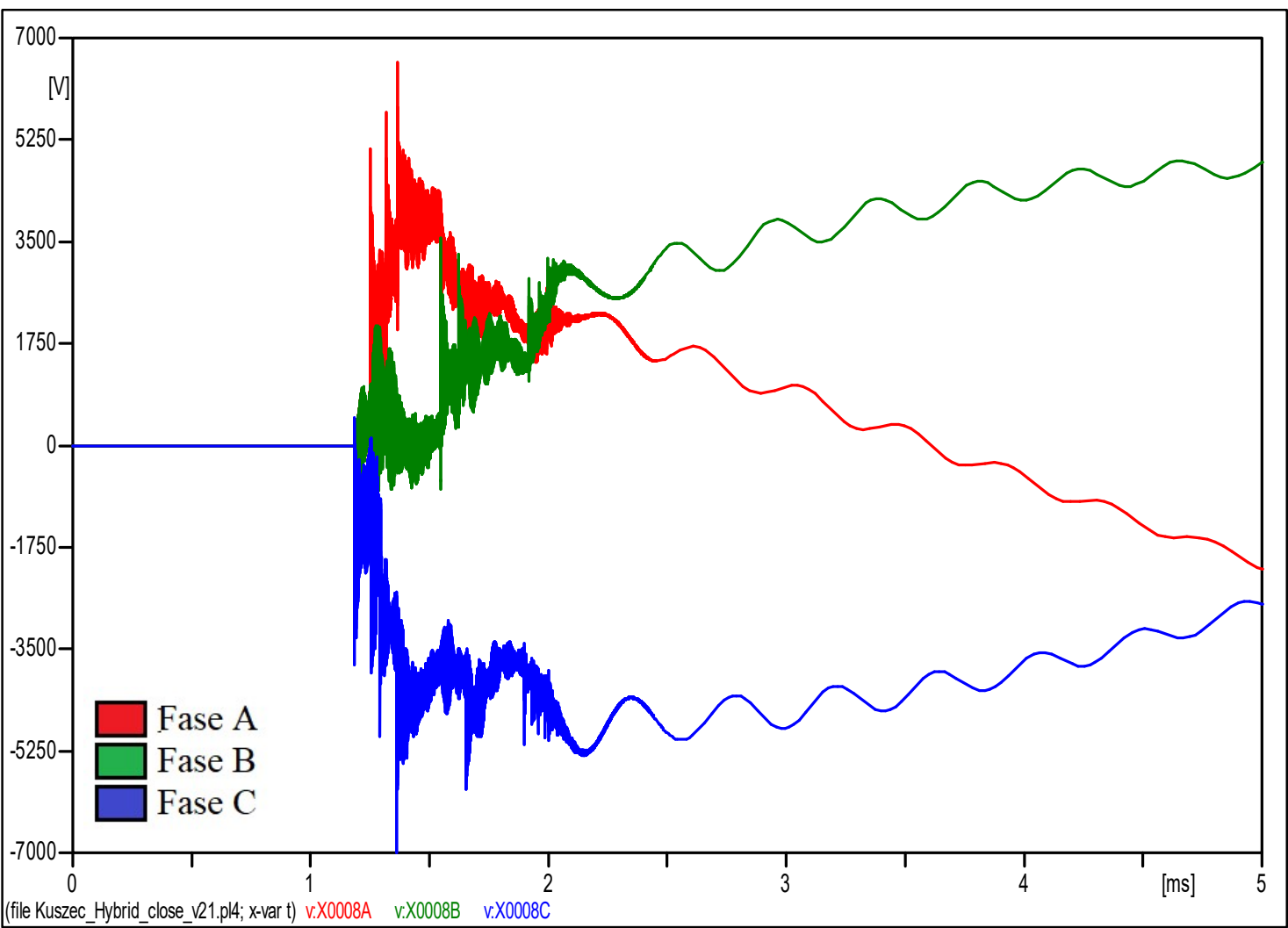

Fonte: Autor

Figura 29 - Tensões no primário do transformador 2 observadas na simulação 3

a) Abertura b) Fechamento

a)

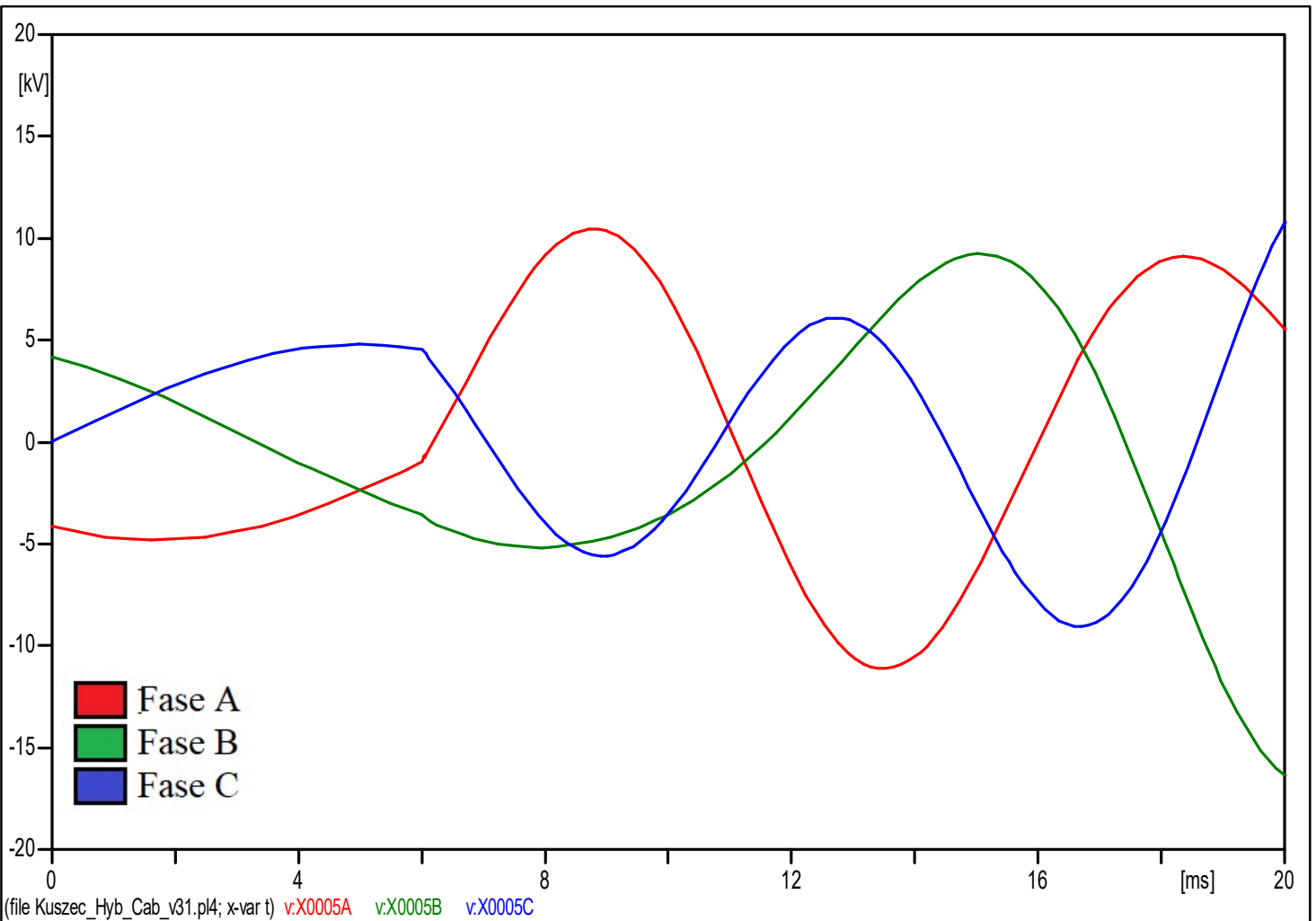


b)

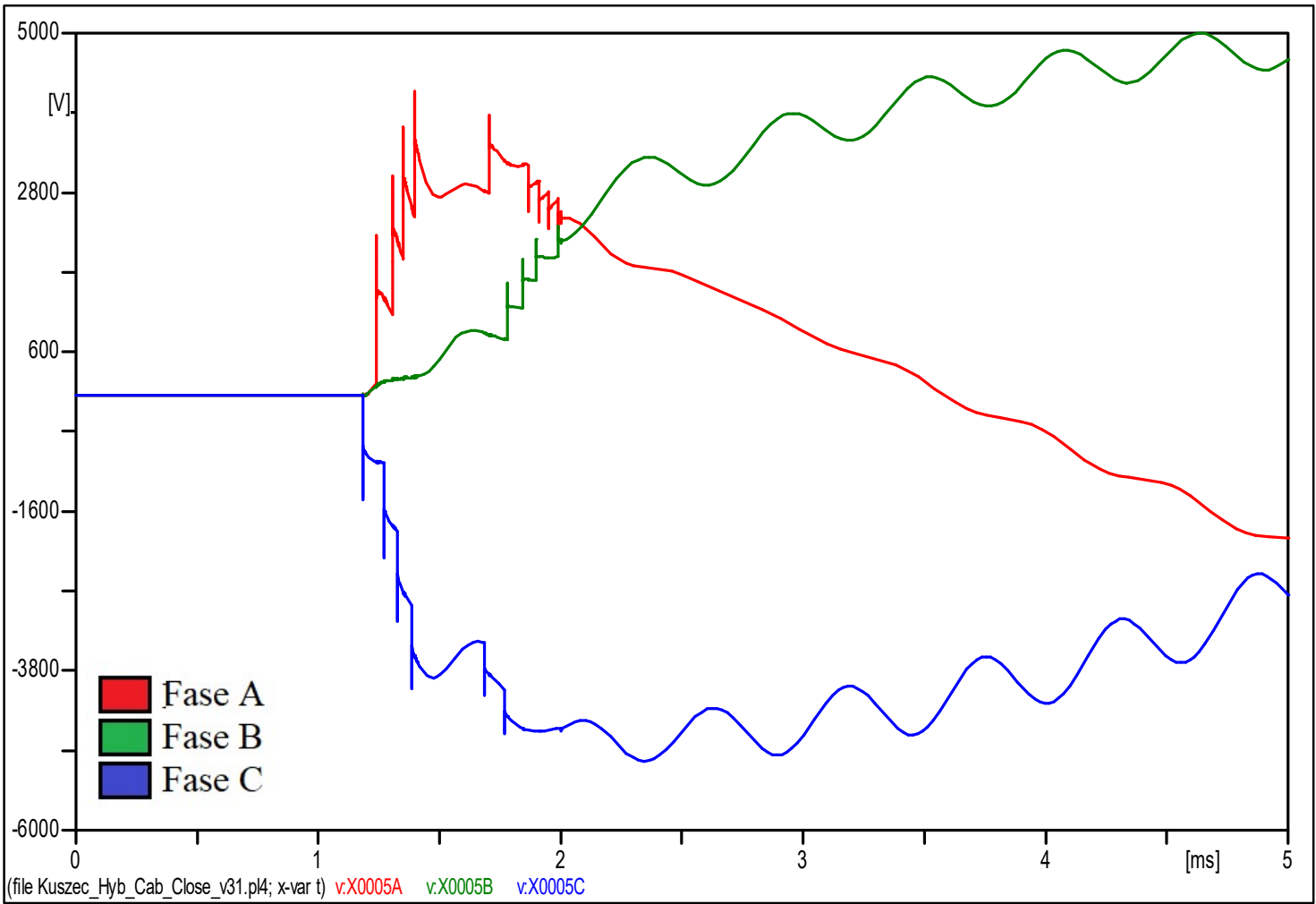

Fonte: Autor

Figura 30 - Tensões no primário do transformador 2 observadas na simulação 4

a) Abertura b) Fechamento

a)

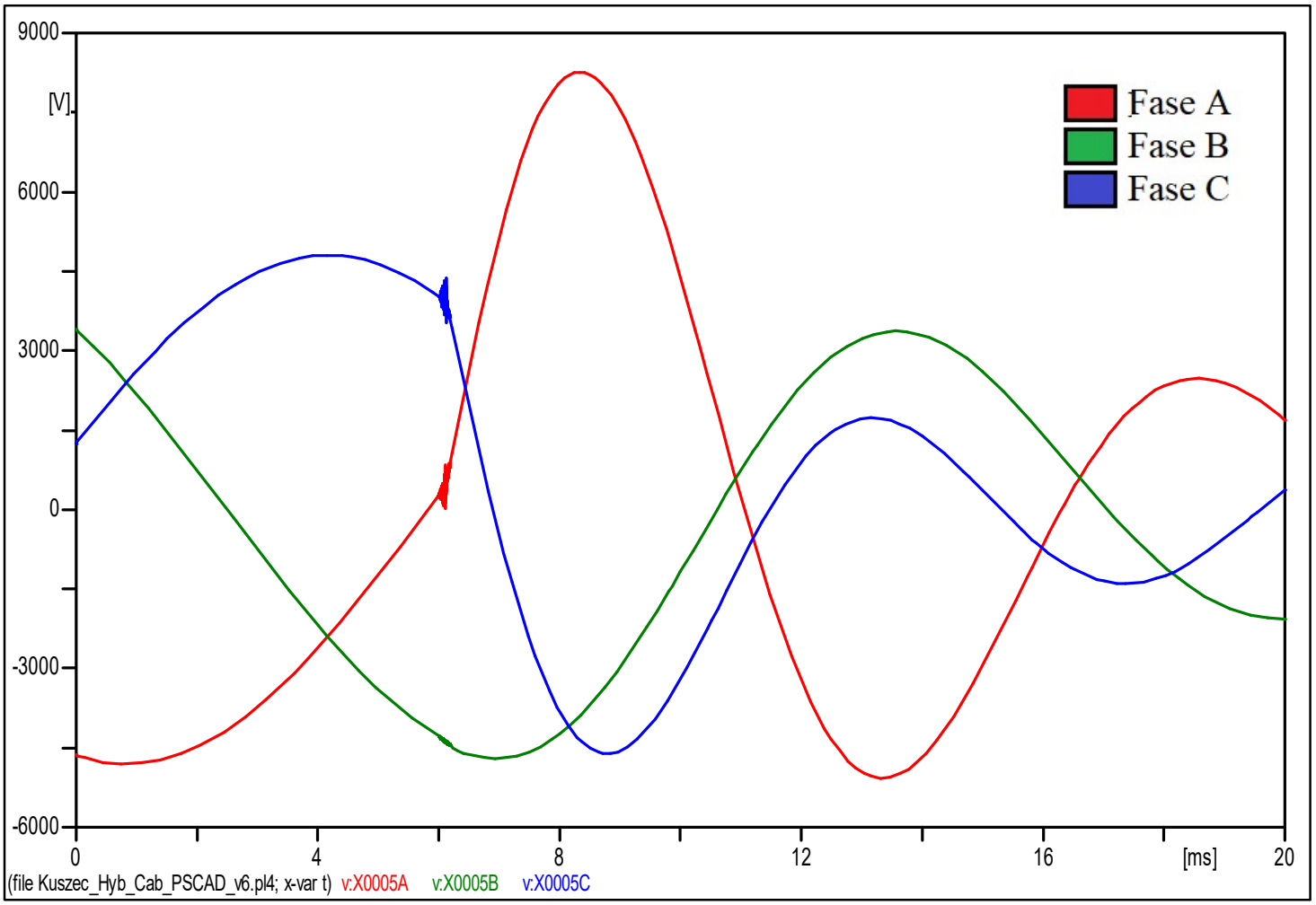


b)

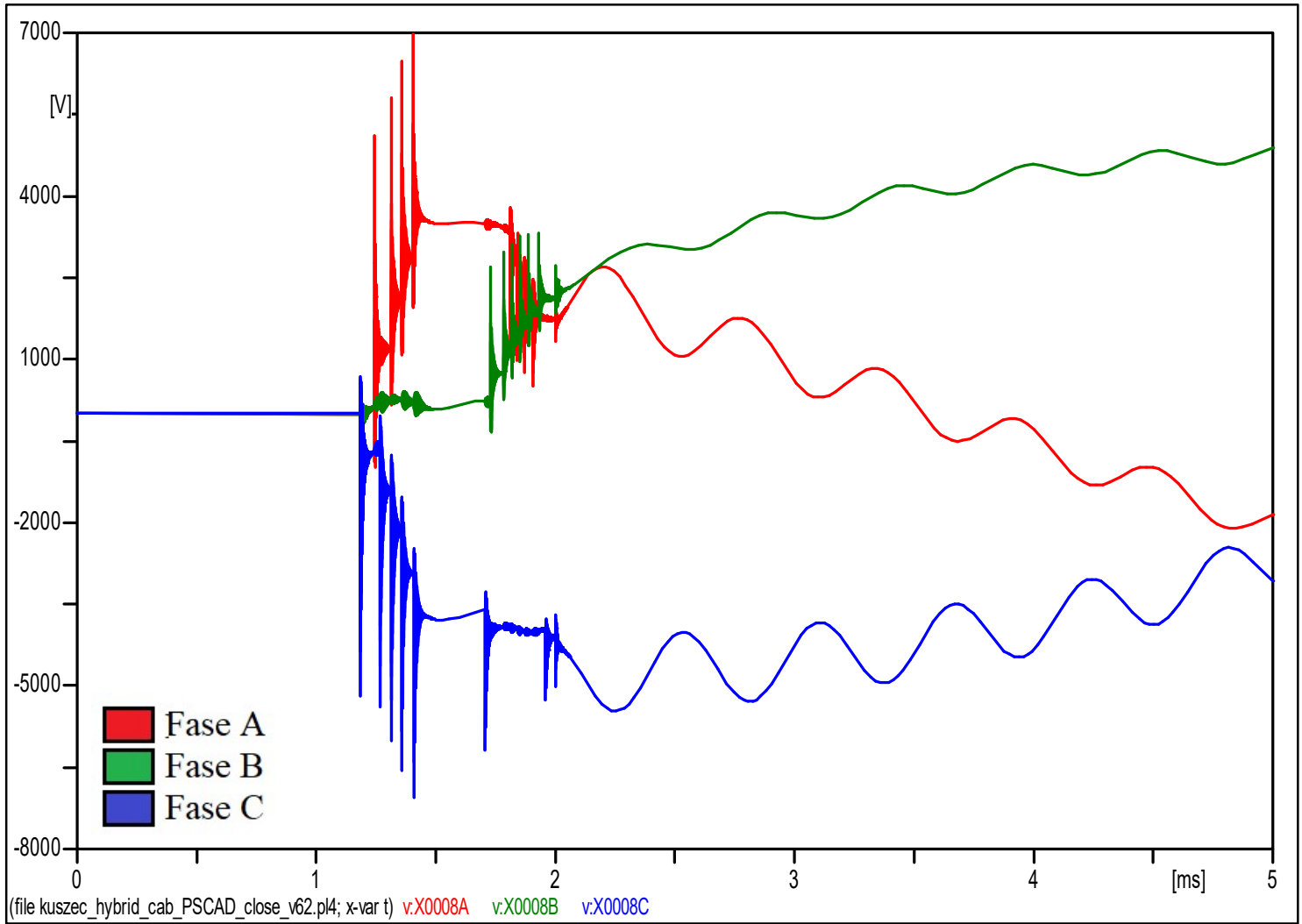

Fonte: Autor

Figura 31 - Tensões no primário do transformador 2 observadas na simulação 5

a) Abertura b) Fechamento

a)

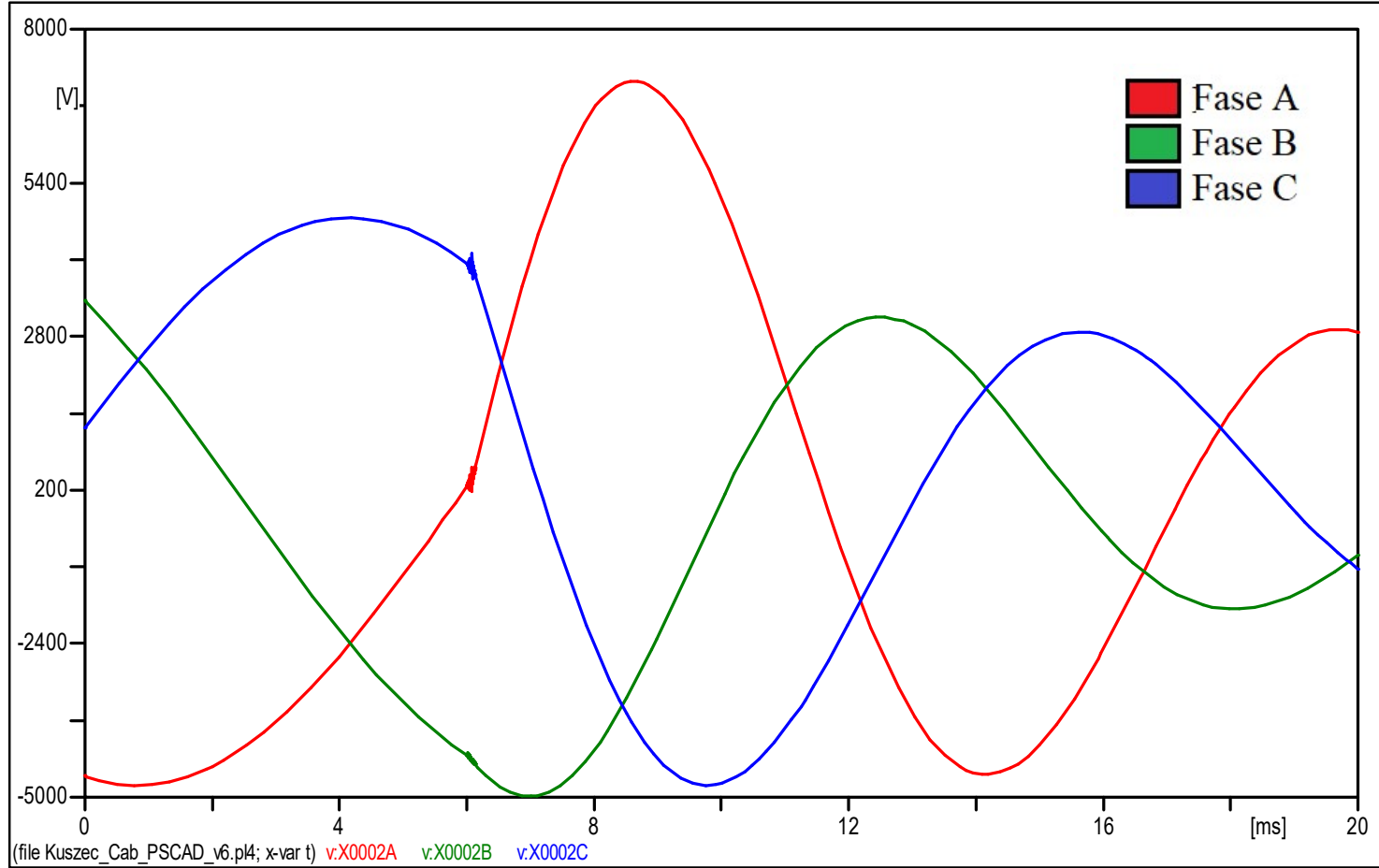


b)

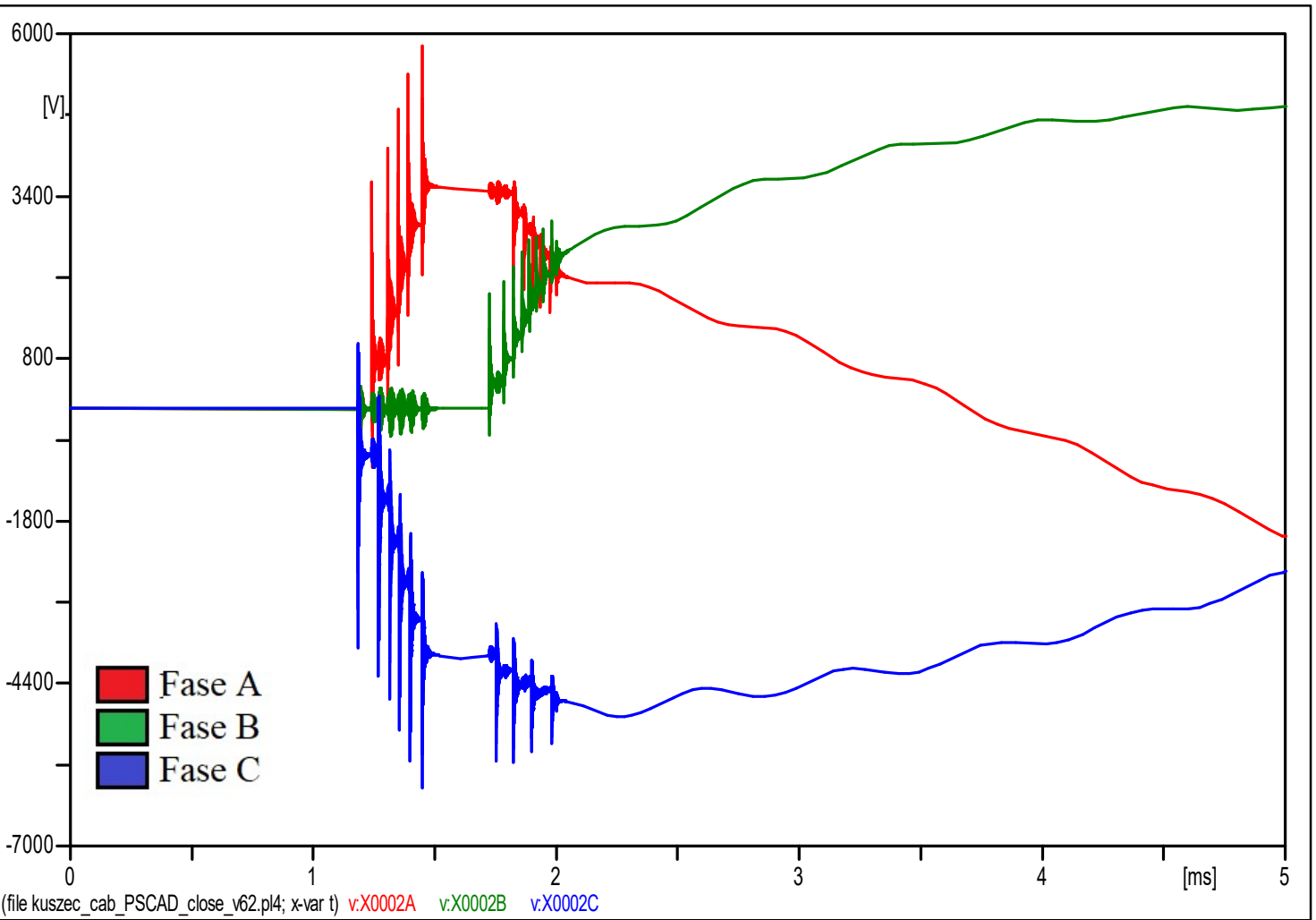

Fonte: Autor

\subsection{Discussão dos Resultados}

Para a simulação 1, considerando cabos modelados com o componente LINEZT_3, com parâmetros estabelecidos para uma frequência fixa $(50 \mathrm{~Hz})$ e o transformador modelado com o modelo BCTRAN e capacitâncias entre o primário e secundário e entre fases, observase, para a manobra de abertura, que o número de reignições é menor do que o verificado no experimento, assim como os valores das tensões de pico nas três fases, os quais também são inferiores aos valores observados no experimento. Já para o fechamento, os comportamentos das tensões são similares, porém o número de pré-ignições é superior e o valor de pico da tensão durante o transitório é inferior ao observado no experimento.

Para a simulação 2, a única alteração em relação a simulação 1 foi substituir os transformadores utilizados por outros do tipo Hybrid. Pode-se perceber que durante a abertura o número de reignições é mais próximo ao constatado no experimento com relação à simulação 1. Além do mais, observa-se que a fase B possui um comportamento transitório após as reignições mais próximo ao do experimento. Constata-se que o valor de pico da tensão durante as reignições é maior do que o encontrado na simulação 1 e mais próximo ao valor da tensão de pico da referência. Para o fechamento, os valores de pico de tensão e o 
número de reignições são mais próximos ao resultado do experimento que a simulação 1, entretanto tem-se uma oscilação maior do resultado durante as reignições.

Para a simulação 3, os cabos LINEZT_3 foram substituídos por cabos com parâmetros distribuídos e variáveis em função do valor da frequência. Para o fechamento, observa-se um gráfico com comportamento similar aos observados nas simulações 1 e 2. Já para a abertura, nota-se no fim da simulação um crescimento das tensões ao invés de uma redução do seu nível. Para confirmar tal desempenho, o circuito foi simulado novamente para um tempo de $30 \mathrm{~ms}$ e as formas de onda das tensões estão apresentadas na Figura 32.

Figura 32 - Tensões no primário do transformador 2 (uso de transformador Hybrid e cabos JMarti por $30 \mathrm{~ms}$ durante a abertura do disjuntor)

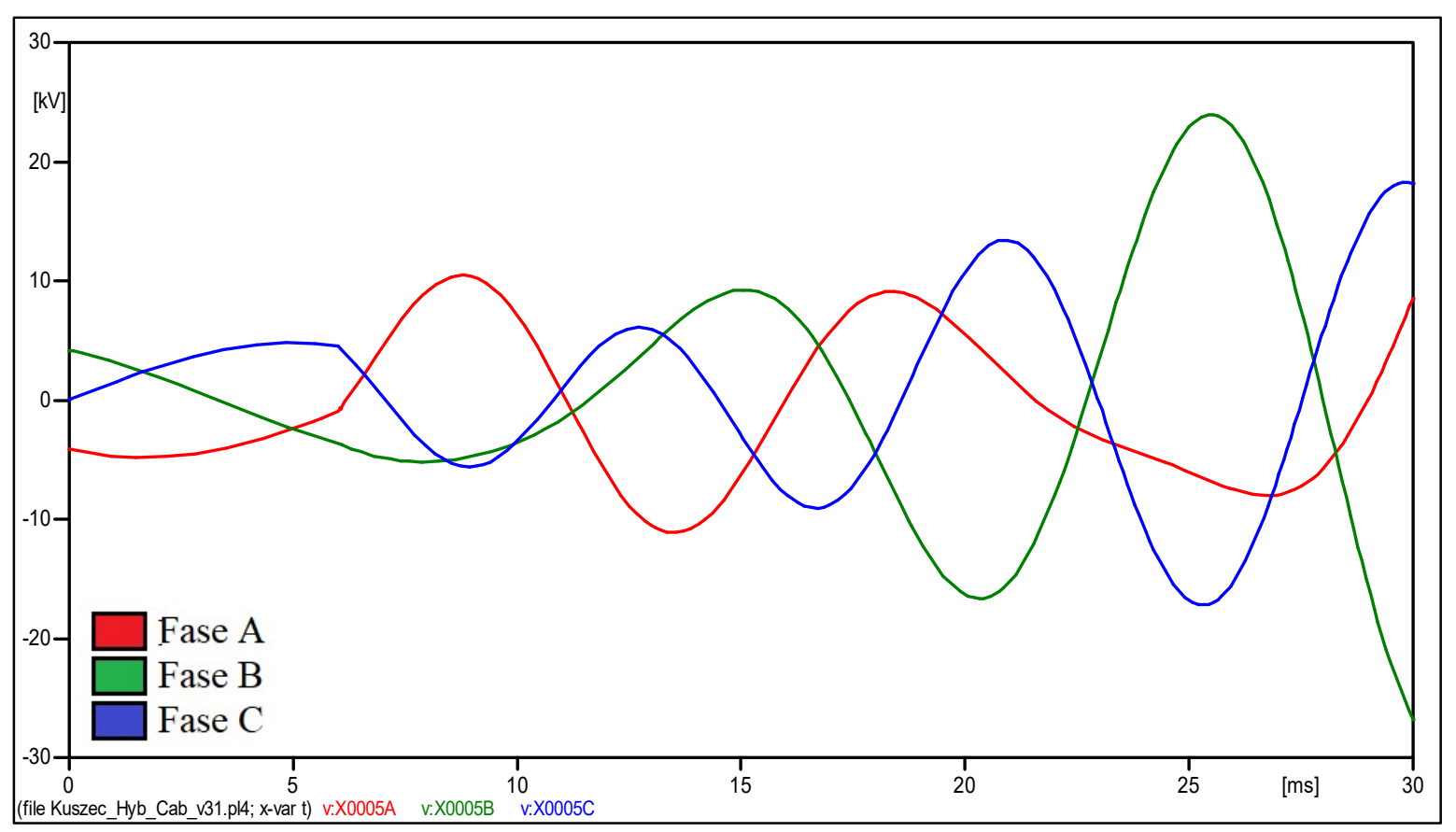

Fonte: Autor

Um comportamento divergente após a completa abertura do disjuntor é observado. Devido a esse resultado divergente, os parâmetros utilizados para modelagem dos cabos elétricos pelo modelo JMarti foram alterados, por exemplo, aumentando o número de pontos por década e alterando-se o valor de frequência no qual a matriz de transformação é criada, e os resultados não foram satisfatórios. Portanto, observa-se uma dificuldade em se modelar os cabos por meio do modelo de JMarti. Cabe comentar que Kuczek, Florwkowski e Piasecki (2016) apontam que o modelo JMarti do ATP possui alguma instabilidade numérica. 
Devido à diferença no resultado da simulação de abertura dos disjuntores e na dificuldade de convergência dos resultados utilizando os cabos LCC template no ATP, optou-se por adequar as funções da impedância característica e de propagação dos cabos no software PSCAD e importar esses resultados para o ATP, modelando o cabo, por fim, com o modelo de JMarti. O comportamento observado na simulação 4, tanto para a abertura quanto para o fechamento, foi melhor do que o observado na simulação 3, permitindo concluir que o algoritmo da adequação das funções da impedância caraterística e de propagação do PSCAD representa o comportamento dos cabos com maior fidelidade quando comparado ao ATP. Entretanto, quando comparado com as simulações 1 e 2, observa-se que para a abertura há uma atenuação dos níveis das tensões durante o transitório de alta frequência causado pelas reignições. De outro lado, como não se têm todas as informações sobre as características do cabo, não é possível saber se o modelo está superestimando as perdas.

Por fim, na simulação 5 o componente LCC template utilizado na simulação anterior foi mantido e os transformadores foram substituídos pelo modelo BCTRAN com a inclusão das capacitâncias. O que se observa é um comportamento muito semelhante entre essa simulação e a simulação 4, havendo uma atenuação ainda maior do transitório de alta frequência observado durante a abertura do disjuntor.

A Tabela 4 apresenta uma análise quantitativa dos resultados obtidos nas simulações, os comparando com os resultados dos testes e apresentando o valor da variação percentual com relação ao experimento para os parâmetros estudados, excluindo a simulação 3. 
Tabela 4 - Comparação dos resultados do experimento com as simulações

\begin{tabular}{|c|c|c|c|c|c|c|c|}
\hline Resultado & $\begin{array}{l}\text { Manobras } \\
\text { do } \\
\text { disjuntor }\end{array}$ & $\begin{array}{c}\text { Tensão } \\
\text { de pico } \\
(k V)\end{array}$ & $\begin{array}{c}\text { Variação } \\
\text { percentual } \\
\text { U (\%) }\end{array}$ & $\begin{array}{c}\text { Variação } \\
\text { de } \\
\text { tensão } \\
\text { du/dt } \\
(\mathrm{kV} / \mu \mathrm{s})\end{array}$ & $\begin{array}{l}\text { Variação } \\
\text { percentual } \\
\text { du/dt (\%) }\end{array}$ & $\begin{array}{c}\text { Número } \\
\text { de } \\
\text { reignições } \\
\text { por fase }\end{array}$ & $\begin{array}{c}\text { Variação } \\
\text { percentual } \\
\text { reignições } \\
\text { (\%) }\end{array}$ \\
\hline \multirow{2}{*}{ Experimento } & Abertura & 9,8 & - & 27 & - & 9 & - \\
\hline & Fechamento & 10,3 & - & 24 & - & 6 & - \\
\hline \multirow{2}{*}{ Simulação 1} & Abertura & 8,3 & $-15,3$ & 19,2 & $-28,8$ & 4 & $-55,5$ \\
\hline & Fechamento & 5,5 & -46 & 18,1 & $-24,5$ & 8 & 33,3 \\
\hline \multirow{2}{*}{ Simulação 2} & Abertura & 9,5 & $-3,1$ & 34,3 & 27,1 & 10 & 11,1 \\
\hline & Fechamento & 7 & -32 & 31,2 & 29,9 & 9 & 50 \\
\hline \multirow{2}{*}{ Simulação 4} & Abertura & 8,2 & $-16,3$ & 9,3 & $-65,6$ & 6 & $-33,3$ \\
\hline & Fechamento & 7,1 & $-31,5$ & 45,2 & 88,4 & 8 & 33,3 \\
\hline \multirow{2}{*}{ Simulação 5} & Abertura & 7,1 & $-27,6$ & 3,83 & $-85,8$ & 5 & $-44,4$ \\
\hline & Fechamento & 6,1 & 40,8 & 24,6 & 2,5 & 10 & 66,7 \\
\hline
\end{tabular}

Fonte: Autor

A partir dos resultados apresentados, que analisaram os diferentes tipos de modelos disponíveis no programa ATP, constata-se, com exceção da simulação 3, uma diferença especialmente durante o transitório de alta frequência na manobra de abertura do disjuntor a vácuo.

Verifica-se que a utilização de modelos de cabos diferentes influencia diretamente a resposta em altas frequências, principalmente durante a abertura do disjuntor, ou seja, no período em que ocorrem reignições. Comparando as simulações 1 e 5 (simulações utilizando o transformador BCTRAN e modelos de cabos diferentes) e as simulações 2 e 4 (simulações utilizando o transformador Hybrid e modelos de cabos diferentes), tal influência pode ser conferida. Nas simulações 1 e 2, modelos mais simples de cabos foram utilizados e constatase que, como o comprimento do cabo é relativamente curto (85 metros para o cabo de maior comprimento), a influência da representação dos parâmetros em função da frequência pode não ser muito significativa, o que, de certo modo, explicaria o comportamento satisfatório dos resultados dessas simulações. Nas simulações 4 e 5, modelos de cabos cujos parâmetros variam em função da frequência foram utilizados e observa-se uma atenuação nas tensões durante as reignições. O trabalho de Kuczek (2015) aponta resultados semelhantes, 
afirmando em seu estudo que a utilização de um modelo de cabo com a variação dos parâmetros com a frequência não apresentou uma convergência satisfatória e introduziu uma complicação adicional na simulação. Desse modo, Kuczek sugere simular o experimento de referência utilizando modelos de cabos com parâmetros constantes.

Um outro aspecto a ser mencionado é que a diferença entre os resultados numéricos das simulações é em parte causada pelos diferentes valores de correntes interrompidas durante a manobra. A Tabela 5 apresenta os valores de correntes interrompidas nas simulações de abertura do disjuntor, considerando o instante de abertura definido de forma a se garantir o corte de corrente próximo ao valor de pico da corrente da fase A.

Tabela 5 - Comparação das correntes interrompidas por fase e por simualação

\begin{tabular}{ccccc}
\hline Simulação & $\begin{array}{c}\text { Tempo de Abertura } \\
(\mathbf{m s})\end{array}$ & Fase A (A) & Fase B (A) & Fase C (A) \\
\hline Simulação 1 & 5,6 & $-0,093$ & 0,037 & 0,055 \\
\hline Simulação 2 & 5,4 & $-0,107$ & 0,032 & 0,075 \\
\hline Simulação 4 & 6,0 & $-0,095$ & 0,01 & 0,088 \\
\hline Simulação 5 & 6,0 & $-0,074$ & 0,02 & 0,055 \\
\hline
\end{tabular}

Fonte: Autor

Por meio da Tabela 5, constata-se que os valores de pico de corrente são diferentes para cada simulação, devido às diferentes combinações de modelos de transformadores e cabos. Tal diferença leva em parte aos distintos valores de tensão durante os transitórios de alta frequência.

Ao se comparar as simulações 1 e 2, as quais utilizaram o mesmo modelo de cabo (LINE_ZT3) e diferentes modelos de transformadores, observa-se uma diferença na resposta de alta frequência. Isso se deve pela utilização do modelo de transformador Hybrid na simulação 2, no qual as resistências e indutâncias são variáveis em função da frequência de forma linear. Entretanto, ainda se observa uma oscilação das tensões no resultado da simulação 2. Assim, verifica-se a dificuldade em se representar o comportamento de altas frequências de transformadores, sendo necessário realizar adaptações em modelos consolidados para se obter uma resposta adequada. Portanto, constata-se a necessidade de modelos mais precisos dos transformadores para altas frequências.

Após o transitório de alta frequência na manobra de abertura, o comportamento das ondas de tensão é influenciado sobretudo pelos modelos dos transformadores, sendo possível 
observar um comportamento similar para todas as simulações. A diferença no tempo de acomodação das tensões para seu valor final, observada nas simulações, deve-se ao nível de amortecimento dos modelos e também do nível de energia trocada pelos componentes do circuito durante as reignições. Nas simulações 1 e 2, constata-se que a acomodação das ondas de tensão é mais rápida e se assemelha ao experimento de referência.

Para a manobra de fechamento, observa-se um comportamento semelhante para todas as simulações, pois a corrente é igual a zero antes das pré-ignições. Desse modo, constatase que a troca de energia entre os componentes do circuito é similar em todas as simulações.

\subsection{Análise de Tensões e Correntes da Simulação 2}

A título ilustrativo, optou-se por apresentar gráficos de tensões e correntes obtidos na simulação 2 durante a abertura do disjuntor a vácuo. Verifica-se na Figura 33 a TRT das três fases sobre os terminais do disjuntor. A amplitude da TRT, após a abertura do disjuntor, é responsável pela primeira reignição. Após o transitório, as ondas de tensão tendem a possuírem valores eficazes iguais à tensão nominal do secundário do transformador 1 .

Figura 33 - Tensão sobre os terminais do disjuntor durante a abertura

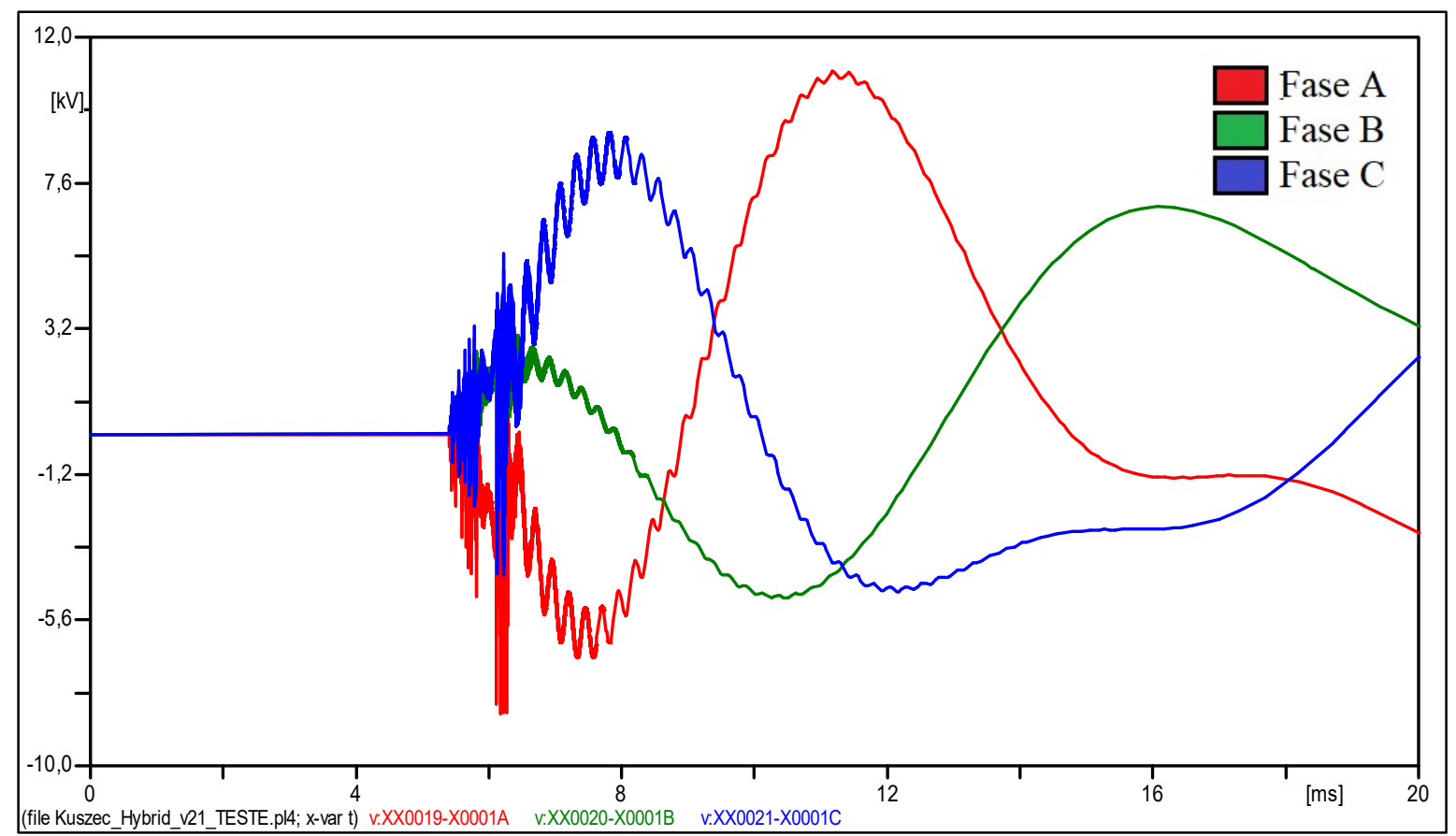

Fonte: Autor 
A Figura 34 apresenta o mesmo gráfico da Figura 33 ampliado, onde, além das três fases, é possível ver a curva da recuperação dielétrica do disjuntor representada nas cores rosa e marrom, pois ela possui a mesma característica tanto em sua forma positiva quanto negativa. Dessa forma, percebe-se os momentos exatos onde a tensão do dielétrico é superada pelas três fases, ocasionando diversas reignições, principalmente, nas fases A e C. $\mathrm{Na}$ fase $\mathrm{B}$, apenas uma reignição é observada durante a simulação. A Figura 34 é complementada pela Figura 35, onde pôde-se determinar que os primeiros cortes de correntes aconteceram em cerca de $-0,1 \mathrm{~A}$ para a fase A, 0,03A para a fase B e 0,07A para a fase C.

Figura 34 - Tensão sobre os terminais do disjuntor durante a abertura ampliada

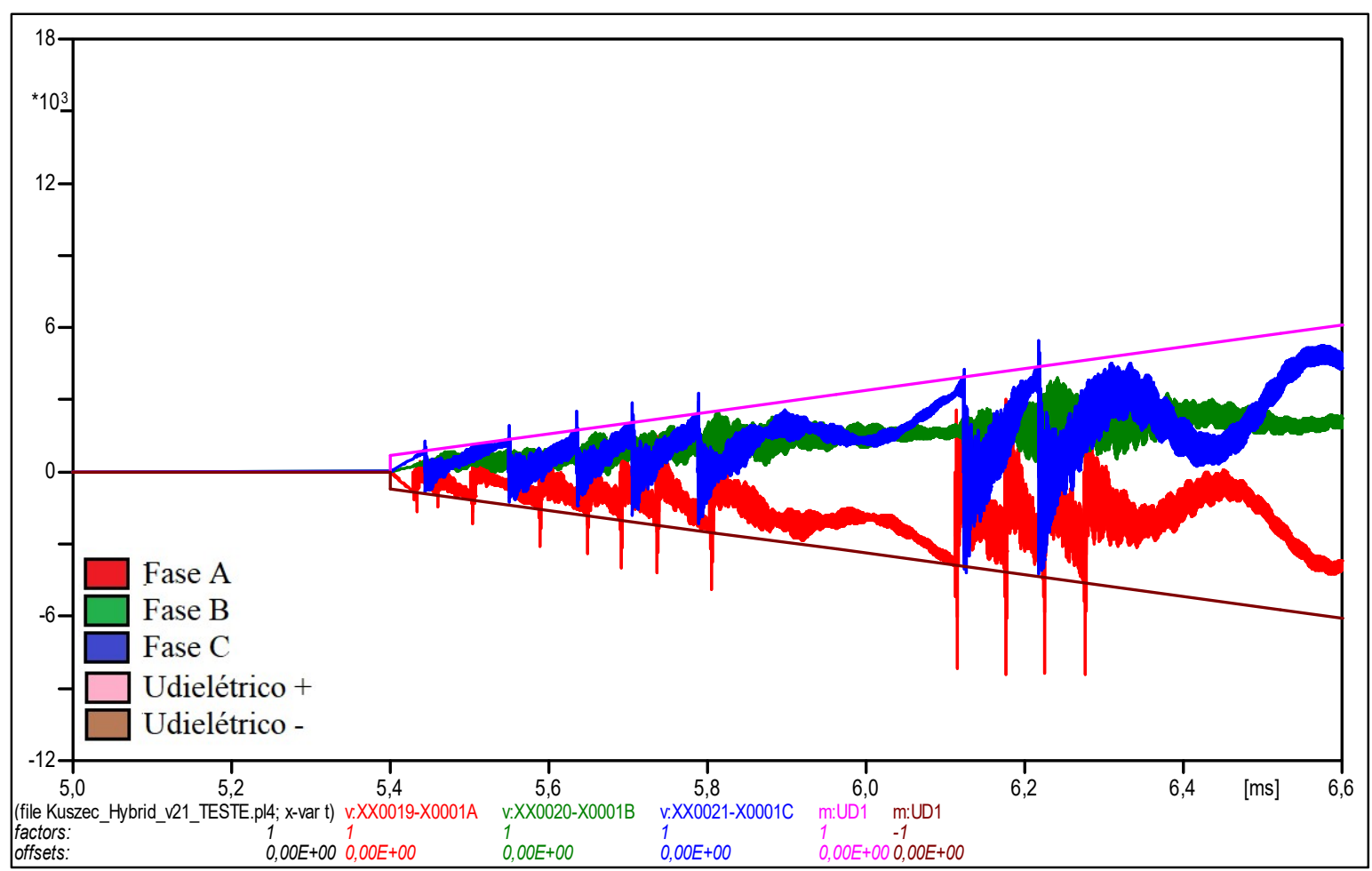

Fonte: Autor 
Figura 35 - Corrente sobre o disjuntor durante a abertura

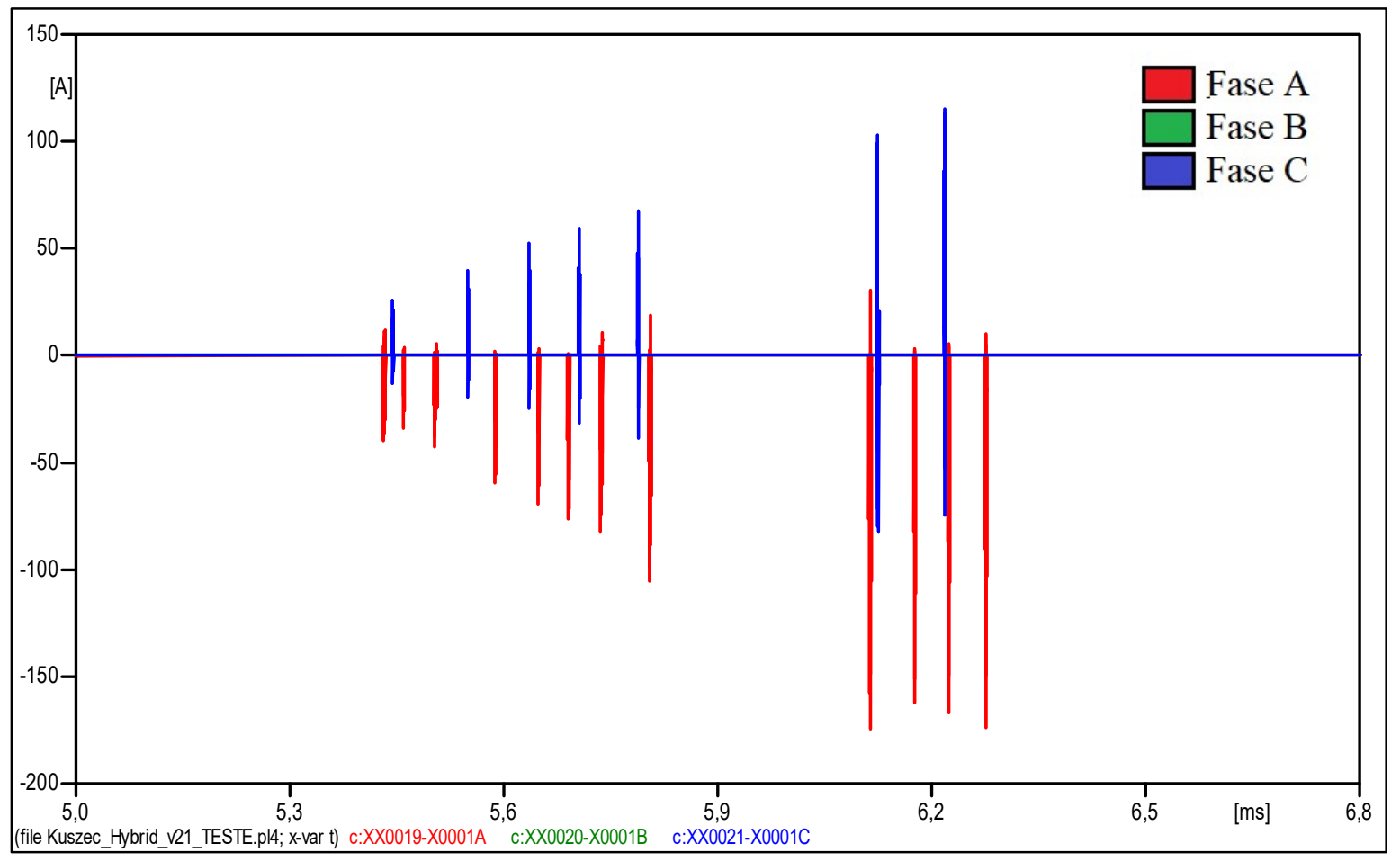

Fonte: Autor

Conforme complementado pela Figura 36, especificamente para a fase A, após as reignições, a corrente é interrompida quando a capacidade de extinção de correntes de alta frequência do disjuntor (curva vermelha) é maior do que a derivada da corrente em relação ao tempo em um determinado instante (curva verde) e quando sua magnitude for maior ou igual ao valor da corrente de corte. Comportamento similar é observado nas demais fases. 
Figura 36 - Capacidade de extinção de correntes na fase A

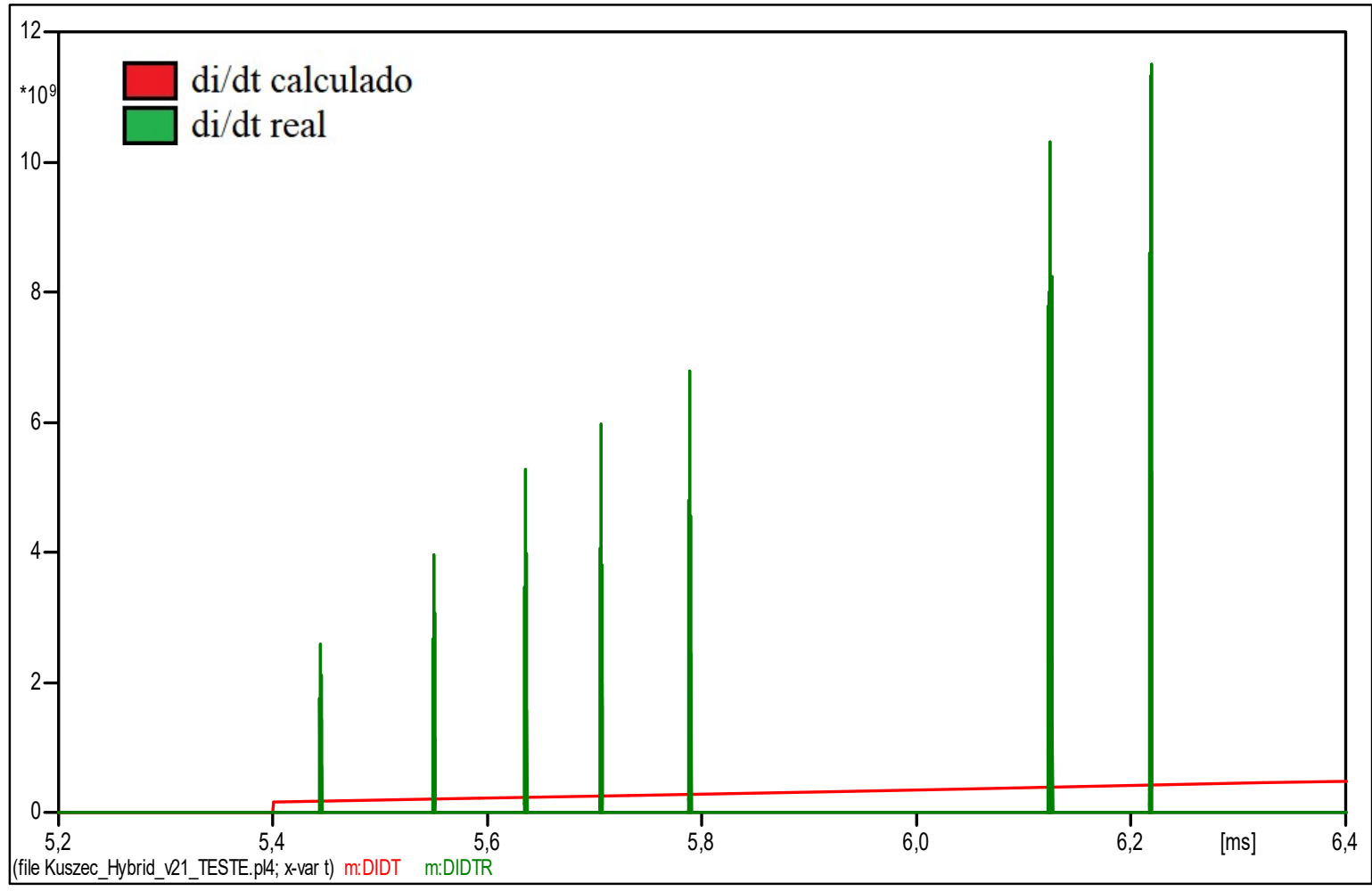

Fonte: Autor

Para o fechamento, as tensões entre os terminais do disjuntor estão apresentadas na Figura 37, além da curva da recuperação dielétrica do disjuntor nas cores rosa e marrom. A Figura 38 apresenta as correntes fluindo pelo disjuntor. 
Figura 37 - TRT durante o fechamento

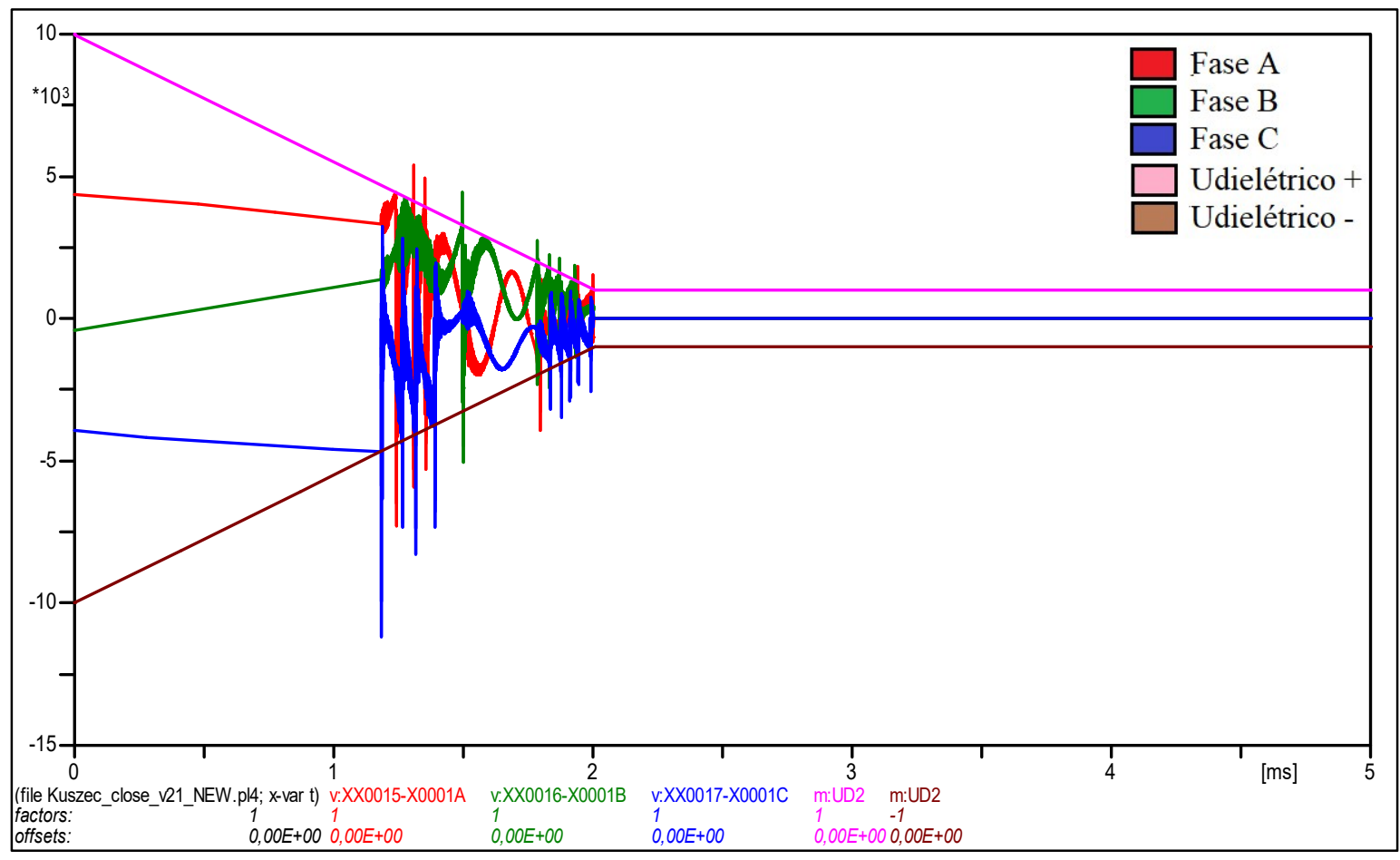

Fonte: Autor

Figura 38 - Correntes sobre o disjuntor durante o fechamento

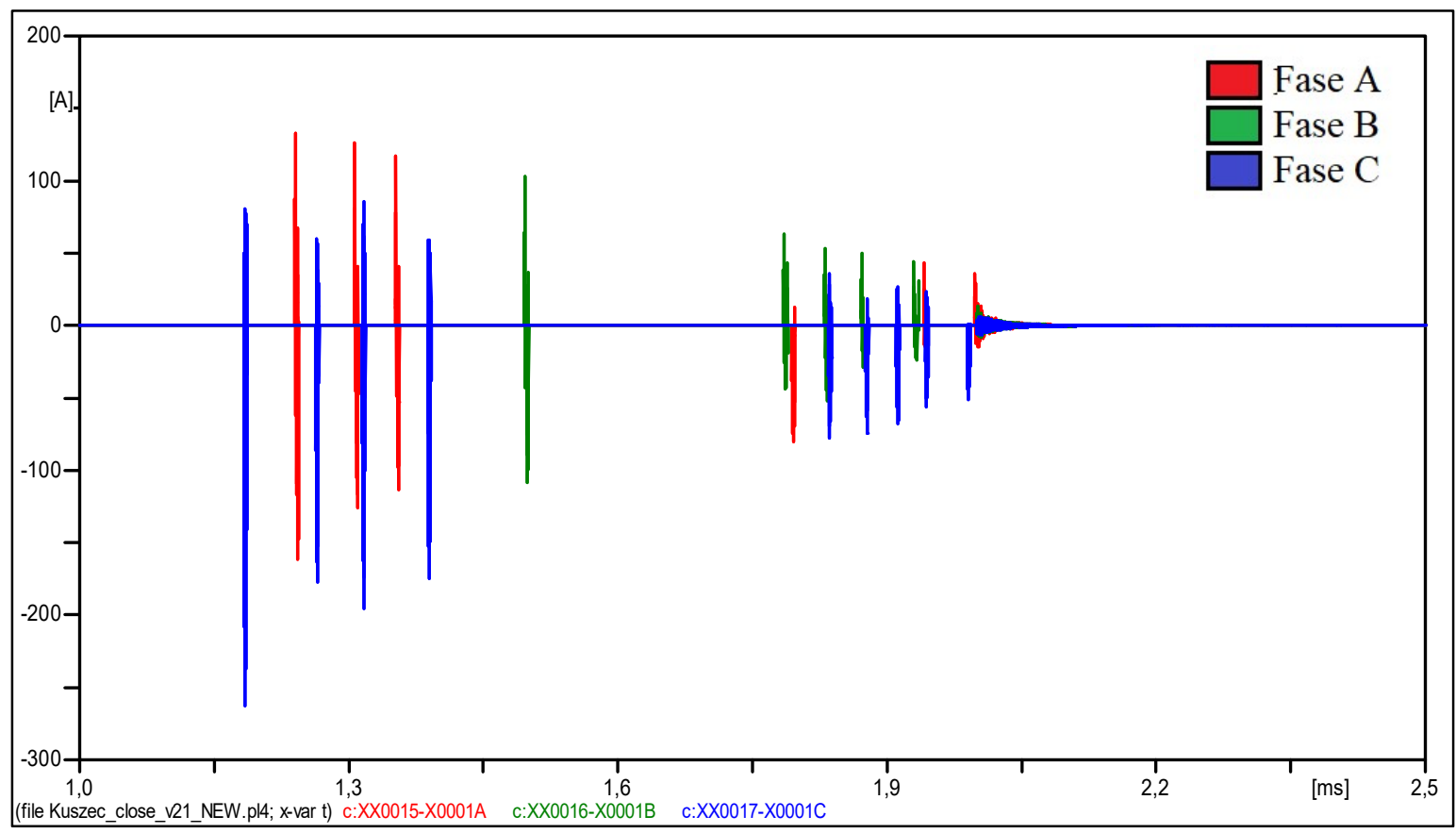

Fonte: Autor 
A Figura 37 apresenta uma ampliação das tensões sobre os disjuntores juntamente com o gráfico da tensão de recuperação do dielétrico, e, portanto, pode-se determinar os momentos exatos quando ocorrem as pré-ignições. Ao contrário do que observado para a abertura, o nível de tensão das pré-ignições e a amplitude das correntes diminui até o ponto em que o disjuntor se fecha e o nível de tensão entre seus terminais se iguala a zero.

O mecanismo de interrupção de correntes de alta frequência possui a mesma característica já apresentada para a abertura. Para o fechamento, isso pode ser observado na Figura 39.

Figura 39 - Capacidade de extinção de correntes na fase A

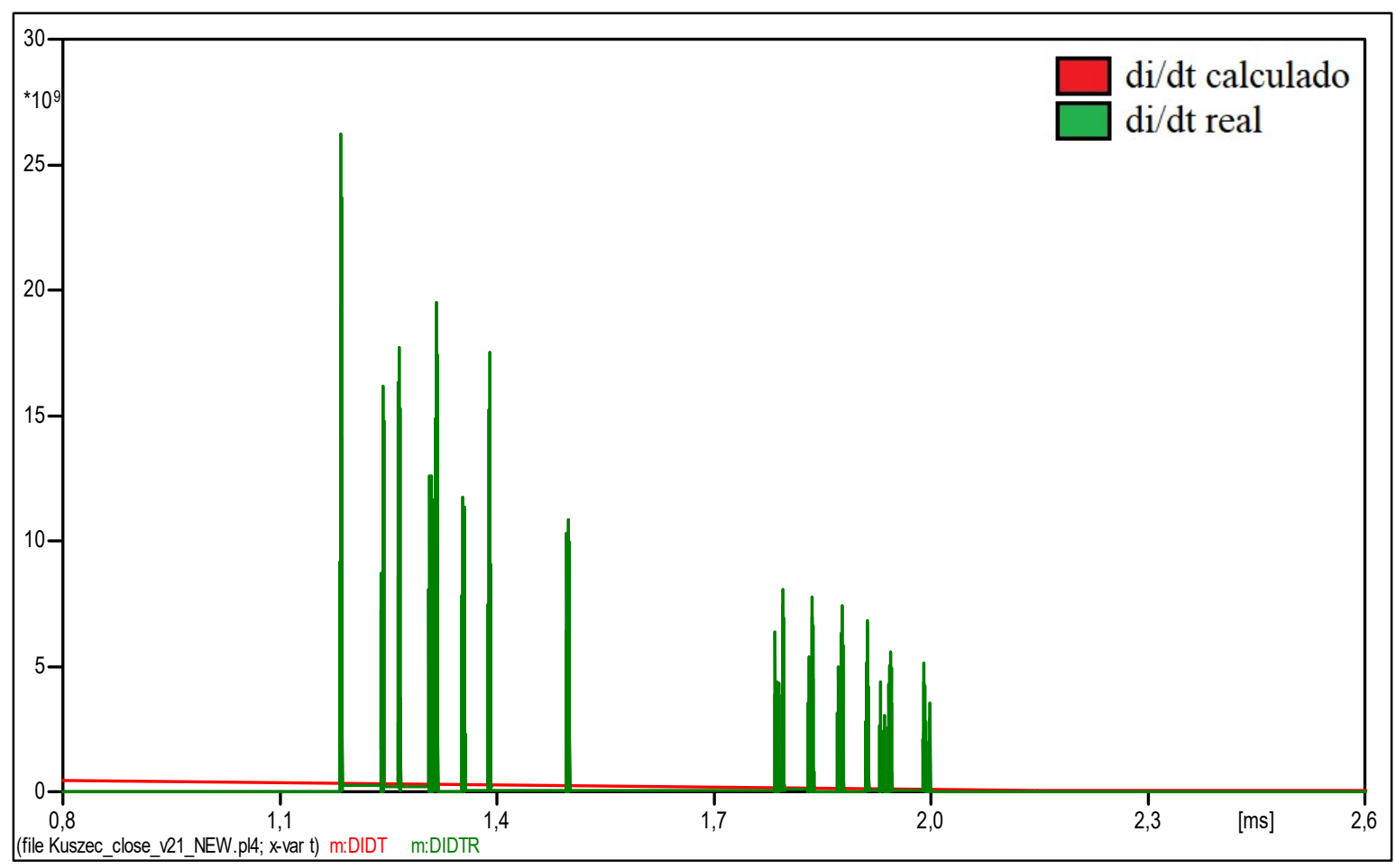

Fonte: Autor

\subsection{Variações da Simulação 2}

A partir da simulação 2, algumas variações foram feitas nos componentes com o intuito de demonstrar as características de circuitos que causam transitórios de sobretensões mais danosos aos equipamentos e como a inclusão das soluções apresentadas no item 2.4 impactam a resposta do circuito. 
Primeiramente, alterou-se o valor do comprimento do cabo conectado após o disjuntor a vácuo de 85 metros para cinco metros. Isso foi feito para diminuir a capacitância do circuito e para tentar reproduzir o agravante de utilização de cabos curtos entre o disjuntor e o transformador, o qual é citado por alguns autores no Quadro 1 no Capítulo 1.1 como causa de sobretensões. A Figura 40 apresenta os resultados da simulação da abertura.

Figura 40 - Tensões no primário do transformador 20kVA - Redução do cabo

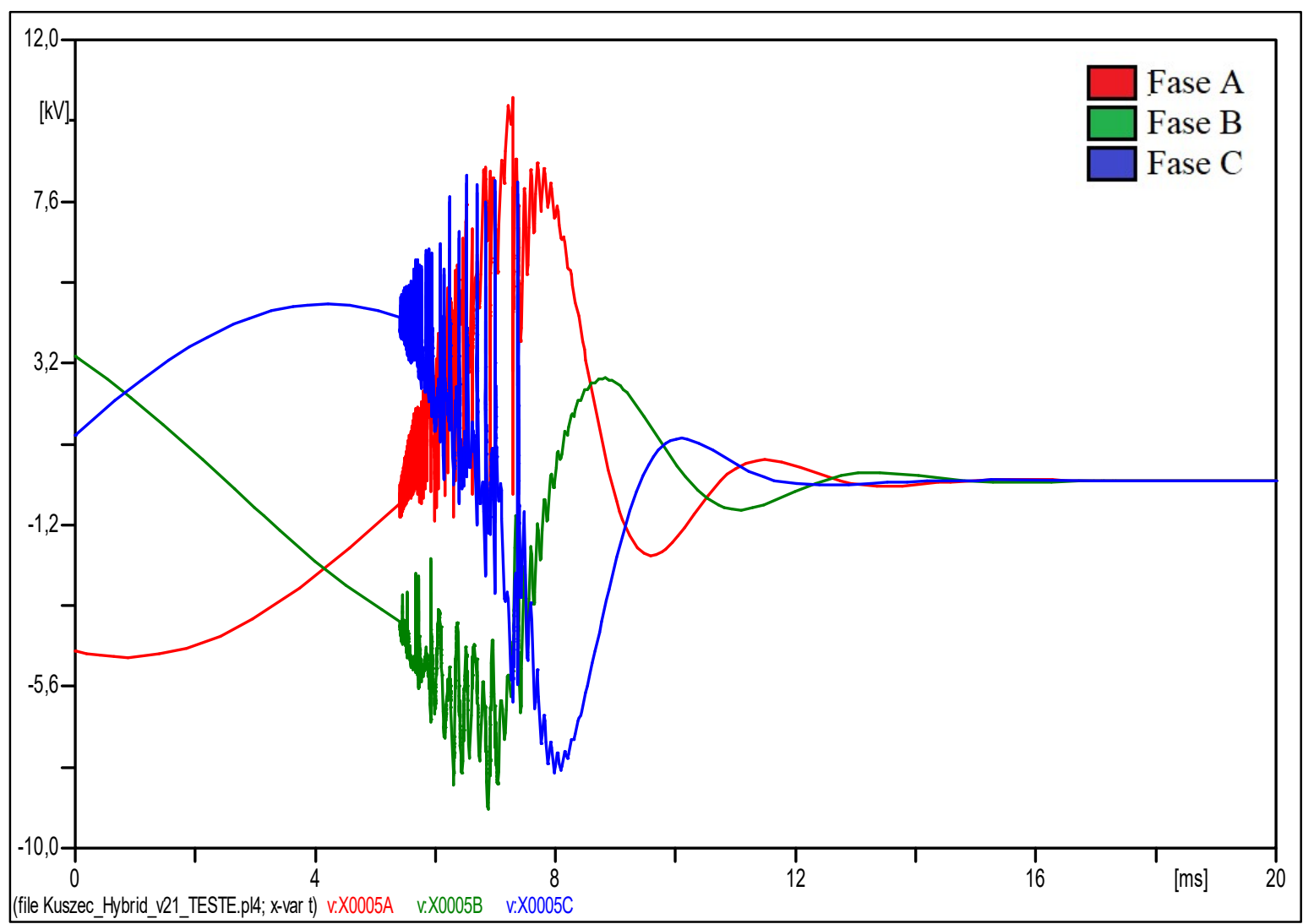

Fonte: Autor

É possível perceber que durante as reignições um nível de tensão mais elevado e um número de reignições superiores aos apresentados nas simulações anteriores ocorrem. Esse nível maior de sobretensão e de número de reignições decorrem de uma capacitância menor presente no circuito. Durante esse transitório, a capacitância atua na absorção da energia magnética liberada pelas indutâncias oriunda de variações abruptas de corrente, causadas pelo corte de corrente ou pelas reignições. Quanto menor o valor da capacitância, maior a variação de tensão observada no circuito. 
Em seguida, foi conectada ao secundário do transformador uma carga indutiva de 10kVA (metade da potência nominal do transformador). A Figura 41 apresenta os resultados da simulação da abertura.

Figura 41 - Tensões no primário do transformador 20kVA - Redução do cabo e carga de 10kVA

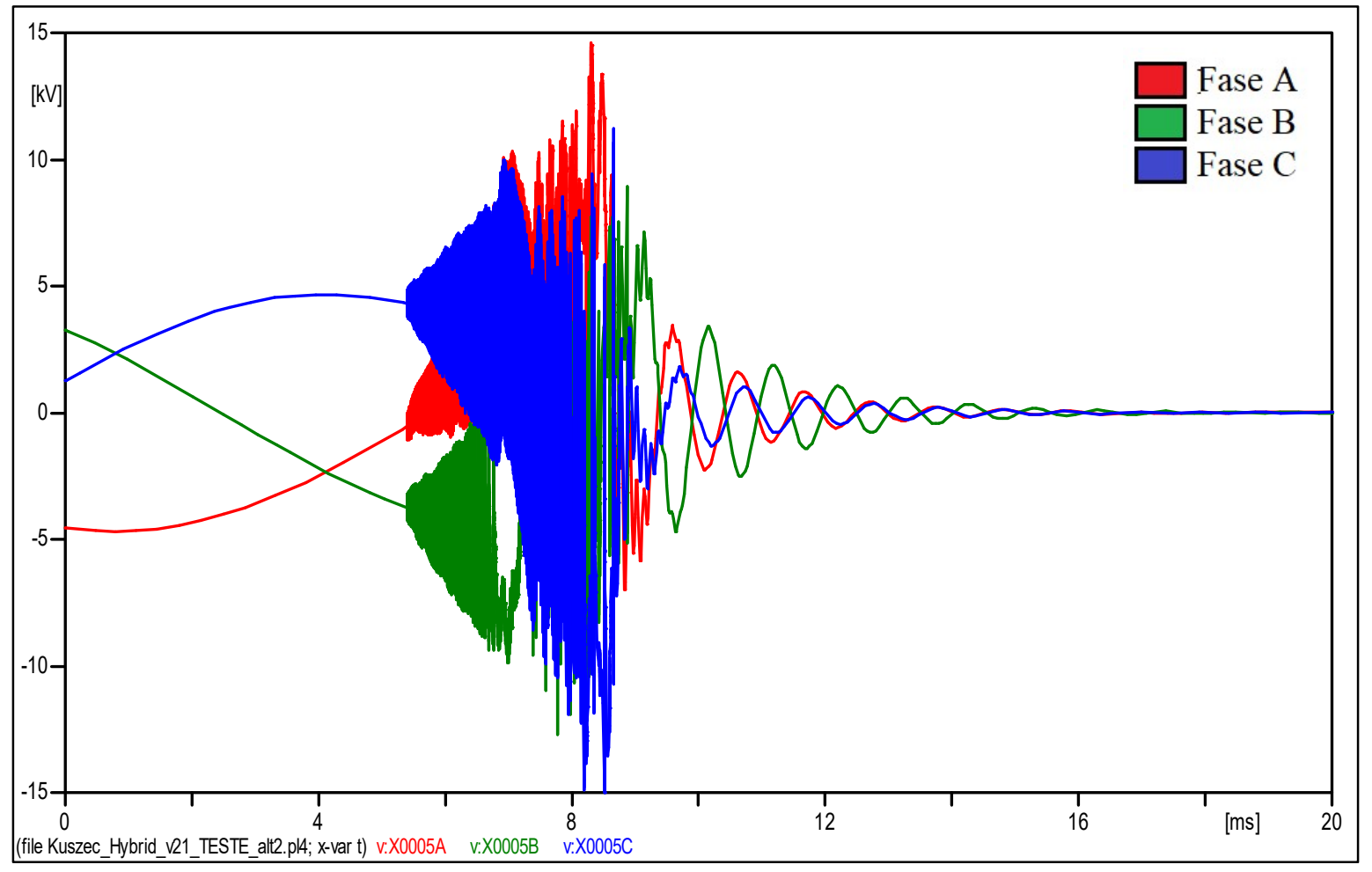

Fonte: Autor

Observa-se que a inclusão da carga indutiva de 10kVA ocasionou em um transitório com uma maior frequência de oscilação e maiores valores de sobretensão, corroborando com o que já foi apresentado sobre o aumento da indutância.

A partir do último circuito simulado, buscou-se incorporar as soluções para esse tipo de problema. A primeira solução incorporada ao circuito foi a inclusão de snubbers RC no primário do transformador 2. A Figura 42 apresenta as tensões no primário do transformador 2 com essa solução. 
Figura 42 - Tensões no primário do transformador 2 após instalação de snubbers RC

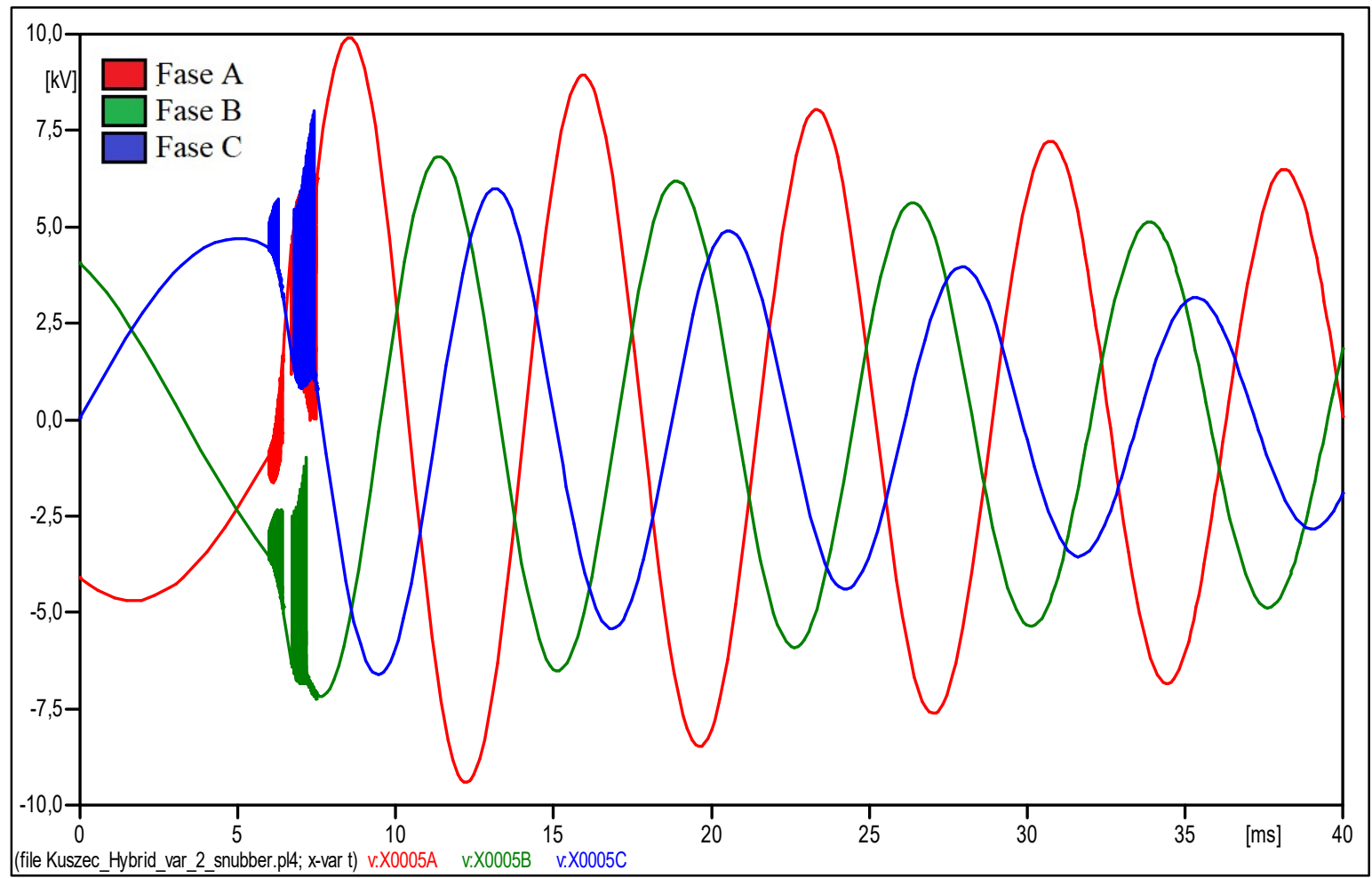

Fonte: Autor

Comparando a Figura 42 com a Figura 41, é notório que a solução contribuiu na redução da tensão de pico do transitório de $16 \mathrm{kV}$ para $10 \mathrm{kV}$, e que ainda reduziu consideravelmente o número de reignições e a frequência do transitório. Entretanto, também é verificado que as tensões demoram um tempo maior para atingirem o valor de regime permanente, tal fato ocorre devido à energia acumulada nas capacitâncias. Considerando as vantagens supracitadas, esse tempo de acomodação da tensão pode ser considerado aceitável.

A segunda solução implementada foi a instalação de para-raios F-T no primário do transformador 2. A Figura 43 apresenta as tensões sobre o primário do transformador 2. 
Figura 43 - Tensões no primário do transformador 2 após instalação de para-raios F-T

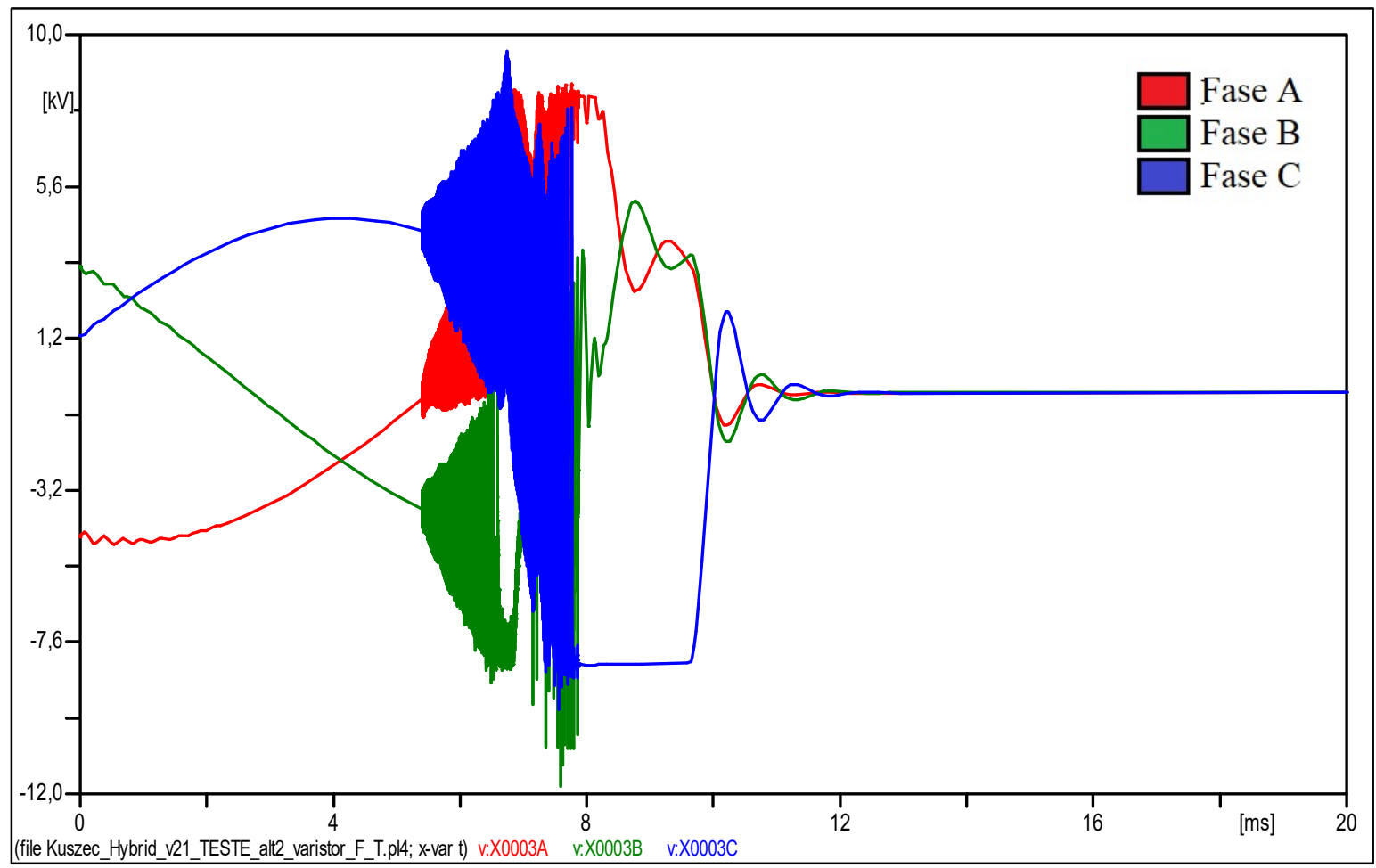

Fonte: Autor

Comparando a Figura 41 à Figura 43, pode-se observar que o transitório é o mesmo nos primeiros instantes, mas que, por volta dos $8 \mathrm{~ms}$, o para-raios passa a atuar e limita as sobretensões transitórias, além de ser mais um caminho para circulação de corrente logo após a manobra do disjuntor. Nota-se que em torno de $12 \mathrm{~ms}$ a tensão se acomoda totalmente no valor de $0 \mathrm{~V}$ nas três fases.

A terceira solução implementada foi a instalação de para-raios F-T e F-F no primário do transformador 2. A Figura 44 apresenta as tensões sobre o primário do transformador 2. 
Figura 44 - Tensões no primário do transformador 2 após instalação de para-raios F-F e F-T

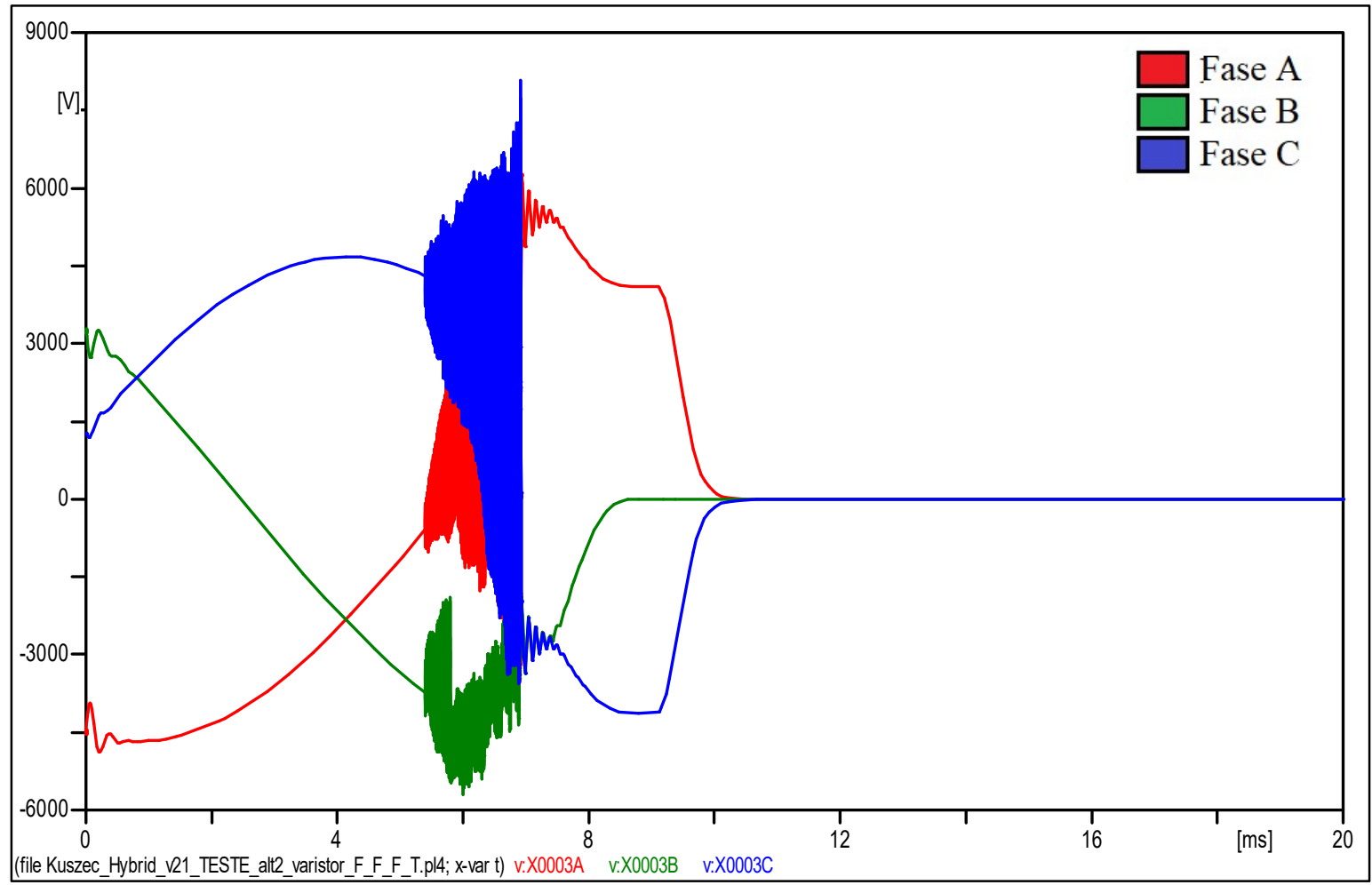

Fonte: Autor

Comparando a Figura 44 à Figura 41, observa-se que a inclusão dos para-raios F-F diminuiu o valor de pico de sobretensão para $8 \mathrm{kV}$ e que eles passam a atuar em $7 \mathrm{~ms}$, o qual representa um tempo de atuação inferior quando comparado com o caso anterior. Além disso, por volta dos $10 \mathrm{~ms}$, as tensões já se acomodaram em $0 \mathrm{~V}$, sendo esse um tempo de acomodação mais rápido quando comparado com o caso anterior. Porém, assim como na simulação anterior, a frequência do transitório durante as reignições é elevada.

A última solução implementada no presente trabalho foi a instalação de para-raios FT e snubbers RC no primário do transformador 2. A Figura 45 apresenta as tensões sobre o primário do transformador 2. 
Figura 45 - Tensões no primário do transformador 2 após instalação de para-raios F-T e snubbers $\mathrm{RC}$

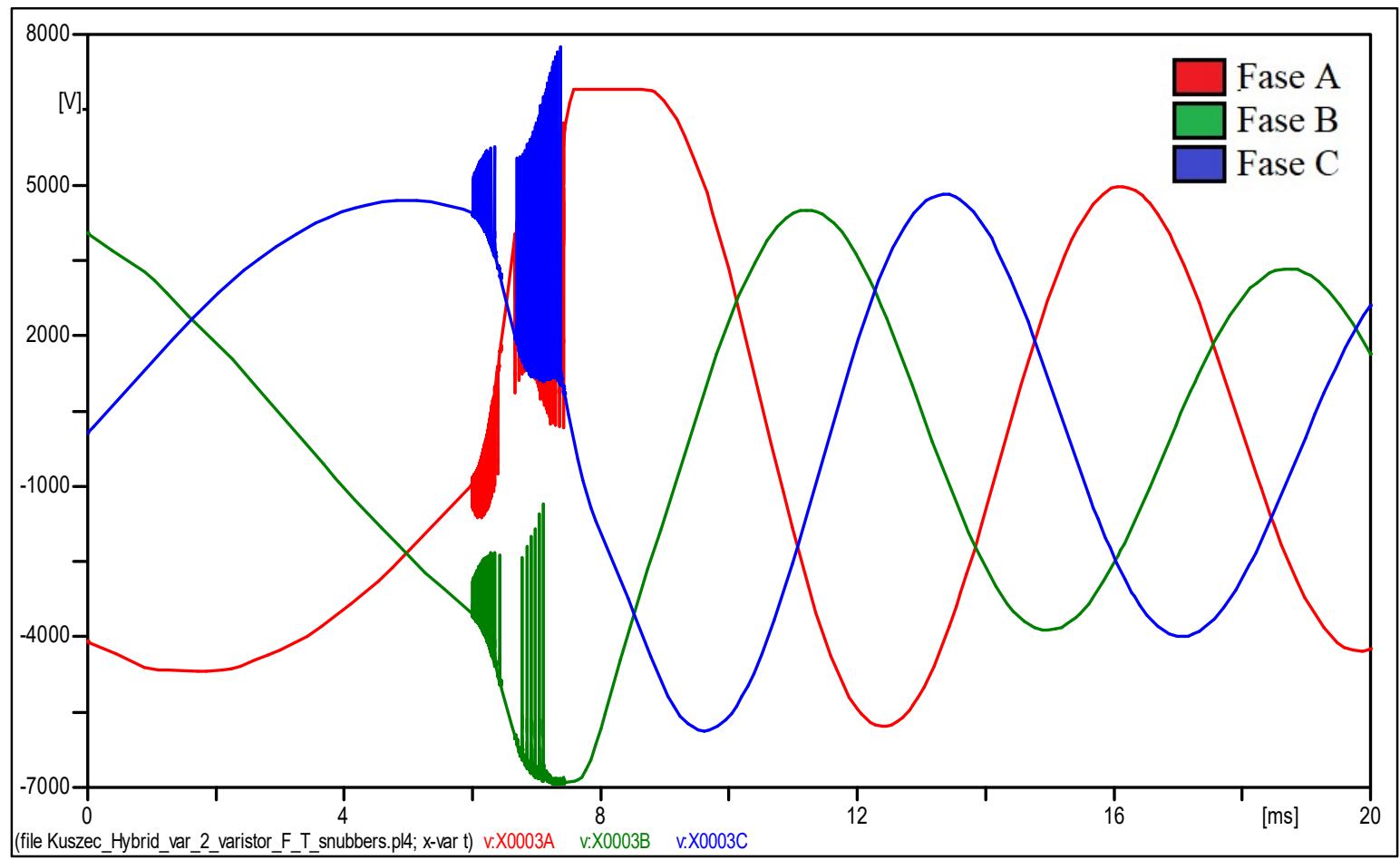

Fonte: Autor

Para esse último caso, observa-se um comportamento similar ao apresentado na Figura 42, ou seja, reduções das reignições e da frequência durante o transitório causada pelo uso dos snubbers RC. Entretanto, nessa solução, os para-raios limitam ainda mais o valor da tensão de pico culminando em um valor abaixo de $8 \mathrm{kV}$, ou seja, o menor valor observado entre todos os casos. Como na primeira solução, o tempo para as tensões se acomodarem em 0V aumenta por causa dos snubbers, porém nessa solução o tempo é menor quando comparado com a solução utilizando apenas snubbers RC. 


\section{CONCLUSÕES}

Por meio deste trabalho pôde-se mostrar os desafios e a importância do desenvolvimento de ferramentas para estudos relativos a sobretensões causadas por manobras de disjuntores a vácuo a serem utilizadas em simulações de plantas elétricas. $\mathrm{O}$ desafio de desenvolver esse tipo de ferramenta reside no comportamento dos arcos elétricos no interior dos disjuntores a vácuo e na natureza aleatória dos fenômenos associados à suas manobras.

Como discutido através das literaturas apresentadas, para o caso de manobras de abertura desses disjuntores, as redes elétricas conectadas aos disjuntores a vácuo podem estar sujeitas aos fenômenos de corte de corrente, reignições e corte de corrente virtual. Já em manobras de fechamento pode-se observar as pré-ignições. Conforme apresentado na literatura e observado por meio das simulações, as sobretensões transitórias de alta frequência estão associadas aos fenômenos supracitados, podendo causar danos e até mesmo a falha de equipamentos conectados aos disjuntores. Os equipamentos mais danificados em decorrências dessas sobretensões são os transformadores a seco. Na prática, as falhas de transformadores a seco ocorrem devido a elevadas taxas de variação de tensão em relação ao tempo, excitando ressonâncias internas dos equipamentos, ou ainda devido à repetição dos impulsos de tensão sobre o isolamento dos transformadores, mesmo com um nível de tensão inferior ao NBI dos equipamentos.

Por meio das simulações, pôde-se ajustar o modelo de disjuntor apresentado na Figura 24, analisar as diferenças nos resultados ao se utilizar diferentes modelos de componentes elétricos, disponíveis em softwares de simulação de transitórios, no circuito simulado comparando com o caso real apresentado na Figura 8.

Através da utilização de diferentes modelos de cabos elétricos e de transformadores nas simulações, verificou-se que os modelos de cabos influenciam principalmente os transitórios de alta frequência durante as reignições. Como o comprimento do cabo é relativamente curto, a influência da representação dos parâmetros em função da frequência pode não ser muito significativa, o que explicaria, de certo modo o bom comportamento das simulações 1 e 2 . Para as simulações 4 e 5 utilizando modelos de cabos cujos parâmetros variam em função da frequência, constatou-se que há uma atenuação das tensões durante o transitório das reignições, porém, como não se têm todas as informações sobre as características do cabo, não é possível saber se o modelo está superestimando as perdas. A 
utilização do modelo de transformador Hybrid também influenciou o comportamento do transitório de alta frequência, porém ainda se observa uma dificuldade em se simular o comportamento em altas frequências de transformadores, sendo necessário buscar outras formas de modelá-lo. A maneira mais simples de obter uma resposta mais realista é utilizando modelos black box, ou seja, é necessário realizar medições no transformador para desenvolver o modelo.

Para o restante do transitório após as reignições, a resposta preponderante advém do modelo de transformador utilizado. A diferença no tempo de acomodação das tensões durante a abertura do disjuntor, observada nas simulações que utilizaram o mesmo modelo de transformador (simulações 1 e 5 e simulações 2 e 4), se deve ao nível de energia liberado pelos componentes do circuito durante as reignições. Tal diferença, em grande parte, vem da amplitude da corrente interrompida, a qual é influenciada pela combinação de modelos de cabos e transformadores.

Para a manobra de fechamento, observa-se um comportamento similar para todas as simulações, pois nesse caso a corrente é igual a zero antes do transitório de alta frequência oriundo das pré-ignições.

A título ilustrativo, cenários onde as sobretensões se agravam foram simulados a partir dos resultados da simulação 2 e observou-se que o aumento da indutância do circuito em relação à capacitância, por meio da utilização de cargas indutivas ou da redução de cabos elétricos, agravam as sobretensões transitórias, devido à maior energia magnética a ser absorvida nos capacitores. Essa energia magnética é oriunda das variações abruptas de corrente, causada pelo corte de corrente e pelas reignições.

Por fim, a partir do último circuito simulado onde o transitório foi agravado pela conexão de uma carga indutiva e redução dos cabos elétricos, as soluções apresentadas no Capítulo 2.4 deste trabalho foram incluídas no circuito e simuladas. As soluções utilizando apenas para-raios apresentaram uma limitação da sobretensão considerável, porém a frequência observada no transitório durante as reignições é elevada. A instalação desse tipo de solução em plantas elétricas ocupam um espaço físico reduzido em comparação às demais. A solução utilizando snubbers $\mathrm{RC}$ reduz tanto a frequência do transitório quanto a magnitude de sobretensão, entretanto torna o transitório mais longo quando comparado com a resposta original e em plantas industriais ocupam mais espaço. A utilização de ambas as soluções é a que traz mais benefícios, pois as vantagens de ambas as soluções são incorporadas, ou seja, uma redução da frequência e da tensão de pico do transitório. 
Entretanto, o espaço necessário para instalação é elevado. Portanto, cabe ao responsável encontrar a solução que alie custos, performance e capacidade espacial de sua instalação.

Para projetistas estudando um determinado circuito, a utilização dos modelos de componentes elétricos apresentados neste trabalho possibilita à esses realizarem simulações e desenvolverem uma ideia básica sobre o comportamento do circuito durante o chaveamento de disjuntores a vácuo, permitindo o estudo de implementação de soluções durante as etapas iniciais de um projeto elétrico.

Como sugestões para trabalhos futuros, propõe-se:

a) Utilização de modelos mais detalhados de alta frequência de transformadores para simulação dos transitórios com disjuntores a vácuo obtidos por meio de medições;

b) Simulações de circuitos utilizando para-raios instalados no ponto médio dos transformadores;

c) Realização de experimentos para determinar a resposta em frequência dos cabos e modelar seu comportamento em função da frequência de forma mais precisa;

d) Análise das energias absorvidas no para-raios F-T e F-F a fim de verificar sua real eficácia;

e) Projeto de transformadores mais robustos diante desses impactos, sem a necessidade de adição de outros equipamentos no circuito para sua proteção; e

f) Estudos dos impactos desse transitórios nos sistemas de isolação dos equipamentos. 


\section{REFERÊNCIAS ${ }^{1}$}

ABDULAHOVIC, T. et al. Vacuum circuit breaker parameter calculations and modelling for power system transient studies. IEEE Transactions on Power Delivery, p. 1-8, Novembro 2014.

ASEA BROWN BOVERI (ABB). Surge Arrester MWK. Wettingen, p. 9. 2017.

ASSOCIAÇÃO BRASILEIRA DE NORMAS TÉCNICAS. ABNT NBR 14039: Instalações Elétricas de Média Tensão de 1,0 kV a 36,2 kV. 2a . ed. [S.1.]: [s.n.], 2005.

ASSOCIAÇÃO BRASILEIRA DE NORMAS TÉCNICAS. ABNT NBR 5356-4: Transformadores de Potência Parte 4 - Guia para ensaio de impulso atmosférico e de manobra para transformadores e reatores. $1^{\mathrm{a}}$. ed. [S.1.]: [s.n.], 2008.

BALAJI, S. P. et al. Effect of repeated impulses on transformer insulation. IEEE Transactions on Dieletrics and Electrical Insulation, v. 18, n. 6, p. 2069-2073, Dezembro 2011.

BALAJI, S. P.; USA, S. Life estimation of transformer insulation under repeated impulses. 2013 IEEE 1st International Conference on Condition Assessment Technique in Electrical Systems. [S.1.]: [s.n.]. 2013. p. 4.

BUDZISZ, J.; WRÓBLEWSKI, Z. Digital model of a vacuum circuit breaker for the analysis of the switching waveforms in electrical circuits. The European Physical Journal B, Wroklaw, Março 2016. 1-8.

COLOMBO, R. Disjuntores em Sistemas de Potência. 1ª ed. São Paulo: Siemens, 1990.

FEHR, R. E. Industrial Power Distribution. 2a . ed. Hoboken: IEEE Press, 2016.

\footnotetext{
${ }^{1}$ De acordo com a Associação Brasileira de Normas Técnicas (ABNT NBR 6023)
} 
FLURSCHEIM, C. H. Power Circuit Breaker Theory and Design. $3^{\mathrm{a}}$. ed. Londres: Institution of Electrical Engineers, v. I, 1985.

GARZON, R. D. High Voltage Circuit Breakers. 2 ${ }^{\mathrm{a}}$. ed. Nova Iorque: Marcel Dekker, Inc, v. I, 2002.

GHAFOURIAN, S. M. et al. General analysis of vacuum circuit breaker switching overvoltages in offshore wind farms. IEEE Transactions on Power Delivery, v. 31, n. 5, p. 2351-2359, Outubro 2016.

GIRODET, A. Dielectric Behaviour of Vacuum Circuit Breakers. Cigré. Paris, p. 2.

GLINKOWSKI, M.; GUTIERREZ, M. R.; BRAUN, D. Voltage escalation and reignition behavior of vacuum generator circuit breakers during load shedding. IEEE Transactions on Power Delivery, v. 12, n. 1, p. 219-226, Janeiro 1997.

GREENWOOD, A. Vacuum Switchgear. 2a . ed. Londres: The Institution of Enginnering and Technology, v. I, 2007.

HELMER, J.; LINDMAYER, M. Mathematical modeling of the high frequency behaviour of vacuum interrupter and comparison with measured transient in power systems. XVIIth International Symposium on Discharges and Electrical Insulation in Vacuum. Berkeley: IEEE. 1996. p. 323-331.

INSTITUTE OF ELECTRICAL AND ELECTRONICS ENGINEERING. IEEE Std C57.98: IEEE guide for transformers impulse tests. Nova Iorque: [s.n.], 2011.

KOSMAC, J.; ZUNKO, P. A statical vacuum circuit breaker model for simulation of transient overvoltages. IEEE Transactions on Power Delivery, v. 10, n. 1, p. 294-300, Janeiro 1995. 
KUCZEK, T. Vacuum Circuit Breaker Switching in Medium Voltage Networks with Photovoltaic Panels. Tese (Doutorado). AGH University of Science and Technology. Cracóvia, p. 165. 2015.

KUCZEK, T.; FLORKOWSKI, M.; PIASECKI, W. Transformer switching with vacuum circuit breaker: Case study of PV inverter LC filters impact on transient overvoltages. IEEE Transactions on Power Delivery, v. 31, n. 1, p. 44-49, Fevereiro 2016.

LARSEN, J. H. et al. Experiences from Middelgrunden 40MW offshore wind park. Copenhagen Offshore Wind. Copenhagen: [s.n.]. 2005. p. 8.

LERCHE, M. Circuit Breaker Characteristics in Medium Voltage Equipment under Various Network Configurations. Dissertação (Mestrado). Universidade Tecnológica da Dinamarca. Lyngby, p. 121. 2009.

LILJESTRAND, L. et al. Transients in collection grids of large offshore wind parks. Wind Energy, v. 11, p. 45-61, Julho 2008.

LILJESTRAND, L. et al. Vacuum circuit breaker and transformer interaction in a cable system. 22nd International Conference on Electricity Distribution, Stockholm, 10-13 Junho 2013. 4.

LINDELL, E.; LILJESTRAND, L. Effect of different types of overvoltage protective devices against vacuum circuit breaker-induced transients in cable systems. IEEE Transactions on Power Delivery, v. 31, n. 4, p. 1571-1579, Agosto 2016.

MAMMADOV, H.; LAZIMOV, T.; IMANOV, S. Improved model of circuit-breaker's dielectric strength restoration, p. 354-356, 2009.

MARCARINI, F. Proteção contra Descargas Atmosféricas utilizando Para-raios de Óxido de Zinco. Universidade Federal de Viçosa. Viçosa, p. 45. 2012. 
MARDEGAN, C. S. et al. The Experience Acquired Sizing Snubbers to Mitigate Switching Transients in Industrial Power Systems. IEEE Transactions on Industry Applications, v. 52, n. 5, p. 3644 - 3654, Outubro 2016.

PANEK, J.; FEHRLE, K. G. Overvoltage phenomena associated with virtual current chopping in three phase circuits. IEEE Transactions on Power Apparatus and Systemss, v. PAS-94, n. 4, p. 1317-1325, Julho 1975.

PASTERNACK. Flexible RG213 coax cable single shielded with black PVC jacket. Irvine: [s.n.], 2015.

PERKINS, J. F. Evaluation of switching surge voltages on medium voltage power systems. IEEE Transactions on Power Apparatus and Systems, v. PAS-101, p. 1727-1734, Junho 1982.

POPOV, M. Switching Three-Phase Distribution Transformers with a Vacuum Circuit Breaker. Tese (Doutorado). Delft University of Technology. Delft, p. 192. 2002.

RAO, B. K.; GAJJAR, G. Development and Application of Vacuum Circuit Breaker Model in Electromagnetic Transient Simulation. Power India Conference. [S.1.]: IEEE. 2006.

ROGUSKI, A. T. Experimental investigation of the dielectric recovery strength between the separating contacts of vacuum circuit breakers. IEEE Transactions on Power Delivery, Varsóvia, v. 4, n. 2, p. 1063-1069, Abril 1989.

SHIPP, D. D. et al. Transformer failure due to circuit-breaker-induced switching transients. IEEE Transaction on Industry Applications, v. 47, n. 2, p. 707-718, Abril 2011.

SHIPP, D. D.; DIONISIE, T. J. Switching Transients, Transformer Failures and Practical Solutions. Institute of Electrical and Electronics Engineer. [S.1.], p. 124. 2016. 
SLADE, P. G. The Vacuum Interrupter: Theory, Design and Application. Boca Raton: CRC Press, v. I, 2008.

SWINDLER, D. L. A comparison of vacuum and SF6 technologies at 5-38kV. IEEE Transactions on Industry Applications, v. IA-20, n. 5, p. 1355-1363, Setembro/Outubro 1984.

TELANDER, S. H.; WILHEIM, M. M.; STUMP, K. B. Surge limites for vacuum circuit breaker switchgear. IEEE Transactions on Power Delivery, v. PWRD-2, n. 1, p. 107-116, Janeiro 1987.

YANG, Q. et al. Field experiments on overvoltage caused by $12-\mathrm{kV}$ vacuum circuit breakers switching shunt reactors. IEEE Transactions on Power Delivery, v. 31, n. 2, p. 657-664, Abril 2016.

ZANETTA JR., L. C. Transitórios Eletromagnéticos em Sistemas de Potência. $1^{\text {a }}$. ed. São Paulo: Edusp, v. 1, 2003.

ZHOU, Q. et al. Analysis of restrike overvoltage of circuit breakers in offshore wind farms. IEEE Transactions on Applied Superconductivity, v. 26, n. 7, Outubro 2016. 


\section{APÊNDICEA - Dados de entrada para as simulações}

Os dados dos transformadores utilizados no experimento de referência estão contidos na Tabela 6. Apenas a relação de tensão do autotransformador está disponível.

Tabela 6 - Dados dos transformadores

\begin{tabular}{|c|c|c|c|c|}
\hline \multicolumn{2}{|c|}{ Dados } & Transformador 1 & Transformador 2 & Autotransformador \\
\hline \multicolumn{2}{|c|}{ Tipo } & Imerso a óleo & Imerso a óleo & - \\
\hline \multicolumn{2}{|c|}{ Potência (kVA) } & 250 & 20 & - \\
\hline \multicolumn{2}{|c|}{ Relação de transformação $(\mathrm{kV} / \mathrm{kV})$} & $15,75 / 0,4$ & $6 / 0,4$ & $0,4 / 0,1$ \\
\hline \multicolumn{2}{|c|}{ Impedância percentual (\%) } & 4,5 & 4,29 & - \\
\hline \multicolumn{2}{|c|}{ Perdas ensaio de curto-circuito (W) } & 3059 & 560 & - \\
\hline \multicolumn{2}{|c|}{ Perdas ensaio a vazio (W) } & 486 & 125 & - \\
\hline \multicolumn{2}{|c|}{ Corrente a vazio (\%) } & 0,25 & 4,23 & - \\
\hline \multicolumn{2}{|c|}{ Grupo vetorial } & Dyn5 & $\mathrm{Yz}$ & - \\
\hline \multirow{4}{*}{$\begin{array}{c}\text { Capacitâncias } \\
\text { (nF) }\end{array}$} & Primário - Terra & 3,0 & 3,0 & - \\
\hline & Secundário - Terra & 4,8 & - & - \\
\hline & $\begin{array}{l}\text { Primário - } \\
\text { Secundário }\end{array}$ & 1,8 & 1,0 & - \\
\hline & $\begin{array}{l}\text { Entre fases } \\
\text { (Primário) }\end{array}$ & 0,2 & 0,2 & - \\
\hline
\end{tabular}

Fontes: Kuczek, Florkowski e Piasecki (2016) e Kuczek (2015)

Os cabos utilizados na média tensão eram cabos coaxiais do tipo RG213/U, cuja impedância de surto é igual a $50 \Omega$, velocidade de propagação da onda igual a $200 \mathrm{~m} / \mu \mathrm{s}$ e resistência para amortecimento de alta frequência igual a $0,05 \mathrm{~m} \Omega / \mathrm{m}(\mathrm{KUCZEK}, 2015)$. Os comprimentos são os indicados na Figura 8. Os dados das características físicas dos cabos estão listados na Tabela 7.

Tabela 7 - Características físicas do cabo RG213/U

\begin{tabular}{cccccc}
\hline Camadas & Material & $\begin{array}{c}\text { Diâmetro } \\
\text { externo }(\mathbf{m m})\end{array}$ & $\begin{array}{c}\text { Resistividade } \\
(\boldsymbol{\Omega} . \mathbf{m})\end{array}$ & $\begin{array}{c}\text { Permissividade } \\
\text { Relativa }\left(\boldsymbol{\varepsilon}_{\mathbf{r}}\right)\end{array}$ & $\begin{array}{c}\text { Permeabilidade } \\
\text { Relativa }\left(\boldsymbol{\mu}_{\mathbf{r}}\right)\end{array}$ \\
\hline Condutor & Cobre & 2,3 & $1,68.10^{-8}$ & - & - \\
\hline Isolante & Polietileno sólido & 7,24 & - & 2,3 & 1,0 \\
\hline Armadura & Cobre & 7,98 & $1,68.10^{-8}$ & - & - \\
\hline Cobertura & PVC & 10,3 & - & 3 & 1,0 \\
\hline
\end{tabular}

Fonte: Pasternack (2015) 
Os dados dos cabos de baixa tensão não foram informados. O disjuntor a vácuo utilizado possui tensão nominal de $12 \mathrm{kV}$, com corrente nominal igual a $1250 \mathrm{~A}$, corrente de curto-circuito igual a $20 \mathrm{kA}$ e corrente de corte igual a $3 \mathrm{~A}$. O tempo de abertura do disjuntor varia de 40 a $60 \mathrm{~ms}$ e o tempo de fechamento de 60 a $80 \mathrm{~ms}$.

Os para-raios utilizados pertencem à família $\mathrm{MWK}$ da $\mathrm{ABB}$, sendo a tensão nominal deles definida como 7,5kV. Os para-raios são de óxido metálico, sem espaço de faísca, projetados e testados de acordo com a IEC 60099-4, com corrente nominal de descarga igual a $10 \mathrm{kA}$ de pico, energia térmica nominal a $40^{\circ} \mathrm{C}$ igual a $5 \mathrm{~kJ} / \mathrm{kV}$ para tensão de operação contínua, impulso de corrente máximo igual a $10 \mathrm{kA}$ de pico e corrente de curto-circuito nominal igual a $20 \mathrm{kA} A_{\mathrm{RMS}}$ por 0,2 segundos. As demais características desses para-raios estão apresentadas na Tabela 8 .

Tabela 8 - Dados elétricos do para-raios MWK

\begin{tabular}{|c|c|c|c|c|c|c|c|c|c|c|c|}
\hline \multirow{3}{*}{$\begin{array}{c}\text { Tensão } \\
\text { de } \\
\text { operação } \\
\text { contínua }\end{array}$} & \multirow{3}{*}{$\begin{array}{c}\text { Tensão } \\
\text { nominal }\end{array}$} & \multicolumn{10}{|c|}{ Tensão residual em um impulso específico de corrente } \\
\hline & & $\begin{array}{r}\text { Imp } \\
\text { cor } \\
\text { íngre } \\
1\end{array}$ & $\begin{array}{l}\text { so de } \\
\text { ente } \\
\text { e onda } \\
\mu s\end{array}$ & Imp & Iso de co & $\begin{array}{l}\text { rente at } \\
8 / 20 \mu \mathrm{s}\end{array}$ & 10sférico & & $\begin{array}{r}\text { Impul } \\
\text { cha }\end{array}$ & $\begin{array}{l}\text { o de corr } \\
\text { eamento } \\
30 / 60 \mu \mathrm{s}\end{array}$ & $\begin{array}{l}\text { nte de } \\
\text { nda }\end{array}$ \\
\hline & & $5 \mathrm{kA}$ & $10 \mathrm{kA}$ & $1 \mathrm{kA}$ & $2,5 \mathrm{kA}$ & $5 \mathrm{kA}$ & $10 \mathrm{kA}$ & $20 \mathrm{kA}$ & $125 \mathrm{~A}$ & $250 A$ & 500A \\
\hline $\mathrm{kV}$ RMS & $\mathrm{kV}$ RMS & $\mathrm{kVPICO}$ & $\mathrm{kV}$ PICO & $\mathrm{kVPICO}$ & $\mathrm{kVPICO}$ & $\mathrm{kV}$ PICO & $\mathrm{kV}$ PICO & $\mathrm{kV}$ PICO & $\mathrm{kV}$ PICO & $\mathrm{kVPICO}$ & $\mathrm{kVPICO}$ \\
\hline 6 & 7,5 & 19,1 & 20,2 & 15,8 & 16,7 & 17,5 & 18,5 & 21,1 & 13,7 & 14,3 & 14,8 \\
\hline
\end{tabular}

Fonte: Asea Brown Boveri - ABB (2017)

A curva característica V-i do para-raios foi montada de acordo com a Figura 10, conforme apresentado na Tabela 9: 
Tabela 9 - Curva V-i

\begin{tabular}{cc}
\hline Valor de pico da corrente (A) & Valor de pico da tensão nominal do sistema (V) \\
\hline 0,0164 & 2571 \\
\hline 0,0289 & 4994,3 \\
\hline 0,0379 & 5950,5 \\
\hline 0,0723 & 7758,8 \\
\hline 0,088 & 8130,8 \\
\hline 0,18 & 8171,3 \\
\hline 1,342 & 8240,3 \\
\hline 3,719 & 8412,8 \\
\hline 7,976 & 8832,8 \\
\hline 10,078 & 8981,3 \\
\hline 182,2 & 9287,3 \\
\hline 758,4 & 9877,4 \\
\hline 1229 & 10612,5 \\
\hline 4165 & 11662,5 \\
\hline 6198 & 13125 \\
\hline 7277 & 15112 \\
\hline
\end{tabular}

Fonte: Autor 